\title{
Nanostructured Biomaterials for Bone Regeneration
}

\author{
Joseph G. Lyons ${ }^{1,2+}$, Mark A. Plantz ${ }^{1,2+}$, Wellington K. Hsu', ${ }^{1,2}$ Erin L. Hsu ${ }^{1,2}$ and \\ Silvia Minardi ${ }^{1,2 *}$ \\ ${ }^{1}$ Department of Orthopaedic Surgery, Northwestern University Feinberg School of Medicine, Chicago, IL, United States, \\ 2 Simpson Querrey Institute, Northwestern University, Chicago, IL, United States
}

OPEN ACCESS

Edited by: Michele lafisco,

National Research Council (CNR), Italy

Reviewed by:

Kai Zheng,

University of Erlangen-Nuremberg,

Germany

Fang Yang

Radboud University Medical Centre

Netherlands

*Correspondence:

Silvia Minardi

silvia.minardi@northwestern.edu

${ }^{t}$ These authors have contributed equally to this work

Specialty section:

This article was submitted to Nanobiotechnology,

a section of the journal Frontiers in Bioengineering and Biotechnology

Received: 28 April 2020

Accepted: 17 July 2020

Published: 21 August 2020

Citation:

Lyons JG, Plantz MA, Hsu WK,

Hsu EL and Minardi S (2020)

Nanostructured Biomaterials for Bone

Regeneration.

Front. Bioeng. Biotechnol. 8:922.

doi: 10.3389/fbioe.2020.00922
This review article addresses the various aspects of nano-biomaterials used in or being pursued for the purpose of promoting bone regeneration. In the last decade, significant growth in the fields of polymer sciences, nanotechnology, and biotechnology has resulted in the development of new nano-biomaterials. These are extensively explored as drug delivery carriers and as implantable devices. At the interface of nanomaterials and biological systems, the organic and synthetic worlds have merged over the past two decades, forming a new scientific field incorporating nano-material design for biological applications. For this field to evolve, there is a need to understand the dynamic forces and molecular components that shape these interactions and influence function, while also considering safety. While there is still much to learn about the bio-physicochemical interactions at the interface, we are at a point where pockets of accumulated knowledge can provide a conceptual framework to guide further exploration and inform future product development. This review is intended as a resource for academics, scientists, and physicians working in the field of orthopedics and bone repair.

Keywords: bone regeneration, biomaterials, nanomaterials, delivery systems, stem cells

\section{INTRODUCTION}

Bone undergoes self-repair of small defects due to the synergistic actions of mesenchymal cells, osteogenic cells, and cells of the immune system (Marsell and Einhorn, 2011). This self-repaired bone contains physico-chemical and mechanical properties that recapitulate the bone which was replaced (Dimitriou et al., 2011). However, larger defects are unable to undergo the same level of self-healing, and regenerative medicine approaches are paramount in addressing these clinical challenges (Ho-Shui-Ling et al., 2018).

Autologous and allograft bone are generally considered the clinical standard-of-care for bone repair (Grabowski and Cornett, 2013; Gupta et al., 2015), despite critical limitations such as supply and quality of host bone, donor site morbidity (Angevine et al., 2005; Gruskay et al., 2014), and immunogenicity, respectively (Stevenson and Horowitz, 1992; Bauer and Muschler, 2000). Osteoinductive growth factors, in particular recombinant human bone morphogenetic protein-2 (rhBMP-2), have demonstrated remarkable efficacy, but a number of concerns and controversies exist regarding the safety of their clinical use and high cost (Burkus et al., 2002, 2003; Carragee et al., 2011; Singh K. et al., 2014; Vavken et al., 2016; Zadegan et al., 2017). Although numerous synthetic bone graft substitutes are available, the problem of delayed and/or compromised healing remains a significant clinical challenge (Zura et al., 2016; Fernandez et al., 2020). 
The ideal biomaterials for bone regeneration should not only be biocompatible and osteoconductive but also osteoinductive. They should be able to leverage the self-healing capabilities of the bone by (i) providing the main structural, compositional, and biochemical cues for the formation of new tissue; (ii) engaging the host's resident immune cells in the regenerative response; (iii) promoting the recruitment, proliferation, and differentiation of progenitor cells; and (iv) recovering an adequate local blood supply to support healing and remodeling (Schmidt-Bleek et al., 2014; Minardi et al., 2015a).

Recently, nanotechnology has become a domain with breakthrough potential to further propel the field of bone regeneration. Nanostructured biomaterials have proven superior at enhancing bone regeneration due to their unique chemical and physical properties (e.g., magnetic, electrical) that are uniquely different from their bulk counterparts (Perez et al., 2013; Wang Q. et al., 2016). These differences stem from an ability to be engineered to precisely mimic the composition and nanoarchitecture of bone, while allowing for the recapitulation of crucial characteristics of its biochemical milieu at the nanoscale (Minardi et al., 2016b). This translates in improved ability to engage the host's immune and progenitor cells at the nanoscale, resulting in enhanced outcomes (Cheng et al., 2013).

In the rational design of regenerative nanotechnologies for bone regeneration, four crucial elements of bone should be considered and recapitulated as closely as possible: (i) composition, (ii) physical stimuli, (iii) architecture and (iv) biochemical cues, as summarized in Figure 1. Inspired by mimicking these 4 fundamental characteristics of bone, a plethora of nanostructured materials have been developed over the last decade to elicit bone regeneration. Technologies that recapitulate more than one of these four fundamental elements have been shown to lead to superior outcomes. This review highlights such ongoing work in the field of nanostructured materials for bone regeneration and their potential in clinical practice.

\section{MIMICKING BONE COMPOSITION: BIOCERAMICS AND COMPOSITE NANOSTRUCTURED BIOMATERIALS}

\section{Bioceramics}

Bone is a natural nanostructured composite, consisting of approximately $60 \%$ (dry weight) mineral, mostly nano-apatitewhich is a calcium phosphate $(\mathrm{CaP})$ ceramic (Minardi et al., 2015a). Accordingly, a number of bioceramics containing calcium and phosphorous have been proposed for bone regeneration (Hench et al., 2014; Jones et al., 2016). Of these, CaP materials most closely mimic the mineral phase of bone and have demonstrated relatively greater osteoinductivity, making $\mathrm{CaP}$ a common material of choice for bone grafts. A number of bioceramics have been used clinically for several decades (Szpalski and Gunzburg, 2002; Giannoudis et al., 2005; Campana et al., 2014; Fernandez de Grado et al., 2018), both for load- and non-load- bearing applications (Roberts and Rosenbaum, 2012).
While conventional bioceramics had poor mechanical properties and unfavorable biodegradability and porosity (Fielding and Bose, 2013; Wen et al., 2017), the latest generation of bioceramics are structured at the nanoscale and have significantly improved bioactivity, biodegradation and mechanical properties, and are reviewed below. Their advantages and disadvantages are summarized in Table $\mathbf{1}$.

\section{Hydroxyapatite-Based Ceramics}

Among $\mathrm{CaP}$ ceramic phases, synthetic hydroxyapatite (HA) has been the one most extensively studied due to its biocompatibility and resemblance to the composition of natural bone mineral (Sadat-Shojai et al., 2013; Šupová, 2015). First generation materials were fabricated with stoichiometric HA $\left[\mathrm{Ca}_{10}\left(\mathrm{PO}_{4}\right)_{6}(\mathrm{OH})\right]$, which has been successfully synthesized and mass produced through several synthesis strategies, including hydrothermal reactions, sol-gel syntheses, and mechanochemical syntheses (Kalita and Bhatt, 2007). However, natural bone mineral is produced in a very dynamic environment with numerous ions present (e.g., $\mathrm{Mg}^{2+}, \mathrm{K}^{+}, \mathrm{Na}^{+}, \mathrm{CO}_{3}^{2-}, \mathrm{HPO}_{4}^{2-}$ ), which frequently substitute ions in the apatite lattice. The apatite present in natural bone is calcium deficient and is characterized by a $\mathrm{Ca} / \mathrm{P}$ ratio lower than the typical 1.67 of stoichiometric $\mathrm{HA}$ (Kalita and Verma, 2010; Dziadek et al., 2017). Ion substitution plays an important role in maintaining the low crystallinity of bone apatite, which is crucial for bone metabolism. This low crystallinity may correspond to higher reactivity in vivo, resulting in faster bone formation and remodeling (Minardi et al., 2015a). In contrast, stoichiometric HA is more crystalline and stable in aqueous solutions, resulting in a less biodegradable material that could impede the formation of new bone through the entirety of a defect space or osteointegration with the surrounding matrix (Liou et al., 2004; Tampieri et al., 2012). To overcome these limitations, numerous biomimetic multi-substituted nano HAs have been developed to mimic the natural mineral phase of bone and enhance bioactivity and solubility (Boanini et al., 2010; Zofková et al., 2013).

Various substituted nanostructured HAs have been proposed, some of which have been used as tools to fine-tune or stimulate specific biological functions. For example, $\mathrm{Mg}^{2+}$ plays a vital role in osteogenesis and is present in young and newly formed bone (De Bruijn et al., 1992). Landi et al. (2006) found that Mg-substituted HA showed enhanced cell adhesion, proliferation, and metabolic activity compared to HA. Due to the smaller ionic radius of $\mathrm{Mg}^{2+}$ relative to $\mathrm{Ca}^{2+}$, the $\mathrm{Mg}$ substituted structure is more unstable when incorporated into the crystal lattice (Fadeev et al., 2003). Mg is also thought to induce nitric oxide production in endothelial cells, a critical component of angiogenesis (Maier et al., 2004). Sr acts to enhance bone formation in vivo by inhibiting osteoclast-mediated bone resorption while upregulating osteoblast activity ( $\mathrm{Li}$ et al., 2009; Ozturan et al., 2011), which is why Sr-based drugs have been long used to treat osteoporosis (e.g., strontium renelate; Capuccini et al., 2008). Thus, Sr-doped nano-HA has also been extensively used in bone regenerative strategies (Wong et al., 2004; Frasnelli et al., 2017; Neves et al., 2017; Ratnayake et al., 2017). Similarly, substitution with Zn has been 


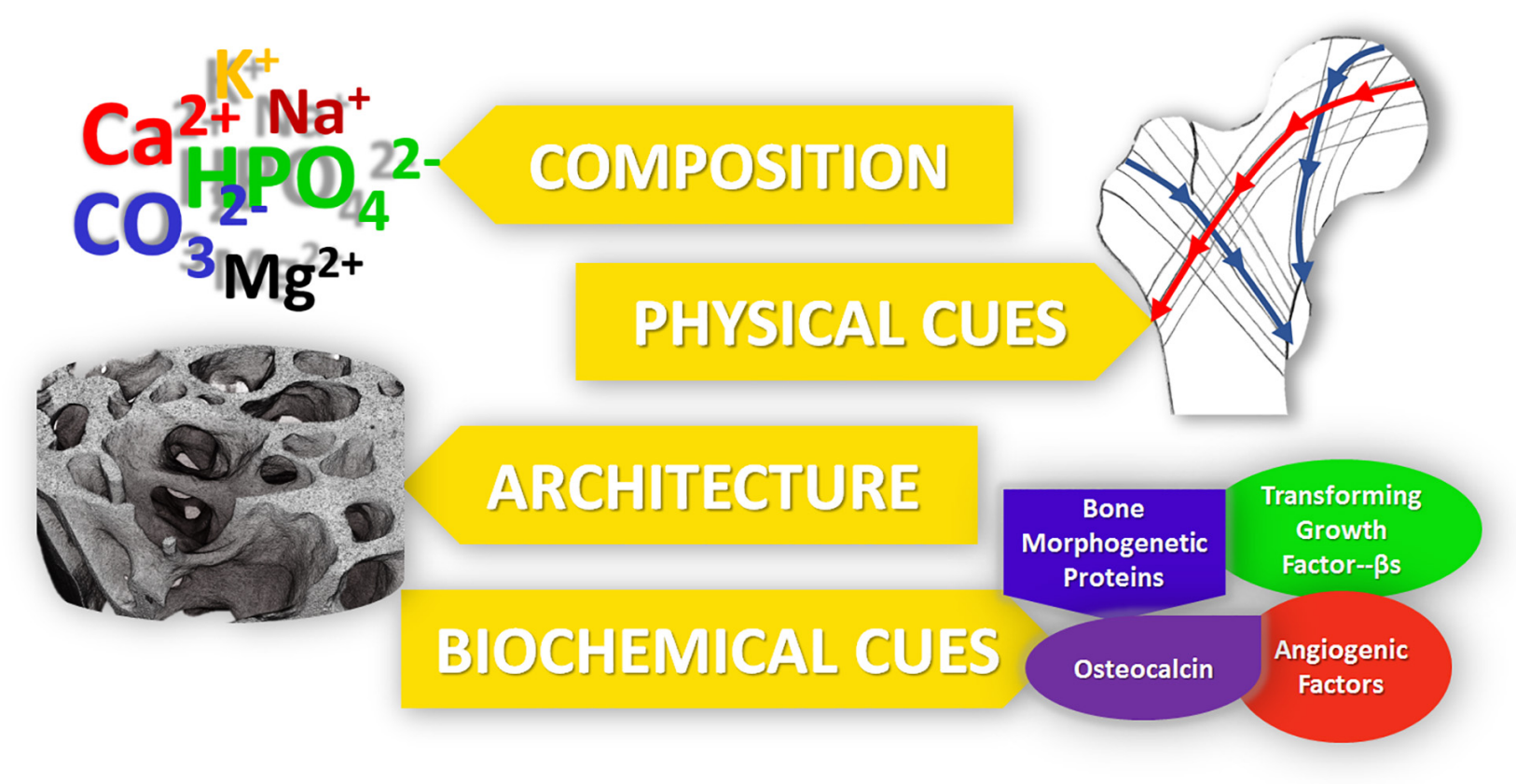

FIGURE 1 | The five main properties of bone, which should be recapitulated into bone regenerative strategies for improved outcomes.

shown to enhance osteogenic activity (Ren et al., 2009), with a proposed mechanism of inhibiting osteoclast resorption and upregulating osteoblastic activity (Hadley et al., 2010; Yamaguchi and Weitzmann, 2011). More recently, Tampieri et al. (2010) proposed a conceptually new type of nanostructured calciumdeficient $\mathrm{HA}$, by substituting it with $\mathrm{Fe}^{2+}$ and $\mathrm{Fe}^{3+}$ to endow the HA with superparamagnetic properties. This magnetic behavior may potentially be exploited for bone regeneration purposes to enhance osteogenesis (Tampieri et al., 2012).

Alternatively, a common anionic substitution involves $\mathrm{CO}_{3}^{2-}$ replacement of the phosphate group within nano-HA, which may influence bone turnover and metabolism (Du et al., 2019). When incorporated in HA, it showed enhanced osteoconductive potential compared to pure HA (Du et al., 2019), while increasing its solubility due to its decreased crystallinity (Wang and Nancollas, 2008). In contrast to these effects, $\mathrm{F}^{-}$doped HA results in decreased solubility (Kim et al., 2004) and increased strength, therefore reducing the brittleness of the CaP (Bianco et al., 2010). Si-HA showed instead improved osteoblast attachment and differentiation, and decreased osteoclast differentiation in vivo (Matesanz et al., 2014).

\section{Tricalcium Phospohate-Based Ceramics}

Another popular type of $\mathrm{CaP}$ ceramic used extensively in orthopedics is tricalcium phosphate (TCP). Two types of TCP have been pursued for bone regeneration: $\alpha$-TCP and $\beta$-TCP. They differ in their atomic arrangements (Wen et al., 2017), but both have a $\mathrm{Ca} / \mathrm{P}$ ratio of 1.5 (Wen et al., 2017). $\beta$ TCP has become the TCP of choice, given its superior rate of degradation and bioactivity over $\alpha$-TCP (Kamitakahara et al., 2008; Ghanaati et al., 2010). Hydroxyapatite and TCP can also be combined in varying ratios within composite scaffolds to tune degradation and potentially enhance osteoconductive and osteoinductive properties (Daculsi, 1998; Arinzeh et al., 2005; Samavedi et al., 2013). Similar to HA, TCPs can also undergo ion-substitution as a tool to create ceramic-based materials that target specific biological pathways in vivo. For example, Mg-doped $\beta$-TCP and Sr-doped $\beta$-TCP-based materials have shown improved bone healing through accelerated osteogenesis and angiogenesis in a large animal model (Bose et al., 2011; Tarafder et al., 2015), with improved mechanical strength compared to the pure TCP scaffolds (Tarafder et al., 2015). Similar to Fe-doped HA, Fe-doped TCP stabilized the $\beta$ TCP phase, and osteoblasts showed enhanced cell adhesion to doped-TCP relative to pure TCP (Vahabzadeh and Bose, 2017). Moreover, cell proliferation was reportedly enhanced in TCP doped with other ions, such as $\mathrm{Mg}^{2+}, \mathrm{Zn}^{2+}, \mathrm{Sr}^{2+}$, and $\mathrm{Li}^{+}$ (Vahabzadeh and Bose, 2017).

Using these ceramic phases, numerous types of nanostructured 3D scaffolds (and bone cements) have been prepared through a variety of ways, including dry methods, wet methods, and high temperature methods (Sadat-Shojai et al., 2013). Dry methods include solid-state and mechanochemical reactions. The solid-state and mechanochemical technique have the advantage of a simple procedure for large scale production, whereas the mechanochemical technique reliably produces a specific nanostructure (Sadat-Shojai et al., 2013). Wet methods are commonly used and include techniques including but not limited to sol-gel synthesis and hydrothermal synthesis. These methods have the advantage of producing nanoparticles with a consistent morphology and size (Shepherd and Best, 2011; Sadat-Shojai et al., 2013). The downfall of these techniques 
TABLE 1 | Summary of the main nanostructured calcium-phosphate based materials for bone regeneration, with their respective advantages and disadvantages.

\begin{tabular}{|c|c|c|c|}
\hline & Advantages & Disadvantages & References \\
\hline \multicolumn{4}{|c|}{ Nanostructured Bioceramics } \\
\hline \multirow[t]{3}{*}{ Nano-bioglasses } & Biocompatible & $\begin{array}{l}\text { Suboptimal } \\
\text { Biodegradation }\end{array}$ & $\begin{array}{l}\text { Vallet-Regí et al., 2003; Izquierdo-Barba } \\
\text { et al., 2013; Ducheyne, 2015; Islam } \\
\text { et al., 2017; Mancuso et al., } 2017\end{array}$ \\
\hline & Enhanced bone integration & $\begin{array}{l}\text { Poor mechanical } \\
\text { properties }\end{array}$ & \\
\hline & Improved biodegradation & & \\
\hline \multirow[t]{6}{*}{ Hydroxyapatite } & High biocompatibility & $\begin{array}{l}\text { Poor mechanical } \\
\text { properties }\end{array}$ & $\begin{array}{l}\text { Liou et al., 2004; Capuccini et al., } \\
\text { 2008; Boanini et al., 2010; Tampieri } \\
\text { et al., 2012; Zofková et al., } 2013\end{array}$ \\
\hline & Resembles mineral phase of bone & & \\
\hline & $\begin{array}{l}\text { Can be doped with multiple ions to closely mimic } \\
\text { bone mineral }\end{array}$ & $\begin{array}{l}\text { Slow degradation rates } \\
\text { in vivo }\end{array}$ & \\
\hline & Osteoconductive & & \\
\hline & $\begin{array}{l}\text { Can be used in a plethora of formulations (e.g., } \\
\text { powder, solid scaffold, cement, coatings) }\end{array}$ & Limited osteoinductivity & \\
\hline & High biocompatibility & & \\
\hline \multirow[t]{5}{*}{ Tricalcium phosphate } & $\begin{array}{l}\text { Provides main bulding blocks for new matrix } \\
\text { deposition }\end{array}$ & $\begin{array}{l}\text { Poor mechanical } \\
\text { properties }\end{array}$ & $\begin{array}{l}\text { Shepherd and Best, 2011; } \\
\text { Sadat-Shojai et al., 2013; Vahabzadeh } \\
\text { and Bose, 2017; Sergi et al., } 2018\end{array}$ \\
\hline & $\begin{array}{l}\text { Can be doped with multiple ions to tune bioactivity } \\
\text { and degradation }\end{array}$ & & \\
\hline & Osteoconductive & & \\
\hline & $\begin{array}{l}\text { Can be used in a plethora of formulations (e.g., } \\
\text { powder, solid scaffold, cement, coatings) }\end{array}$ & & \\
\hline & Faster in vivo degradation & & \\
\hline \multicolumn{4}{|l|}{ Nanocomposites } \\
\hline \multirow[t]{5}{*}{$\begin{array}{l}\text { Ceramic/polymer } \\
\text { composites (e.g., } \\
\text { HA/PLGA, HA/Alginate) }\end{array}$} & High biocompatibility & $\begin{array}{l}\text { May have limited } \\
\text { osteoinductivity }\end{array}$ & $\begin{array}{l}\text { Kim et al., 2005; Miao et al., 2005; } \\
\text { Tampieri et al., 2005; Heo et al., 2009; } \\
\text { Akman et al., 2010; Bernstein et al., } \\
\text { 2010; Cruz, 2010; Bhumiratana et al., } \\
\text { 2011; Wang Z. et al., 2016; Zhu et al., } \\
\text { 2017; Bian et al., } 2019\end{array}$ \\
\hline & Ease of fabrication & $\begin{array}{l}\text { Fabrication requires } \\
\text { organic solvents }\end{array}$ & \\
\hline & $\begin{array}{l}\text { Can be used to prepare scaffolds with complex 3D } \\
\text { architecture }\end{array}$ & & \\
\hline & Improved mechanical properties of scaffolds & & \\
\hline & Tunable degradation rate & & \\
\hline \multirow[t]{4}{*}{ Bio-hybrid composites } & High biocompatibility & $\begin{array}{l}\text { Poor mechanical } \\
\text { properties (not load } \\
\text { bearing) }\end{array}$ & $\begin{array}{l}\text { Tampieri et al., 2008; Tampieri et al., } \\
\text { 2011; Minardi et al., 2015a; Minardi } \\
\text { et al., } 2019\end{array}$ \\
\hline & Fabrication not requiring organic solvents & & \\
\hline & Highly biomimetic & & \\
\hline & Excellent bioactivity & & \\
\hline
\end{tabular}

is that the products can often have multiple phases present (Sadat-Shojai et al., 2013). High temperature processes such as combustion and pyrolysis are capable of bypassing the problem of multiple phases, however control over the byproducts limits this method's applications (Sadat-Shojai et al., 2013). Moreover, there a numerous techniques to introduce porosity within 3D CaP scaffolds, including a polymeric sponge technique (Monmaturapoj and Yatongchai, 2011), foaming technique (Sopyan et al., 2007), supercritical foaming technique (DiazGomez et al., 2017), gel casting of foams (Sopyan et al., 2007), and slip casting (Sopyan et al., 2007). Although all of these nanostructured ceramics are limited by poor mechanical properties, their strong osteoconductive potential makes them attractive for use as coating materials for load bearing implants, where such use may enhance osteointegration or even have antibacterial properties (Sergi et al., 2018).

Although nanostructured calcium-deficient $\mathrm{CaP}$ materials have provided enhanced biomimicry of the mineral phase of native bone, they have not proven capable of recapitulating all of its subtle and complex physiochemical properties. Thus, strategies based on nanostructured composites have been developed to fulfill this goal. 


\section{Nanostructured Composites}

Biomimicry is an increasingly popular strategy in regenerative medicine, aiming to engineer materials that closely resemble the target tissue (Nandakumar et al., 2013). Since bone is a natural composite-made of an inorganic component (mostly multi-substituted HA) and an organic component (mostly type I collagen)-researchers have long focused on developing nanostructured ceramic/polymer composite materials with the purpose of recreating the composition and function of natural bone. Nanostructured composites for bone regeneration leverage the osteoconductivity of synthetic $\mathrm{CaP}$ ceramic phases and the unique mechanical properties of polymers. For example, both synthetic polymers like poly(L-lactic acid) (PLLA; Cruz, 2010; Zhu et al., 2017), poly(e-caprolactone) (PCL; Heo et al., 2009; Bernstein et al., 2010), poly(lactic-co-glycolic acid) (PLGA; Miao et al., 2005; Wang Z. et al., 2016) as well as naturally occurring polymers such as gelatin (Kim et al., 2005), silk (Bhumiratana et al., 2011), chitosan (Akman et al., 2010), alginate (Tampieri et al., 2005), and collagen (Bian et al., 2019) have been combined with HA and TCP to fabricate a plethora of composite materials over the past three decades. These composites have been fabricated in a myriad of ways: electrospinning, gas foaming, solvent casting and particulate leaching, phase separation, and melt mixing have been widely used to fabricate scaffolds (Alizadeh-Osgouei et al., 2019). The major drawback, common to all these approaches in the manufacturing of porous structures is the inability of conventional methods to completely control the architecture of scaffolds, such as pore size and interconnections. Furthermore, the use of solvents required by some of these methods can impact scaffold biocompatibility (Alizadeh-Osgouei et al., 2019). Additive manufacturing is a new and modern technique that shows great potential to offer complete control of architectural details such as pore size, which significantly affects the properties of ceramic-based scaffolds. 3D-printing techniques have received much attention due to the capacity to fabricate specific and complex structures (further discussed in paragraph 4) (Kumar et al., 2019).

Numerous composite materials have been fabricated with natural polymers, with the underlying hypothesis that mimicking natural bone matrix would harness regeneration. A plethora of $\mathrm{CaP} /$ natural polymer composites have been described. The first generation of such composites was prepared by blending the desired ceramic phase with the natural polymer of choice in aqueous solutions (Ridi et al., 2017). Although these materials contained the two main components of bone matrix, they lacked vital chemical, physical, and topographical information at the nanoscale, which cells need to repair bone (Tampieri et al., 2011). The organic matrix (mostly type I collagen) of natural bone acts as a template for the nucleation of the mineral phase, directing its deposition, and guiding the growth of the mineral crystals along its fibers via interaction of its functional groups (e.g., carbonyl groups) with the apatite crystals. It is believed that the mineralization begins in correspondence of the hole zones of the collagen fibrils (intrafibrillar mineralization) (Figure 2). This highly regulated chemical-physical interaction between the inorganic and organic phase not only directs the orientation of the forming apatite crystals, but also limits

\section{MINERALIZED COLLAGEN FIBRIL}
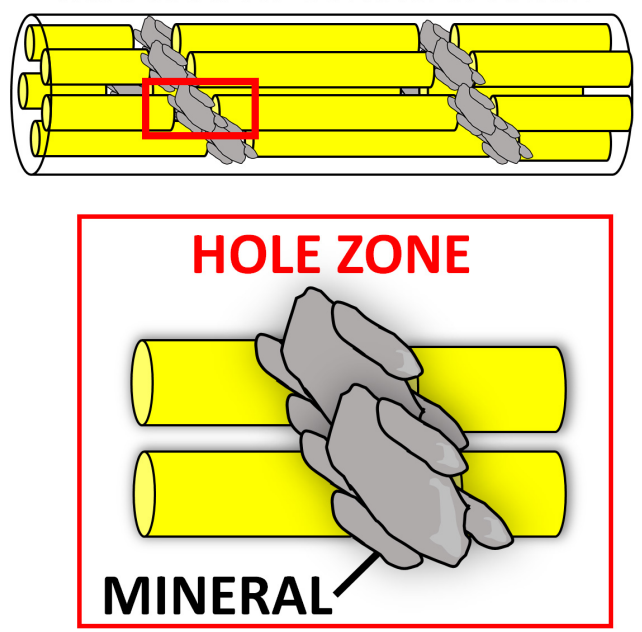

FIGURE 2 | Intrafibrillar mineralization occurring during bone biomineralization. The nucleation of the mineral (gray) is thought to begin at the "hole zones" of the collagen fibrils (in red box), between single collagen molecules (yellow), as depicted in this schematic.

their crystallinity, which is paramount to the formation of a nanocomposite material (i.e., bone extracellular matrix [ECM]) (Kim D. et al., 2018). The unique characteristics of both stiffness and flexibility of the bone result from this intimate interaction between these two components (Nair et al., 2014). Thus, several groups have focused on the development of biologically inspired synthesis methods to mineralize natural polymers by mimicking the process of bone biomineralization. In these syntheses, the ceramic phase is deposited onto the organic template during its self-assembly through a $\mathrm{pH}$-driven process which resembles that of bone biomineralization. Using this synthetic approach, the mineral phase is not simply mixed with the organic template, but nucleated directly onto it and intimately bonded to the organic matrix, resulting in nanostrustured "bio-hybrid composites" (Minardi et al., 2015a). Accordingly, many studies have described the bio-inspired mineralization with nanoapatite phases of several natural polymers, such as chitosan (Palazzo et al., 2015), alginate (Tampieri et al., 2005), gelatin (Landi et al., 2008), and type I collagen (Tampieri et al., 2008). The main advantages of these materials are: (i) their ability to mimic bone matrix at the nanoscale, storing the crucial nanocompositional and topographical information necessary for cell migration, proliferation and osteogenic differentiation (Minardi et al., 2015a); (ii) their high degree of interconnected porosity, conventionally achieved by freeze-drying (Wu et al., 2010a), which facilitates cell infiltration and neovascularization (O'Brien et al., 2004); (iii) their syntheses do not require harsh conditions, allowing for the incorporation of a variety of delivery systems and bioactive molecules (Minardi et al., 2016b). This class of nano bone substitutes has shown great promise in a plethora of in vitro studies as well as in non-load bearing in vivo models. More recently, increasingly sophisticated bio-hybrid composites were developed, which appear able to incorporate multi-substituted 
biomimetic apatite phases. For example, a Mg-doped apatite/type I collagen nanocomposite was shown to closely resemble the structure and composition of the human trabecular bone niche, significantly improving the osteogenic differentiation of human mesenchymal stem cells (MSCs) in vitro and bone regeneration in both ectopic (Minardi et al., 2015a) and orthotopic large animal models (Minardi et al., 2019). Using this biologically inspired synthesis method, some researchers are currently working to develop bio-inspired hybrid nanocomposites with enhanced osteogenic features endowed with magnetic properties (D'Amora et al., 2016; Tampieri et al., 2016). Their potential for bone regeneration will be discussed further in section "Magnetically Responsive Materials" of this review.

\section{Nanostructured Bio-Glasses}

Bioactive glasses are mainly comprised of calcium oxide, silicate, borate, and phosphorous (Hench et al., 2014). By varying the relative amounts of these components, different bioactive glasses can be manufactured and, over the past three decades, many variants have been proposed for bone regenerative applications (van Vugt et al., 2017). Several are available clinically (Jones et al., 2016), and have demonstrated biocompatibility, osteoconductivity, and biodegradability (Kong et al., 2018).

Bioglasses can be prepared by melt-quench or sol-gel process (Vichery and Nedelec, 2016). While the first generations of bioglasses were solid or macroporous, the latest nanostructured versions, synthesized through the sol-gel approach, have unique nanostructural features, including improved nanotextural properties, highly ordered structure, and controlled pore size and pore interconnectivity (Islam et al., 2017; Mancuso et al., 2017). Such nano-features greatly enhance osseointegration compared to first generation bulk bioglasses. The graft-bone integration begins with the solubilization of surface ions resulting in a silica gel layer. A nanostructured calcium phosphate phase (i.e., hydroxyapatite) starts to nucleate on this layer, activating local osteoblasts to form new bone (Ducheyne, 2015). This mechanism contributes to the nano-bioglass degradation, while promoting bone formation. Even their degradation depends on their composition and nanostructure and can be tailored from days to months; for example, borate-based bioglasses have been shown to degrade much faster than silicate varieties (Balasubramanian et al., 2018; Furlan et al., 2018). Recent studies showed that increasing the surface area and porosity of nanostructured bioglasses can greatly accelerate their biodegradation, as well as biointegration (Kong et al., 2018).

The ability to release bioactive ions during degradation is one of the most important features of these bioglasses (Mouriño et al., 2019). For instance, it is known that the early vascularization of biomaterials plays an essential role in bone regeneration (Almubarak et al., 2016). Toward this end, numerous nanoparticles and mesoporous bioactive glasses have been specifically developed to enhance not only osteogenesis but also early angiogenesis through the release of pro-angiogenic ions (Kim J.-J. et al., 2017). Namely, strontium-doped bioglass nanoparticles have shown to increase both osteoblast activity (Fiorilli et al., 2018; Leite et al., 2018; Zhao et al., 2018), as well as induce osteoblasts to secrete angiogenesis-associated cytokines for early vascularization, ultimately resulting in improved bone repair (Zarins et al., 2016; Zhao et al., 2018). Similarly, bioglasses releasing copper or cobalt ions have also been proposed, due to their angiogenic properties (Bari et al., 2017; Weng et al., 2017; Kargozar et al., 2018; Zheng et al., 2018). Silver- (Kaya et al., 2018) or manganese-doped nanobioglasses (Nawaz et al., 2018) have instead been developed to deliver antimicrobial activity, and to aid in the healing process by preventing infections.

Due to their highly ordered mesopores and surface area, nanobioglasses can also be excellent delivery vehicles for bioactive molecules (e.g., drugs and proteins) to further boost bone repair (Baino et al., 2017; Wang et al., 2019; Lalzawmliana et al., 2020). For example, Lee J.-H. et al. (2017) reported a significant enhancement in osteoblast activity, secretion of ECM molecules and calcification through the controlled release of phenamil (a drug known as a potent BMP signaling activator) and strontium ions from mesoporous bioglass nanoparticles. In recent proofof-concept in vivo studies, others have demonstrated how mesoporous nanobioglasses can also be an ideal delivery system for growth factors, such as IGF (Lalzawmliana et al., 2019) or FGF (Kang et al., 2015), with significantly imporved regenerative outcomes in preclinical animal models.

\section{MIMICKING THE ELECTRICAL ENVIRONMENT OF BONE: NANOMATERIALS HARNESSING PIEZOELECTRICITY, CONDUCTIVITY AND MAGNETISM}

The field of bone mechanobiology has vastly improved since the advent of nanotechnology, expanding our fundamental knowledge of how mechanical forces regulate the process of bone homeostasis and remodeling (Chen et al., 2010). Although the origin remains a topic of debate, mechanical stress-generated electric potentials are known to be important in modulating cellular behavior to control growth and the remodeling process (Perez et al., 2015; Ribeiro et al., 2015b; Zhang et al., 2016). In addition to stress-generated potentials, electric fields present endogenously in living tissues, as well as electrical stimulation applied externally have also been shown to influence cell behavior and promote tissue growth (McCaig et al., 2005; Balint et al., 2013; Kang et al., 2014; Reid and Zhao, 2014; Funk, 2015). Accordingly, manipulation of the electrical environment has emerged as a promising strategy to enhance bone regeneration, with nanotechnological approaches offering tremendous potential for achieving this aim. Collectively, the nanomaterials recapitulating or leveraging the physical stimuli naturally present in the bone can be categorized as (i) piezoelectric, (ii) electrically conductive, and (iii) magnetic materials and are briefly summarized in Table 2. The impact of nanotechnology on their development and rational design is reviewed below.

\section{Piezoelectric Materials}

Piezoelectricity is observed when a mechanical deformation causes the formation of a net dipole moment and subsequent 
TABLE 2 | Advantages and disadvantages of nanostructured materials harnessing physical stimuli for bone regeneration.

\begin{tabular}{lll}
\hline \multicolumn{1}{c}{ Advantages } & Disadvantages \\
\hline Nanostructured piezoelectic materials & \\
Piezoelectric Ceramics & Robust piezoelectric characteristics & Potential for cytotoxicity \\
(e.g., BT, BN, ZnO) & Desirable osteoinductive potential &
\end{tabular}

\section{References}

\begin{tabular}{|c|c|c|c|}
\hline & & & rajlall, 2017; Enterami et al., 2018; Kao et al., 2 \\
\hline $\begin{array}{l}\text { Piezoelectric Polymers } \\
\text { (e.g., PVDF and its } \\
\text { copolymers, PLLA, } \\
\text { PHBV) }\end{array}$ & $\begin{array}{l}\text { Biocompatibility and non-toxicity } \\
\text { Manufacturing flexibility } \\
\text { High strength and impact } \\
\text { resistance }\end{array}$ & Unfavorable biodegradability & \\
\hline $\begin{array}{l}\text { Piezoelectric } \\
\text { Polymer-Ceramic } \\
\text { Composites }\end{array}$ & $\begin{array}{l}\text { Ability to tailor and enhance several } \\
\text { properties of the composite } \\
\text { construct: mechanical properties, } \\
\text { piezoelectric coefficient, } \\
\text { biodegradability, bioactivity }\end{array}$ & $\begin{array}{l}\text { Lack of data regarding the } \\
\text { piezoelectric properties of certain } \\
\text { composite materials }\end{array}$ & \\
\hline Nanostructured electri & cally conductive materials & & \\
\hline $\begin{array}{l}\text { Conductive } \\
\text { Nanomaterials } \\
\text { (non-polymeric, e.g., } \\
\text { graphene, gold } \\
\text { nanoparticles) }\end{array}$ & $\begin{array}{l}\text { Excellent mechanical properties } \\
\text { High electrical conductivity ensuring } \\
\text { reliable delivery of bioelectric signals }\end{array}$ & $\begin{array}{l}\text { Non-degradability } \\
\text { Questions/concerns regarding } \\
\text { biocompatibility and long-term } \\
\text { safety }\end{array}$ & $\begin{array}{l}\text { Kim S. et al., 2011; Otero et al., 2012; Bitounis et al., 2013; Liu } \\
\text { et al., 2013; Nurunnabi et al., 2015; Sridhar et al., 2015; Assaf } \\
\text { et al., 2017; Kim J.W. et al., 2017; Silva et al., 2017; Wang et al., } \\
\text { 2017; Zhou et al., 2017; Chan et al., 2018; Cheng et al., 2018; } \\
\text { Lalegul-Ulker et al., } 2018\end{array}$ \\
\hline $\begin{array}{l}\text { Conductive } \\
\text { Nanopolymers (e.g., } \\
\text { polyheterocycle family } \\
\text { of conductive polymers) }\end{array}$ & $\begin{array}{l}\text { Improved biocompatibility and } \\
\text { biodegradability } \\
\text { Manufacturing flexibility }\end{array}$ & $\begin{array}{l}\text { Unfavorable mechanical properties } \\
\text { and processability } \\
\text { Relative lack of animal studies } \\
\text { evaluating in vivo performance }\end{array}$ & \\
\hline Nanostructured Magne & tically Responsive Materials & & \\
\hline $\begin{array}{l}\text { Magnetic Nanoparticles } \\
\text { (MNPs) and } \\
\text { Magnetoelectric } \\
\text { Composites }\end{array}$ & $\begin{array}{l}\text { Superparamagnetic properties } \\
\text { Ability to deliver cues via remote } \\
\text { (external) stimulation }\end{array}$ & $\begin{array}{l}\text { Uncertain biocompatibility and } \\
\text { long-term safety }\end{array}$ & $\begin{array}{l}\text { Pisanic et al., 2007; Häfeli et al., 2009; Huang et al., 2009; Bock } \\
\text { et al., 2010; Wu et al., 2010b; Wu Y. et al., 2010; Wei et al., 2011; } \\
\text { Zhu et al., 2011; Panseri et al., 2012; Tampieri et al., 2012; Alarifi } \\
\text { et al., 2014; Singh R.K. et al., 2014; Shen et al., 2015; Li X. et al., } \\
\text { 2016; Ribeiro et al., 2016; Yun et al., } 2016\end{array}$ \\
\hline
\end{tabular}

Maeder et al., 2004; Boccaccini and Blaker, 2005; Opoku et al., 2015; Panda and Sahoo, 2015; Rocca et al., 2015; Fernandes et al., 2016; Li X. et al., 2016; Zhang et al., 2016; Bramhill et al., 2017; Damaraju et al., 2017; Ribeiro et al., 2017; Tajbakhsh and
Hajiali, 2017; Ehterami et al., 2018; Kao et al., 2019

Kim S. et al., 2011; Otero et al., 2012; Bitounis et al., 2013; Liu et al., 2013; Nurunnabi et al., 2015; Sridhar et al., 2015; Assaf et al., 2017; Kim J.W. et al., 2017; Silva et al., 2017; Wang et al., 2017; Zhou et al., 2017; Chan et al., 2018; Cheng et al., 2018; Lalegul-Ulker et al., 2018

Pisanic et al., 2007; Häfeli et al., 2009; Huang et al., 2009; Bock 2016; Ribeiro et al., 2016; Yun et al., 2016 polarization of the material (Tichý, 2010). Bone is a piezoelectric nanostructured material, and this property was invoked as a potential mechanism by which cells could detect and respond to mechanical stress (Fukada and Yasuda, 1957). The role for piezoelectricity in bone remodeling continues to be debated, and there has been renewed appeal for its physiologic importance in the process of bone mechanosensation (Halperin et al., 2004; Noris-Suarez et al., 2007). As such, with the emergence of nanotechnological approaches there has been a rapid increase in the number of publications on piezoelectric materials for bone regeneration (Tandon et al., 2018). They can be thought of as sensitive mechano-electrical transducers, and as such, they are typically applied to the implantation areas which are exposed to mechanical loads (Zhang K. et al., 2018; Chorsi et al., 2019). A number of different piezoelectric materials have been investigated for bone regeneration applications, which are briefly reviewed here.

\section{Inorganic Piezoelectric Materials: Piezoelectric Ceramics}

Nanopiezoceramic materials investigated for bone regeneration applications include barium titanate (BT), boron nitride (BN), and zinc oxide $(\mathrm{ZnO})$. While these materials possess a high piezoelectric coefficient, some of them display lower biocompatibility at high doses, which can represent a major limitation for their use in tissue engineering applications (Maeder et al., 2004; Opoku et al., 2015; Panda and Sahoo, 2015; Kao et al., 2019). Nevertheless, each of these piezoceramics has shown osteoinductive capabilities in vitro, supporting their use in the development of bone regenerative biomaterials, where they are often incorporated in a variety of ways into $3 \mathrm{D}$ scaffolds in order to impart piezoelectric characteristics to augment bone formation. For example, BT nanoparticles have been shown to enhance the osteogenic differentiation of MSCs, and osteoblastic cells demonstrated superior adhesion, proliferation, and migration into the pores of scaffolds comprised of BT, while BN nanotubes (BNNTs) demonstrate high protein adsorption ability and promotion of enhanced MSC attachment, proliferation, and osteogenic differentiation (Rocca et al., 2015; Li X. et al., 2016; Tajbakhsh and Hajiali, 2017; Ehterami et al., 2018). Finally, the incorporation of $\mathrm{ZnO}$ nanoparticles has proven capable of enhancing both the bioactivity and even the mechanical properties of such composite materials (Shalumon et al., 2011; Feng et al., 2014; Kao et al., 2019).

\section{Organic Piezoelectric Materials: Piezoelectric Polymers}

Piezoelectric polymers have also received increasing attention for bone regeneration applications in recent years (Tichý, 2010). Typically fabricated either as films, rods, 
or tubes/fibers (Ribeiro et al., 2015b), they exhibit sound mechanical properties, including superior strength and impact resistance when compared to inorganic materials. Biocompatibility, piezoelectric activity, and significant osteogenic capacity have also been demonstrated both in vitro and in vivo (Zhang et al., 2016; Damaraju et al., 2017; Ribeiro et al., 2017; Kao et al., 2019). Among these, PVDF [poly(vinylidene fluoride)] and its copolymers, PLLA, and PHBV (poly-3-hydroxybutyrate-3-hydroxy valerate) are the most studied.

Poly(vinylidene fluoride) and its copolymers can provide the necessary electromechanical stimulation for the differentiation of human MSCs into the osteogenic lineage in vitro (Damaraju et al., 2013, 2017; Nunes-Pereira et al., 2015; Ribeiro et al., 2015a; Zhang et al., 2016), as well as the capacity to effectively promote bone regeneration in vivo in rodent models (Zhang et al., 2016; Ribeiro et al., 2017). In addition to its potential utility as a bone graft substitute, PVDF has also shown promise as a suitable coating for existing implant materials in order to enhance osteogenesis (Zhou Z. et al., 2016). The primary concern with PVDF and its copolymers is the lack of biodegradability, which limits clinical potential. This limitation is being addressed with the development of newer-generation piezoelectric polymerbased materials with tailorable degradation properties. Poly-3hydroxybutyrate-3-hydroxy valerate and PLLA, both of which are biodegradable, have emerged as promising candidates (Duan et al., 2011), demonstrating osteogenic capacity both in vitro and in vivo (Ikada et al., 1996; Sultana and Wang, 2012; Wang et al., 2013). PLLA has also been explored for bone regeneration utility beyond its use as a bone graft substitute. Due to its biodegradability, non-toxicity, and advantageous mechanical properties, PLLA is an attractive material for clinical application in the fabrication of biodegradable fixation devices such as screws, pins, and suture anchors, where a bioresorbable implant is desirable to avoid the risk of complicating revision surgery or the requirement for an additional procedure for implant removal (Bucholz et al., 1994; Barber et al., 1995; Prokop et al., 2005; Gkiokas et al., 2012).

\section{Piezoelectric Polymer - Ceramic Composite Materials}

Piezoelectric polymers and ceramics have also been used in combination to fabricate a variety of composite materials (Boccaccini and Blaker, 2005; Bramhill et al., 2017). Polymer matrix composites harness the manufacturing flexibility afforded by polymers and the substantial piezoelectric properties of otherwise brittle ceramics to produce complex forms ideally suited to support bone formation, including porous scaffolds (Zhang et al., 2014; Liu et al., 2016), layered structures (Dubey et al., 2015), nanoparticles (Marino et al., 2015, 2017; Niskanen et al., 2016), and dense disks (Dubey et al., 2013). Of the polymer matrix composites, PLLA-based composites have been used most extensively in the field of bone regeneration (Fernandes et al., 2016; Tajbakhsh and Hajiali, 2017). Composite membranes incorporating PVDF-TrFE and $\mathrm{BT}$ have also been found to support bone formation in several investigations (Gimenes et al., 2004; Scalize et al., 2016; Zhang et al., 2016), suggesting significant potential for clinical application owing to the improved osteogenic capability demonstrated in vitro and in vivo in rodent bone defect models. Of the ceramic matrix composites, HA/BT-based materials are the most studied, with a number of studies demonstrating the osteoinductive capability of such composites (Jianqing et al., 1997; Baxter et al., 2009; Dubey et al., 2014; Jiao et al., 2017; Ehterami et al., 2018).

The emergence of piezoelectric materials and their rapidly increasing usage has motivated investigators to adopt new and innovative approaches to create biomaterials with desirable properties. Techniques which are gaining interest include 3D printing (Kim et al., 2014; Schult et al., 2016; Bodkhe et al., 2017), fabrication of piezoelectric nanofibers using solution blow spinning (Bolbasov et al., 2014, 2016; Daristotle et al., 2016), and the development of systems capable of applying controlled mechanical stimulation to piezoelectric scaffolds (Trumbull et al., 2016; Zhou X. et al., 2016).

A lack of quantitative data on the piezoelectric coefficient of many composite materials is a limitation to this newly emerging class of materials. However, although this area of research remains in its relative infancy, nanopiezoelectric materials show tremendous promise for bone regeneration.

\section{Electrically Conductive Materials}

In cases when the patient is immobilized, whether due to a fracture or other health condition, or in a non-load bearing healing setting, the natural mechanical stimulus does not occur and the effectiveness of piezoelectric materials is subsequently diminished (Mehta et al., 2012). Such limitations call for the development of new approaches capable of delivering electrical cues via alternative means, either by remote stimulation or through innovative nanomaterials activated by micromotion. Electrically conductive materials provide such an innovative tool, serving as the substrate through which external electrical stimulation is converted into bioelectric signals and delivered to the site (Chen et al., 2019).

Electrical stimulation therapy has occasionally been attempted as a supplement to promote bone healing in the case of fractures and spinal arthrodesis, although with arguable success, for decades (Gan and Glazer, 2006; Goldstein et al., 2010; Einhorn and Gerstenfeld, 2015). Researchers have more recently begun to explore conductive materials capable of propagating electrical signals to the site of repair in order to accelerate bone regeneration. Unlike piezoelectric materials, these require an externally applied power source to produce electrical signals. On one hand, this approach requires optimization of a number of different parameters including the frequency, amplitude, duration, and nature (alternating/direct) of the signal which may complicate assessment of efficacy (Dubey et al., 2011). On the other hand, it affords a great degree of control over the stimulus which cannot be achieved with the use of piezoelectric materials, allowing the functionality of the material to be tailored to its specific application.

One method for producing electroactive biomaterials capable of serving as conduits for the delivery of external electrical stimulation to cells involves the use of a polymer matrix incorporating conductive nanomaterials such as graphene (Assaf et al., 2017), carbon nanofibers (Whulanza et al., 2013), or 
metallic particles (e.g., gold nanoparticles) (Sridhar et al., 2015). Of these, graphene family materials have been found to possess excellent mechanical and conductive properties (Kim S. et al., 2011; Bitounis et al., 2013; Kim J.W. et al., 2017), support proliferation (Kalbacova et al., 2010) and osteogenic differentiation of MSCs (Nayak et al., 2011; Bressan et al., 2014), yield high degrees of mineralization (Lee et al., 2011; Xie et al., 2015), and even exert antimicrobial action (Pang et al., 2017). A number of graphene-based materials have been developed in the form of scaffolds, scaffold reinforcement materials, and surface coatings for existing materials, with demonstrated capacity to promote and enhance new bone formation in vivo (Silva et al., 2017; Wang et al., 2017; Zhou et al., 2017). Significant limitations to graphene and other similar electroactive materials include their non-degradability and uncertain biocompatibility, as well as questions regarding their long-term safety (Nurunnabi et al., 2015; Cheng et al., 2018).

To address these limitations, other methods of obtaining electroactive biomaterials which utilize intrinsically conductive polymers (CPs) have been explored. Such an approach offers the advantages of improved biocompatibility and biodegradability, in addition to manufacturing flexibility allowing incorporation of other components (Lalegul-Ulker et al., 2018). Among several CPs in use, the polyheterocycle family, including polypyrole (PPy), polyaniline (PANI), and polythiophene (PTh) and its derivative poly(3,4-ethylenedioxythiophene) (PEDOT), are the most extensively studied for bone regeneration applications (Otero et al., 2012). These materials exhibit desirable electrical conductivity sufficient to promote cell proliferation and osteogenic differentiation (Liu et al., 2013), but are limited by inherently poor mechanical properties and processability (Chan et al., 2018), prompting the development of conductive polymeric composites. For example, CPs can be blended with various other natural and/or synthetic non-CPs to fine-tune degradation and mechanical properties (Kaur et al., 2015). Conductive copolymers incorporating other electroactive polymeric components provide for further enhancement of biocompatibility, biodegradability, and electroactivity (Cui et al., 2012). Conductive polymer-based conducting nanofibers, conducting hydrogels, and $3 \mathrm{D}$ conductive composite scaffolds are additional examples of electroactive biomaterials being explored for bone regeneration applications (Sajesh et al., 2013; Li L. et al., 2016; Guex et al., 2017; Chen et al., 2018). While numerous investigations have generated exciting results supporting the osteogenic capabilities of conducting polymers and their composites in vitro, there remains a need for more animal studies to validate the performance of this promising family of electroactive biomaterials.

\section{Magnetically Responsive Materials}

Magnetic stimulation therapy, like electrical stimulation therapy, has been used clinically for a number of years (Assiotis et al., 2012). While the underlying mechanisms of action are unclear, in vitro studies suggest that pulsed and static magnetic fields are capable of enhancing osteoblast differentiation (Jansen et al., 2010; Wang et al., 2014; Marędziak et al., 2016), and animal studies have shown promise for promoting bony healing and integration into graft materials (Fredericks et al., 2000; Puricelli et al., 2006).

When describing the magnetic behavior of a material, ferro- and ferrimagnetism refer to a material's ability to be magnetized by an external magnetic field and remain magnetized upon its removal. Paramagnetism, on the other hand, is defined by a material's lack of retained magnetism upon removal of the external magnetic field, a desirable property in tissue engineering applications, as aggregation of the material's magnetic particles in vivo could lead to local toxicity (Balavijayalakshmi et al., 2014). Of particular interest are magnetic nanoparticles (MNPs) owing to their special superparamagnetic properties. Superparamagnetic behavior, exhibited by small ferro- or ferrimagnetic nanoparticles, do not retain magnetism in the absence of external magnetic fields; however, their magnetic susceptibility is much greater than that of standard paramagnetic materials, permitting precise magnetic control and functionalization for a given application (Reddy et al., 2012). Among MNPs, iron oxide nanoparticles, typically maghemite $\left(\mathrm{Fe}_{2} \mathrm{O}_{3}\right)$ or magnetite $\left(\mathrm{Fe}_{3} \mathrm{O}_{4}\right)$, have been the most commonly used (Liu et al., 2016), as they have demonstrated osteoinductive capacity in vitro, even in the absence of external magnetic stimulation (Huang et al., 2009; Bock et al., 2010; Wei et al., 2011). Thus, MNPs have been incorporated into conventional bioceramic or polymeric scaffolds, adding intrinsic magnetic properties capable of enhancing osteogenic potential. Results from in vivo studies suggest that the magnetic field resulting from the presence of incorporated MNPs, albeit small, can indeed drive the formation of new bone, even without external magnetic stimulation. Wu and colleagues incorporated iron oxide MNPs into a CaP bioceramic scaffold and found this material capable of enhancing osteogenesis in a rodent model of ectopic bone formation (Wu Y. et al., 2010), while Singh and associates produced a PCL biopolymeric nanofibrous scaffold incorporating iron oxide MNPs, which demonstrated the ability to enhance bone formation in a rodent segmental bone defect model (Singh R.K. et al., 2014).

MNP incorporation provides further functionality by rendering the biomaterial magnetically responsive, permitting the use of controlled external magnetic field stimulation to potentially regulate and direct cellular behavior toward osteogenesis and even angiogenesis (Sapir et al., 2012). Yun et al. (2016) studied the effects of external magnetic stimulation applied to magnetic PCL/MNP scaffolds on osteoblast differentiation and bone formation and found that external stimulation not only promoted in vitro osteoblastic differentiation, but also significantly enhanced new bone formation, compared to the magnetic scaffold alone, in mouse calvarium defects.

New and innovative methods in this arena continue to emerge. In a combined approach, magnetoelectric composite materials bridge the magnetic and piezoelectric properties of bone to produce a potentially synergistic regenerative effect. Such materials respond to magnetic stimulation with mechanical deformation (due to the magnetostriction of one component, that is the change in shape occurring during magnetization), resulting in electrical polarization (due to the piezoelectric behavior of 
the other component). Thus, bioelectrical cues can be delivered to a desired cellular environment with precise remote control (Ribeiro et al., 2016).

Since their introduction, concerns regarding the cytotoxic effects of iron oxides have justifiably arisen, with a documented relationship between their clinical use and the outbreak of acute adverse events, such as nephrogenic systemic fibrosis, formation of apoptotic bodies, inflammation, and other toxic effects (Pisanic et al., 2007; Häfeli et al., 2009; Wu et al., 2010b; Zhu et al., 2011; Alarifi et al., 2014; Shen et al., 2015). This has provoked efforts to produce magnetic biomaterials with improved biological features, such as doping well-known biocompatible nanomaterials with a magnetic phase to replace magnetite and the other iron oxides. Recently, Tampieri and colleagues reported fabrication of biocompatible FeHA nanoparticles with a superparamagnetic-like phase by doping $\mathrm{HA}$ with iron $\left(\mathrm{Fe}^{2+} / \mathrm{Fe}^{3+}\right)$ ions (Tampieri et al., 2012). In vitro studies showed that these FeHA nanoparticles were capable of enhancing cell proliferation to a greater degree than HA particles alone, without reducing cell viability. Furthermore, the in vivo biocompatibility of FeHA was demonstrated in a pilot animal study of a rabbit critical bone defect (Panseri et al., 2012). While approaches to bone regeneration based on magnetic stimulation and magnetically responsive biomaterials are in the early stages of development, the results to date suggest promise for such strategies in bone regeneration applications going forward.

\section{MATERIALS MIMICKING BONE ARCHITECTURE: 3D PRINTED AND BIOMORPHIC CERAMICS}

Native bone displays structural features with levels of organization spanning several orders of magnitude ( $\mathrm{nm}$ to $\mathrm{cm}$ scale) (Chen et al., 2008). This multiscale hierarchical structure, as well as the interactions between its organic and mineral components at the molecular level, contribute significantly to biological and mechanical properties of bone (Gupta et al., 2005). Thus, utilization of these features to guide the hierarchical design of biomaterials represents a potential strategy to promote bone regeneration. This section focuses on nanostructured scaffold materials designed to recapitulate native nanocues by providing mimicry of the structural features of the natural bone matrix.

\section{Architectural Considerations}

For bone tissue engineering applications, a scaffold should possess appropriate structural and mechanical properties to sustain physiological loads in order to preserve weight-bearing function, while also possessing intrinsic biocompatibility in order to facilitate favorable biomaterial-native bone interactions, which serve to enhance tissue regeneration and implant integration (Ikeda et al., 2009). Many early bone tissue engineering designs sought to accomplish this goal through synthetic structures which imparted bulk properties to the constructs, such as adequate mechanical strength and sufficient transport properties for cell infiltration and tissue organization (Christenson et al., 2007).
These designs, although successful in replicating many of the macroscopic properties of native bone, often failed prior to full healing (Burdick and Anseth, 2002; Murugan and Ramakrishna, 2005). A key factor identified in these failures was inadequate tissue regeneration around the material shortly after implantation, owing to poor interaction of the biomaterial with the host tissue (Christenson et al., 2007). In fact, the process of bone formation is governed by interactions and informational cues derived from structural features spanning multiple length scales from nanoscale to macroscale (Gusic et al., 2014). Nanoscale interactions in particular have been shown to be crucial in controlling cell functions such as proliferation, migration, and adhesion in native tissues (Benoit and Anseth, 2005). Indeed, all living systems are governed by molecular behavior at nanometer scales (Zhang et al., 2012). As in other tissues, the cellular organization and corresponding tissue properties of bone are highly dependent on the nanostructural features of the ECM, since cells are predisposed to interact with nanostructured surfaces (Kaplan et al., 1994; Taton, 2001; Liu et al., 2006). This may help to explain why early generation tissue substitutes-produced through macroand microfabrication techniques that were unable to recreate sophisticated structures that mimic the subtleties of the ECMshowed suboptimal performance. Recent paradigm shifts to nanoscience-enabled techniques have resulted in the emergence of novel nanotechnological approaches that enable more precise recapitulation of the architectural features of native bone, offering greater potential for modulating cellular behavior and enhancing bone regeneration (Webster et al., 2000; Murphy et al., 2010; Saiz et al., 2013; Tang et al., 2016).

Native bone is characterized by unique topological features derived from its micro- and nanostructured surfaces and interfaces, which are crucial to its function and growth and therefore promising targets for biomimicry (Nadeem et al., 2015). Nanotechnology offers new opportunities to capitalize on the structure-function relationships in bone by replicating a number of these integral features. By providing the substrate upon which cells attach and proliferate, surface topography can modulate cellular behavior and function (Boyan et al., 2002). Native bone is composed of collagen fibrils with rod or needle-like HA deposits scattered across their surface. These deposits produce surface roughness which has been shown to promote both adhesion of osteoblasts as well as differentiation of MSCs to the osteogenic lineage (Nadeem et al., 2015). Based on this, researchers have developed approaches to introduce surface roughness onto scaffold materials in order to more effectively mimic the mineralized interface encountered by cells adhering to native bone ECM (Henkel et al., 2013). Farshid and colleagues (Farshid et al., 2017), for instance, introduced microscale surface roughness onto polymeric scaffolds through the incorporation of boron nitride nanotubes and nanoplatelets, which resulted in greater collagen deposition and cell attachment by pre-osteoblasts in vitro. In another approach, Shakir et al. (2018) utilized nano-HA to enhance the surface roughness of a resin-based chitosan scaffold, which they found capable of promoting superior bone regeneration in vivo in a rat calvarium defect model. 
Given that the HA deposits producing surface roughness in native bone have dimensions in the nanoscale, fabrication of surfaces with nanostructured topography can prove even more beneficial to inducing osteogenesis than simply producing roughness at the microscale (Lim et al., 2005). Indeed, Lim and colleagues (Lim et al., 2005) generated nanoscale surface roughness by introducing "nanoislands" of varying size to a polymeric substrate and investigated their effects on osteoblastic cell behavior. They found that a smaller island height produced greater cell adhesion and spreading as well as increased alkaline phosphatase activity, demonstrating the advantages of downscaling the dimensions of topographical features. Other surface nanotopographies, such nanogrooves and nanopits, have also been shown to enhance osteoblast differentiation and osteogenic cell function in several studies (Dalby et al., 2007; Liu et al., 2014; Gong, 2015; Xu et al., 2017).

In addition to surface topography, cell and ECM alignment within the native bone represents a structural feature integral to its growth and function, and is thus a promising target for biomimicry (Takano et al., 1999). The anisotropic characteristics of bone tissue-a result of its unique adaptive response to external forces-is due to the longitudinal alignment of its collagen fibers, and there is evidence that MSCs more readily differentiate to an osteogenic phenotype when confined into such an alignment (Ber et al., 2005; Li et al., 2007). This phenomenon is thought to be mediated by contact guidance mechanisms whereby instructive physical cues, generated through the local interactions which occur in specific cellular orientations and alignment, act to regulate cell morphology and function (Boyan, 1996; Badami et al., 2006). Tissue engineering strategies which are capable of exploiting these mechanisms may therefore allow cell fate to be precisely directed for its intended application. For the purposes of bone tissue engineering, simulation of the alignment found in the native bone may potentially promote bone regeneration by driving stem cells toward an osteogenic lineage and enhancing their functions through the recapitulation of the native cues (Ber et al., 2005; Nadeem et al., 2015).

To achieve the desired alignment, one approach involves the creation of micron and/or nanoscale grooves on the substrate material, which allows cells to grow and spontaneously elongate along the direction of groove alignment (Perizzolo et al., 2001; Zhu et al., 2005; Badami et al., 2006). Nadeem et al. (2015) utilized such an approach through the introduction of integrated surface micropatterns to their $3 \mathrm{D} \mathrm{CaP} /$ gelatin biomaterials, producing cell-instructive scaffolds which were osteoinductive in vitro and promoted greater bone formation and osseointegration in vivo in a rabbit radial segmental defect model. A more direct approach toward biomimicry is to simply replicate the aligned fibers seen in the native collagenous architecture of bone. Innovative techniques utilizing aligned nanofibers created, for example, by electrospinning, have made it possible to accomplish this form of biomimicry with extraordinary precision (Jose et al., 2009; Anjaneyulu et al., 2017). By replicating the morphological and chemical structure of the natural ECM at the nanoscale level, nanofibrous scaffold materials offer greater potential to modulate cellular function and guide cell growth (Murugan and Ramakrishna, 2005; Leung and Ko, 2011; Paşcu et al., 2013).
Additionally, such materials provide increased surface area-tovolume ratios and porosity, thereby enhancing osteoconductivity, as well as desirable biocompatibility, biodegradability, and mechanical strength (Haider et al., 2018).

\section{D Printing}

The internal porosity of native bone is yet another important structural feature which bone regenerative engineering approaches have targeted for biomimicry. The presence of an interconnected, $3 \mathrm{D}$, porous architecture is a critical requirement for any bone tissue engineering strategy in order to allow for cell migration and the transport of nutrients and waste (Lee et al., 2014). Nanofibrous scaffolds prove especially advantageous in this regard, as the small fiber diameter creates a highly porous matrix enabling effective cell migration and proliferation throughout the scaffold (Rezwan et al., 2006; Zhang et al., 2008; $\mathrm{Xu}$ et al., 2017). In addition to overall porosity, average pore size is another significant consideration. Although the optimal pore size to promote bone regeneration within engineered scaffolds has not been definitively established, in general, smaller pore sizes will promote initial cell adhesion due to higher substrate surface area, while larger pores will enable greater cellular infiltration from surrounding tissue, a critical requirement for vascular ingrowth and subsequent tissue maintenance (Kenar et al., 2006; Murphy et al., 2010; Cox et al., 2015). While nanofibrous scaffolds provide a high overall porosity, nanofibers created by electrospinning tend to produce constructs with reduced average pore size compared to larger fiber scaffolds, resulting in decreased cell penetration depth (Badami et al., 2006). The need for more precise control of porosity and pore size within scaffold materials has prompted the implementation of novel 3D printing systems which may offer such capabilities. 3D printing technologies such as fused deposition modeling, stereolithography, and selective laser sintering have enabled the production of scaffolds with greater spatial resolution and fidelity than traditional fabrication methods, while also offering the ability to introduce precise pore gradients which more effectively mimic the physical cues for growth found in native bone tissue (Bracaglia et al., 2017; Alehosseini et al., 2018; Malikmammadov et al., 2018; Babilotte et al., 2019). While 3D printing approaches to the design of scaffolds for bone tissue engineering are quite new and still being explored for their utility, they also offer strong potential for the $3 \mathrm{D}$ patterning of surface roughness and other key physical features, providing even further recapitulation of the native cues present in bone (Murphy and Atala, 2014).

Mimicking the architecture of native bone is an essential component of material design for bone regeneration applications. These materials must provide an environment suitable for cellular recruitment, adhesion, proliferation, and pro-osteogenic differentiation. There is an abundance of technologies that provide tight control over topography, porosity, and mechanical properties of various materials that have proven useful for bone regeneration. Providing a suitable environment for osteogenesis is a crucial aspect of material design for bone regeneration, but it is not the only consideration. These materials must also be durable, biocompatible, and capable of integrating with 
surrounding tissues, among other properties, to be relevant for clinical applications.

\section{Scaffolds Synthesized Through Biomorphic Transformation}

Long bone and critical-sized defects caused by trauma, nonunion, or tumors represent a difficult clinical challenge in need of more reliable solutions (Berner et al., 2012; Roffi et al., 2017). Most currently available synthetic scaffolds have not proven capable of providing the necessary osteo- and vascular conductivity within the innermost portions of the scaffold. This could be attributed to a disorganized and tortuous porosity impeding cell penetration into the scaffold and subsequent tissue development; sufficient mechanical strength to promote integration with host tissues can also be a challenge (Mastrogiacomo et al., 2006).

In the attempt to overcome these limitations, "biomorphic transformations" have been developed. These synthetic approaches consist of a series of steps involving pyrolysis and complex chemical reactions (mainly liquid or gas infiltration processes), allowing for the chemical transformation of natural substrates into ceramic scaffolds, while preserving their original fine architecture from the nano up to the macro scale. Among natural templates, one is particularly advantageous as a solution to long bone defect healing-wood. Wood presents a unique hierarchical architecture on a cellular micro and nano-structure scale (Fratzl and Weinkamer, 2007). The pattern of fiber bundles and channel-like porous areas of selected types of wood (e.g., rattan) is surprisingly similar to that found in long bone (Tampieri et al., 2009). There have been a few remarkable attempts to utilize wood as a scaffold for the synthesis of biomimetic hierarchically organized load bearing scaffolds for long bone repair. In 2009, a biomimetic HA bone scaffold from natural wood with highly organized multiscale porosity was first proposed (Tampieri et al., 2009). The resulting material was a porous nanostructured apatite scaffold with a hierarchical structure, representing an inorganic substitute for bone graft that allowed for cellular invasion while providing space for vascularization (Tampieri et al., 2009). Recently, they used a similar approach of bio-ceramization of a wood template to prepare a hollow cylindrical ceramic scaffold to resemble cortical bone, and filled it with a spongy $\mathrm{HA} /$ collagen bio-hybrid scaffold to resemble spongy bone. They assessed the osteoconductivity of the construct in a sheep critical size load bearing model $(2 \mathrm{~cm}$ metatarsus defect), finding significant osteointegration at the bone/scaffold interface (Filardo et al., 2014). Using the same large animal model, in a follow-up study, they increased the diameter of the lumen of the external cortical-like biomorphic scaffold (Filardo et al., 2019). Osteointegration was observed in all samples, but the group with the largest internal diameter $(11 \mathrm{~mm})$ showed the best results in terms of bone-to-implant contact and new bone growth inside the scaffold. Additionally, the investigators posited that scaffold degradation in the cortical area-which induced osteointegration and new bone formation-is possible evidence of activation of load-induced biochemical signaling within the bone healing cascade.
Bigoni et al. (2020) reported that the mechanical properties of these biomorphic HA scaffolds have superior mechanical properties (higher strength, stiffness, and toughness at low density) when compared to usual porous ceramics obtained through sintering; probably due to the unique hierarchically organized multiscale resolution down to the nano-scale, which is not yet present in common ceramics.

While there is much potential for wood-based scaffolds and biomorphic transformation, certain drawbacks exist in comparison with other approaches. For instance, the process of biomorphic synthesis requires complex and strict control of reaction kinetics to avoid deformations and structural defects and to maintain the multiscale porosity (i.e., down to the nanoporosity) (Tampieri et al., 2018). Further, it relies on gassolid reactions that are strongly affected by different phenomena relating to adsorption of the gaseous reactant by the solid, kinetics of nucleation and growth of synthesized inorganic phase at the surface, and the penetration of the gaseous reactant within the innermost portion of the structure (Szekely, 2012). This control is vital when fabricating larger pieces, since diffusive phenomena affect the rate of phase transformation (Bigoni et al., 2020). Without strict control of this process, the advantages of wood as a template cannot be capitalized upon.

\section{MIMICKING BONE'S BIOCHEMICAL NICHE: DELIVERY OF BIOACTIVE MOLECULES}

A variety of bioactive molecules compose the biochemical milieu of bone (Minardi et al., 2020). Several strategies have been proposed to deliver biochemical cues (e.g., growth factors, cytokines) to recapitulate this environment and enhance bone regeneration, as summarized in Figure 3. Initial attempts consisted of the direct adsorption or crosslinking of biomolecules to implants, which resulted in suboptimal outcomes, mostly due to burst release and molecule denaturation (Fan et al., 2012).

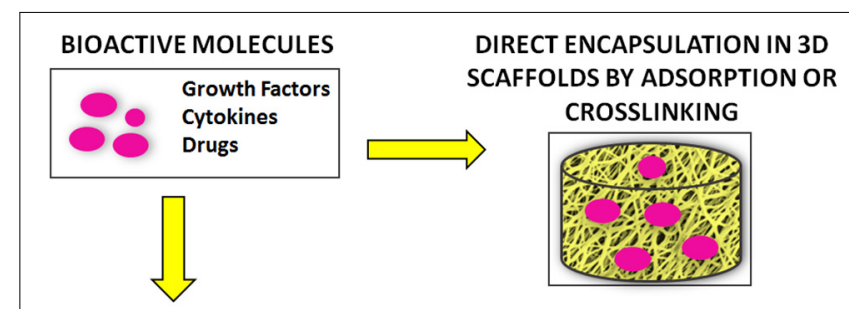

ENCAPSULATION IN NANOSTRUCTURED DELIVERY SYSTEMS

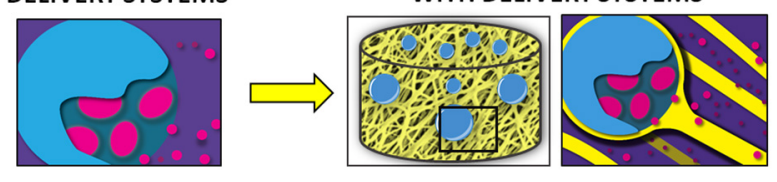

FIGURE 3 | Summary of the main strategies for the delivery of bioactive molecules for bone regeneration. 
TABLE 3 | Main types of nanostructured delivery systems used in bone regeneration, with their respective advantages and disadvantages.

\begin{tabular}{|c|c|c|c|}
\hline & Advantages & Disadvantages & References \\
\hline \multicolumn{4}{|c|}{ Inorganic nanostructured delivery systems } \\
\hline $\begin{array}{l}\text { Ceramics (e.g., HA, } \\
\text { TCP) }\end{array}$ & $\begin{array}{l}\text { Intrinsic osteoconductivity } \\
\text { Surface functionalization } \\
\text { Widely available }\end{array}$ & $\begin{array}{l}\text { Unfavorable biodegradability profile } \\
\text { Low yield of payload loading }\end{array}$ & $\begin{array}{l}\text { Matsumoto et al., 2004; Dong et al., 2007; Habraken et al., } \\
\text { 2007; LeGeros, 2008; Yuan et al., 2010; Xie et al., 2010; } \\
\text { Bose and Tarafder, 2012; Jeon et al., 2012; Fielding and } \\
\text { Bose, 2013; Fan et al., 2014; Wen et al., } 2017\end{array}$ \\
\hline $\begin{array}{l}\text { Metallic or metalloid } \\
\text { oxides (e.g., silica) }\end{array}$ & $\begin{array}{l}\text { Tailorable mesoporous structure } \\
\text { Surface functionalization with } \\
\text { and/or encapsulation of bioactive } \\
\text { molecules } \\
\text { Modifiable architecture and } \\
\text { topography } \\
\text { Optimization of cell adhesion and } \\
\text { proliferation }\end{array}$ & $\begin{array}{l}\text { Cytotoxicity at certain particle sizes } \\
\text { and/or concentrations }\end{array}$ & $\begin{array}{l}\text { Oh et al., 2005; Raja et al., 2005; Magrez et al., 2009; Lai } \\
\text { et al., 2011; Lallana et al., 2012; Portan et al., 2012; Tang } \\
\text { et al., 2012; Setyawati et al., 2013; Shadjou and } \\
\text { Hasanzadeh, 2015; Zhou et al., 2015; Cui et al., 2018; } \\
\text { Tang et al., 2014; Hu et al., 2012; Huang et al., 2014; Kwon } \\
\text { et al., 2017; Liu et al., } 2017\end{array}$ \\
\hline \multicolumn{4}{|c|}{ Organic nanostructured delivery systems } \\
\hline $\begin{array}{l}\text { Synthetic polymers } \\
\text { (e.g., PLA, PLGA) }\end{array}$ & $\begin{array}{l}\text { Widely available } \\
\text { Overall favorable biocompatibility } \\
\text { Many modifiable properties: e.g., } \\
\text { L/G ratio, molecular weight. } \\
\text { Modifiable with cross-linkers or } \\
\text { surface functionalization }\end{array}$ & $\begin{array}{l}\text { Low yield of payload loading } \\
\text { Burst release } \\
\text { Difficulty in accomplishing } \\
\text { sustained release } \\
\text { Certain polymers have cytotoxic } \\
\text { degradation products }\end{array}$ & $\begin{array}{l}\text { Alcantar et al., 2000; Habraken et al., 2007; Lü et al., 2009; } \\
\text { Puppi et al., 2010; Anderson and Shive, 2012; Makadia } \\
\text { and Siegel, 2011; Jacob et al., } 2018\end{array}$ \\
\hline $\begin{array}{l}\text { Natural polymers (e.g., } \\
\text { gelatin, chitosan) }\end{array}$ & $\begin{array}{l}\text { Widely available } \\
\text { Favorable biocompatibility and } \\
\text { biodegradability } \\
\text { Biomimetic properties } \\
\text { Modifiable with cross-linkers or } \\
\text { surface functionalization }\end{array}$ & $\begin{array}{l}\text { Low yield of payload loading } \\
\text { Rapid degradation in vivo } \\
\text { Burst release } \\
\text { Difficulty in accomplishing } \\
\text { sustained release }\end{array}$ & $\begin{array}{l}\text { Friess, 1998; Aframian et al., 2002; Malafaya et al., 2007; } \\
\text { Niu et al., 2009; He et al., 2011; Vo et al., 2012; Farokhi } \\
\text { et al., 2014; Amjadian et al., 2016; Cai et al., 2016; Ding } \\
\text { et al., 2016; Shen et al., 2016; Jacob et al., 2018; Oliveira } \\
\text { et al., } 2019\end{array}$ \\
\hline \multicolumn{4}{|c|}{ Composite nanostructured delivery systems } \\
\hline Composites & $\begin{array}{l}\text { High loading efficiency } \\
\text { Highly tunable release kinetics } \\
\text { Sustained release } \\
\text { Optimization of unique properties of } \\
\text { each material }\end{array}$ & $\begin{array}{l}\text { Generally require more complex } \\
\text { syntheses }\end{array}$ & $\begin{array}{l}\text { Li et al., 2006; Liu et al., 2009; Niu et al., 2009; Reves et al., } \\
\text { 2011; Fan et al., 2012; Singh et al., 2015; Minardi et al., } \\
\text { 2015b; Kim B.-S. et al., 2018; Wang et al., 2018; Zhang Q. } \\
\text { et al., 2018; Minardi et al., 2020 }\end{array}$ \\
\hline
\end{tabular}

Delivery systems offer more effective and precise control over release (Minardi et al., 2014). Among delivery systems, nanostructured varieties have proven superior, as they can be finely tuned to provide a higher yield of loading and sustained release over time, while allowing for complex temporally controlled release kinetics (Minardi et al., 2016b). The most common nanostructured delivery systems developed for bone regeneration are reviewed below and summarized in Table 3.

\section{Nanostructured Delivery Systems}

Osteogenic growth factors, including bone morphogenetic proteins (BMP-2 and BMP-7), or the transforming growth factor$\beta$ (TGF- $\beta$ ) family, are known to play a crucial role in cell proliferation, differentiation, and ultimately osteogenesis (Chen et al., 2004). As FDA-approved in 2002, BMP-2 is delivered with an absorbable collagen sponge (ACS) $\left[\mathrm{INFUSE}^{\mathrm{TM}}\right.$ ] for clinical applications (McKay et al., 2007). Although efficacious, supraphysiologic doses of the growth factor are required, which have been associated with a number of adverse side effects (Tannoury and An, 2014). Given these challenges, there is significant research interest in the development of novel delivery systems to provide controlled release of lower doses of BMP-2 and other bioactive molecules important for bone regeneration.
Toward this end, a wide array of nano-structured systems capable of delivering bioactive signals and molecules have been proposed.

\section{Inorganic Nanostructured Delivery Systems}

Utilizing ceramic materials for drug delivery in the field of bone regeneration presents advantages, as these materials themselves have osteoconductive properties (Habraken et al., 2007; LeGeros, 2008; Yuan et al., 2010). Commonly used ceramics include CaPs, such as HA and TCP. In the first generation of HA-based delivery systems, HA was directly adsorbed with bioactive molecules such as BMP-2 (Matsumoto et al., 2004; Dong et al., 2007; Xie et al., 2010), however, side effects associated with their burst release quickly demanded alternative strategies (Xie et al., 2010), such as chemically bonding bioactive molecules to the surface of the ceramic particles, which provides a more controlled and sustained release over time (Fan et al., 2014). The surface of $\mathrm{CaP}$ particles can be functionalized to bind a wide array of bioactive molecules for bone regeneration (Bose and Tarafder, 2012). For example, nano-HA particles can be functionalized to bind to and provide sustained release of BMP-2 to stimulate osteogenesis in vitro (Jeon et al., 2012).

Metallic or metalloid oxide nanomaterials such as silica $\left(\mathrm{SiO}_{2}\right)$ and titanium oxide $\left(\mathrm{TiO}_{2}\right)$ nanotubes have also been functionalized into nano-structured delivery systems for different 
bioactive molecules for bone regenerative applications (Lai et al., 2011; Shadjou and Hasanzadeh, 2015; Zhou et al., 2015). Silica-based nanomaterials (e.g., mesoporous silica) have been engineered to provide controlled release of different biomolecules (Shadjou and Hasanzadeh, 2015). These materials are generally biocompatible and can be easily functionalized with a number of different linker molecules (Lallana et al., 2012). Zhou et al. (2015) utilized silica nanoparticles to enable dual-delivery of BMP-2 and dexamethasone, and Cui et al. (2018) have utilized a silica-based nanomaterial delivery system for controlled release of BMP-2-related peptide both in vitro and in vivo. The tailorable mesoporous structure and the ability to bind a variety of different molecules are notable advantages of these silica-based materials (Tang et al., 2012). Additionally, the architecture and topography of these compounds can be engineered to promote cell adhesion, proliferation, and differentiation-all critical requirements for in vivo applications (Tang et al., 2014).

$\mathrm{TiO}_{2}$ nanotubes for delivery of drugs and other biomolecules have also been described ( $\mathrm{Hu}$ et al., 2012; Huang et al., 2014; Kwon et al., 2017). These can be designed to both encapsulate and display the molecule of interest on the material surface (Huang et al., 2014). One group directly functionalized the surface of $\mathrm{TiO}_{2}$ nanotubes with BMP-2, which promoted osteogenic differentiation in vitro (Lai et al., 2011). In addition to biomolecule delivery, the surface of $\mathrm{TiO}_{2}$ nanotubes can be activated and coated with ceramics like $\mathrm{CaP}$ or $\mathrm{HA}$ (Oh et al., 2005; Raja et al., 2005). However, concerns have arisen regarding the toxicity of $\mathrm{TiO}_{2}$-based nanomaterials, with one study suggesting that the strong adherence of osteoblasts to the metallic material may induce apoptosis (Portan et al., 2012; Setyawati et al., 2013; Liu et al., 2017). Dose-dependent cytotoxic effects of $\mathrm{TiO}_{2}$ nanofilaments have also been described elsewhere (Magrez et al., 2009).

\section{Organic Nanostructured Delivery Systems}

Alternatively, polymer-based delivery systems have been fabricated using both synthetic and natural materials (Jacob et al., 2018). Commonly used synthetic polymers include polyethylene glycol (PEG), poly(L-lactic acid) (PLA), PCL, PLGA, and poly(L-lactic acid) fumarate (PLAF). Polyethylene glycol and PLA are comprised of single monomers, while PCL, PLGA, and PLAF are copolymers. There has been extensive use of synthetic polymers as delivery systems for bone regeneration applications, including delivery of BMP-2, dexamethasone, antibiotics, and other pharmacologics (Puppi et al., 2010). Polyethylene glycol, PCL, and PLGA are all biocompatible (Alcantar et al., 2000; Anderson and Shive, 2012), although PLGA is generally favored, because it is FDA-approved and has been demonstrated to be non-inflammatory in various studies (Habraken et al., 2007; Lü et al., 2009; Makadia and Siegel, 2011). Additionally, various properties of PLGA-the L/G ratio, molecular weight, and stereochemistry-can be modified to control the polymer's properties and degradation rate (Habraken et al., 2007). Polymers such as PLA and PLGA can yield cytotoxic acidic degradation products (Habraken et al., 2007). Therefore, controlled degradation is important for both drug delivery and to minimize toxicity.
Natural polymers used for the controlled release of bioactive molecules to promote bone regeneration include gelatin, chitosan, alginate, collagen, silk fibroin, hyaluronic acid, and fibrin, among others (Jacob et al., 2018). These materials are advantageous given their biocompatibility and biomimetic properties, which result from a close resemblance of native ECM, and are also fully biodegradable (Malafaya et al., 2007; Vo et al., 2012). Natural polymers have been described in systems delivering BMP-2 (Niu et al., 2009; Shen et al., 2016), vascular endothelial growth factor (VEGF; Farokhi et al., 2014), antibiotics (Cai et al., 2016), and immunomodulators (Amjadian et al., 2016). However, there are known limitations to using natural polymers as the foundation for delivery systems. For example, controlling the release of molecules from these polymers is challenging. Collagen is known to degrade rapidly in vivo through protease action (Friess, 1998); however, various chemical modifications-including cross-linking (Aframian et al., 2002; He et al., 2011; Oliveira et al., 2019) or combination with other compounds (e.g., composite materials) (Niu et al., 2009; Ding et al., 2016)- have enabled researchers to significantly prolong the degradation rates of these natural polymers. Other limitations of natural polymers include fabrication costs, batch variability, and harvesting (Vo et al., 2012).

\section{Composite Nanostructured Delivery Systems}

Composite materials are often developed to overcome specific limitations of a given material, such as those described above. The optimal properties of each individual material can be leveraged when combining multiple components into one delivery system. Contributing to the sustained release of osteogenic factors, which is critical for in vivo outcomes, composite materials provide additional functionality that can be used to fine-tune the temporal release profile of a given compound. Some common examples include ceramic/polymer composites, polymer blends, and silica/polymer composites. Several different polymer and HA composite materials for controlled delivery of BMP-2 have been described, including silk fibroin/poly(ethylene oxide)/nano-HA (Li et al., 2006), gelatin/fibrin/nano-HA (Liu et al., 2009), collagen/poly(Llactic acid)/nano-HA (Niu et al., 2009), chitosan/nano-HA (Reves et al., 2011), and $\varepsilon$-polycaprolactone/HA (Kim B.S. et al., 2018). The polymer components can be crosslinked and functionalized, whereas the ceramic components provide osteoconductive properties. Multiple polymers have been combined to create polymer blends, which provide further control of degradation rates (Wang et al., 2018). Metal/metalloid and polymer composites for drug delivery are a popular and expanding area of research in bone tissue engineering. Although metallic oxides like silica can be engineered to provide burst release of biomolecules, further functionalization with polymers can provide sustained release over time. Poly(lactic-coglycolic acid)-mesoporous silicon composites have also gained significant traction as a delivery system. For example, PLGAmesoporous silicon microspheres have been engineered to deliver therapeutics, including BMP-2 (Minardi et al., 2020) and other bioactive molecules (Minardi et al., 2015b); these have demonstrated excellent release profiles, biocompatibility, 
and osteogenic profiles both in vitro and in vivo. Other groups have utilized similar composite systems for bone tissue engineering applications (Fan et al., 2012; Zhang Q. et al., 2018). In another study, Singh et al. (2015) created a composite of PCL nanofibers coated with a mesoporous silica shell that was capable of binding to and providing sustained release of several bioactive molecules, with a subsequent upregulation of osteogenic differentiation in vitro.

\section{Biomaterials Functionalized With Nanostructured Delivery Systems}

Scaffolds can be engineered to provide both spatially- and temporally controlled release of important biomolecules that facilitate bone regeneration and healing (Minardi et al., 2014, 2016b). While temporally controlled release is important to orchestrate the cascade of molecular and cellular events necessary to bone healing, the spatial release of biomolecules in vivo ensures that it occurs at the defect or desired area of interest for clinical applications (Minardi et al., 2016b). The most popular types of scaffolds (hydrogels (Nguyen and West, 2002), ceramics (Habraken et al., 2007), 3D-printed materials (Yi et al., 2016), and various composite materials (Yi et al., 2016) have all been proposed in combination with nanostructured delivery systems. These scaffolds can be functionalized with various bioactive components and molecules (Minardi et al., 2016b), including growth factors, peptides and mimicker molecules, immunomodulatory molecules, antibiotics, and even entire cells. Well-established as a potent stimulator of osteogenesis, incorporation of BMP-2 or BMP-2 mimetics into scaffolds is understandably an active area of research. Angiogenic factors such as VEGF, platelet derived growth factor (PDGF), and fibroblast growth factor (FGF) have also been shown to play an important role in bone regeneration and to support the maturation of the newly formed bone (David Roodman, 2003; Kaigler et al., 2006; De la Riva et al., 2010).

In addition to growth factors, systems can be functionalized to deliver other important bioactive molecules for bone healing, including immunomodulatory therapeutics and antibiotics to optimize bone healing. The host inflammatory response plays a critical role in osteogenesis and bone healing (Walsh et al., 2006; Guihard et al., 2012, 2015; Corradetti et al., 2015), and incorporation of immunomodulatory molecules within scaffolds provides another means to optimize bone healing and scaffold integration. Given that the risk of infection, including osteomyelitis, is significant after placement of implants (Lucke et al., 2003), the controlled release of antibiotics has the potential to provide a huge advantage to implanted devices and subsequent bone healing (Adams et al., 2009). Functionalization with these various molecules can occur via several different mechanisms, including incorporation of nanostructured systems within the scaffold, cross-linking and surface modifications, adsorption, direct loading of cells, among others. For example, various types of scaffolds-fibrous gelatin, poly(L-lactide), and HA particle composite (Amjadian et al., 2016) and electrospun nanofiber disks ( $\mathrm{Li}$ et al., 2015)-have been functionalized to deliver local dexamethasone to improve osteogenesis. Herein, we list and review the most common and successful strategies for incorporation of delivery systems into 3-dimensional implants for bone regeneration.

\section{Direct Incorporation of Nano-Delivery Systems in 3D Constructs}

Direct incorporation of bioactive molecules and nanostructured delivery systems has been accomplished using a number of different techniques. One common modality is the hydrogel. Numerous polymeric hydrogels have been developed (Hoare and Kohane, 2008), as they can be engineered to both control the release of biomolecules (Gibbs et al., 2016) and enhance cellular adhesion and differentiation (Tibbitt and Anseth, 2009). These hydrogels are typically biocompatible and can be easily functionalized with cell adhesion ligands by modification of their surface (Hoffman, 2012). Some challenges persist, including their fabrication and clinical deployment (Hoare and Kohane, 2008). Hydrogels also inherently lack a solid framework, can be difficult to handle, and they may be difficult to sterilize, which can limit the clinical utility of these materials (Hoffman, 2012). Madl et al. (2014) engineered alginate hydrogels functionalized with a peptide mimetic of BMP-2, which were shown to upregulate markers of osteogenic differentiation and increase mineralization in vitro. Delivery systems of angiogenic factors such as VEGF have also been incorporated into polymeric hydrogel scaffolds for delivery in vivo (Kempen et al., 2009).

\section{Surface Modification and Cross-Linking of Nano-Delivery Systems to 3D Constructs}

Surface modification and cross-linking are other modes of biomaterials functionalization. Surface chemistries can facilitate stable, covalent binding of molecules, with the potential to provide tightly controlled release (Nie et al., 2007). Heparinbased linkers, for example, are commonly used to link growth factors to surfaces (Liang and Kiick, 2014). Various examples of these linkers have been described for local delivery of BMP-2 (Kim S.E. et al., 2011; Yun et al., 2013) and angiogenic factors like VEGF (Lode et al., 2008; Singh et al., 2011) and PDGF (Lee et al., 2012). Delivery systems of BMP-2 have also been incorporated directly onto the surface of 3D-printed ceramic scaffolds using polymer emulsion (Kim B.-S. et al., 2018).

Surface modification with immunomodulatory molecules has also been described. For example, Spiller et al. (2015) functionalized a decellularized scaffold with IL-4 via biotinstreptavidin binding and/or IFN- $\gamma$ via adsorption, to facilitate rapid release of IFN- $\gamma$ to promote pro-inflammatory M1 macrophages and sustained release of IL-4 to promote prohealing M2 macrophages. Other groups have functionalized scaffolds with immunomodulatory molecules, including IL-4 (Minardi et al., 2016a), IL-10 (Rodell et al., 2015), and IL33 (Liu et al., 2018) for various applications. The delivery of immunomodulatory molecules is relatively novel, particularly for bone tissue engineering, and this area of research is at a pivotal stage. Notably, scaffolds functionalized with IFN- $\gamma$ have demonstrated increased vascularization relative to controls (Spiller et al., 2015). 


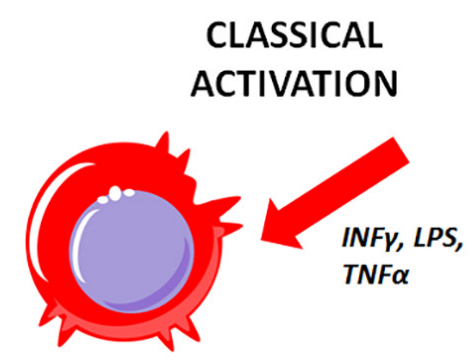

M1 MACROPHAGES

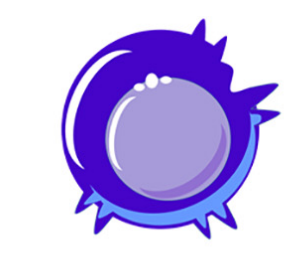

MO MACROPHAGES

II-10, TGF $\beta$, PDGF, VEGF, ARGINASE, etc.

\section{ALTERNATIVE ACTIVATION}

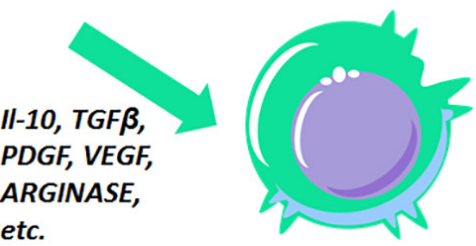

M2 MACROPHAGES

PRO-INFLAMMATORY

IMIMUNOMODULATIORY

\section{CYTOTOXICITY \& TISSUE INJURY}

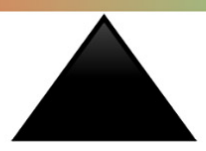

TISSUE REPAIR \& REMODELING

FIGURE 4 | Role of classically and alternatively activated macrophages in inflammation, tissue injury and regeneration.

Many other scaffolds have been engineered to provide a more sustained release of encapsulated BMP-2 (Yang et al., 2013; Rahman et al., 2014; Gan et al., 2015; Kim B.-S. et al., 2018; Mohammadi et al., 2018). Sun et al. (2018) fabricated a porous scaffold comprised of sintered HA nanoparticles, functionalized with either BMP-2 or BMP-2-related peptide, and both options provided significant osteogenic potential when assessed in a critical-size cranial defect model in rats. Hu et al. (2012) anodized a titanium substrate to form $\mathrm{TiO}_{2}$ nanotubes that were loaded with BMP-2 for sustained release, which showed promising upregulation of osteogenic differentiation in vitro.

\section{Multifunctional Nanofiber Scaffolds as Drug Delivery Systems}

Some nanostructured materials can simultaneously be used for the loading and release of bioactive molecules or to bind endogenous growth factors as well as to fabricate $3 \mathrm{D}$ scaffolds. A prime example is the use of peptide amphiphiles. Stupp and coworkers engineered a heparin-binding peptide amphiphile (HBPA) nanogel capable of binding and mimicking physiologic BMP-2 signaling (Lee et al., 2013). This BMP-2binding PA promoted bone regeneration in a rat critical size femoral defect model with 10-fold lower doses than typically required (Lee et al., 2013). Additional approaches by this group have shown that BMP-2-binding PA nanogels provide significant bone regenerative capacity in an established preclinical posterolateral lumbar fusion (PLF) model with 10-fold lower doses of BMP-2 than typically required (Lee et al., 2015). In another study, hydrogels were designed with BMP-2 mimicking peptides that were capable of inducing osteogenic differentiation of rat MSCs in vitro. This osteogenic capacity was confirmed in vivo using a rat cranial defect model (Liang et al., 2019). In a recent study, peptide amphiphiles were functionalized with supramolecular glycopeptide nanostructures containing sulfated monosaccharides (Lee S. S. et al., 2017), given that heparan sulfate chains are a critical motif for the binding of many osteogenic growth factors under physiologic conditions ( $\mathrm{Xu}$ and Esko, 2014). When assessed in vivo using an established rat PLF model, the PA nanostructures combined with a 100 -fold lower dose of BMP-2 than typically required (100 ng of BMP2 per animal) yielded an impressive $100 \%$ fusion rate (Lee S. S. et al., 2017). PA nanostructures combined with an even lower dose of BMP-2 (10 ng/animal, or $5 \mathrm{ng} / \mathrm{scaffold})$ or without BMP-2 did not yield fusion, although PA nanofibers alone were minimally bioactive when assessed in vitro in C2C12 cells (Lee S. S. et al., 2017). The pre-clinical data regarding the use of PAbased materials for bone regeneration are promising. Although it is possible to control the nano-scale properties of the PAs, functionalize with different binding motifs, and gel the material into a macrostructure for in vivo applications, some future challenges include optimizing these materials for different clinical applications, ensuring minimal batch-to-batch variability, and large-scale fabrication of these materials.

These studies are but a few examples of the surface chemistries that can be employed to functionalize scaffolds with bioactive molecules. Given the multitude of variables that can be manipulated, the potential for drug delivery and bone regeneration applications are ever-expanding.

\section{DISCUSSION AND CONCLUSION}

While each of the previously discussed approaches to bone regeneration show promise, bone defects are not all alike. For instance, the repair of large bone defects resulting from trauma requires a mechanically competent scaffold (Masquelet et al., 2000). Arthroplasty, on the other hand, calls for strategies that improve implant lifespan, as the longevity of conventional 
materials remains a major limitation in this setting (Smith et al., 2018). For this application, the key to success lies in improving the osseointegration of existing implants through surface modifications (Serra et al., 2013; Puertolas and Kurtz, 2014). Orthopedic infection is another major challenge to implant-based bone healing, and additional material characteristics, such as antimicrobial properties, should be considered.

Even so, the biological environment for bone healing may also be compromised as a result of numerous patient-related factors, local and/or systemic, including advanced age, gender, tobacco, and/or alcohol use, pre-existing chronic illness, and the use of certain medications (Andrzejowski and Giannoudis, 2019). For example, the bone healing deficiencies observed in older patients or smokers may require cell-based approaches or growth factors such as rhBMP-2, which may reliably stimulate healing but can be associated with significant adverse effects. Another example is the use of biologics, which is a strategy of choice in several orthopedic procedures, but that remains inappropriate in oncologic patients, where this may potentially exert local or even systemic tumor-promoting effects (Serakinci et al., 2014; Holzapfel et al., 2016). Together, these influences act through a variety of mechanisms to predispose some patients to impaired bone regeneration, which can only be overcome by personalized regenerative strategies. By providing more precise and individualized treatment modalities, nanotechnological approaches to bone regeneration may provide more effective and longer-lasting implants, decreased infection rates, and improved bony healing, which could ultimately translate to improved patient outcomes. In particular, nanotechnology has allowed for the design of materials that can approach the challenge of augmenting bone regeneration from different angles, such as simultaneously mimicking the bone nano-composition and structure, while serving as a delivery vehicle for bioactive molecules and/or cells (Zhao et al., 2011). Nano-biomaterials that are able to recapitulate more than one of the aspects of bone as reviewed herein may certainly offer superior performances in challenging clinical settings. For example, nanotechnology offers oncologic patients novel means of integrating drug delivery functions into osteoinductive biomaterials which in turn can be used for both the regeneration of bone defects as well as the targeted treatment of the cancer (Acharya and Sahoo, 2011; Gu et al., 2013; Rawat et al., 2015).

Given that each bone defect and combination of pre-existing conditions may call for different regenerative strategies or a combination of them, it is also crucial not to overlook the role of the host's immune system in bone healing. In fact, the immune system not only protects the body from pathogens but also orchestrates the response to foreign materials, and monitors for possible alterations in tissue homeostasis through a mechanism known as inflammation (Taraballi et al., 2018). While many researchers have investigated methods to minimize the immune response to materials to preserve their regenerative potential, in recent years there has been a shift toward the development of technologies able to preferentially engage the host's immune cells. In fact, inflammation and the subsequent recruitment of immune cells to the diseases site are paramount to initiate healing (Taraballi et al., 2018). Nonetheless, while inflammation is desirable due to its key role in initiating tissue repair, it does need to be controlled in order to avoid the initiation of a foreign body response against bone regenerative materials (Franz et al., 2011).

Inflammation consists of the infiltration, proliferation, and polarization of hematopoietic and non-hematopoietic cells, that are recruited and activated by specific bioactive factors produced within the lesion (Taraballi et al., 2018). Among the cells involved in this highly orchestrated process, macrophages have been found to be the primary players (Wynn and Vannella, 2016; Michalski and McCauley, 2017). Classically activated macrophages (M1) are the first to be recruited to the site of injury and are gradually replaced by the alternatively activated macrophages (M2) if a regenerative response is initiated (Minardi et al., 2016a). M2 macrophages are immunomodulatory and coordinate tissue repair-producing anti-inflammatory molecules such as IL-10 and TGF- $\beta$; this triggers angiogenesis and matrix remodeling, while suppressing the M1-mediated inflammation (Figure 4; Minardi et al., 2016a).

Currently, the two main strategies to modulate the macrophage-driven inflammatory response are through (i) materials functionalized with nanodelivery systems for the release of immunomodulatory mediators (Spiller et al., 2015); (ii) materials engineered at the nanoscale so that their composition and structure itself may induce macrophage polarization toward the M2 lineage (Vasconcelos et al., 2016; Zhang R. et al., 2018; Lee et al., 2019). Compared to classical cell-based regenerative strategies, immunomodulatory strategies leverage on the selfhealing capabilities of the body, thus resulting less technically challenging, since they do not require the direct encapsulation or delivery of live cells.

Although the field of immunomodulatory materials is still in its relative infancy, nanostructured materials have proven to have the necessary level of sophistication to address the challenges of this new arena. Nanostructured immunomodulatory materials will be amongst the most disruptive bone regenerative technologies, as the future of bone regeneration is clearly headed toward increasingly personalized approaches.

\section{AUTHOR CONTRIBUTIONS}

$\mathrm{SM}, \mathrm{EH}$, and WH conceived and outlined the review. All authors wrote and edited the manuscript and designed the schematics.

\section{FUNDING}

Partial salary support was provided for the authors through the NIH grants 5R01AR069580 and 5R01AR072721.

\section{ACKNOWLEDGMENTS}

We thank Parker Marsh and Jonathan Paul for assisting with the collection and review of some of the references cited in this manuscript. 


\section{REFERENCES}

Acharya, S., and Sahoo, S. K. (2011). PLGA nanoparticles containing various anticancer agents and tumour delivery by EPR effect. Adv. Drug Deliv. Rev. 63, 170-183. doi: 10.1016/j.addr.2010.10.008

Adams, C. S., Antoci, V. Jr., Harrison, G., Patal, P., Freeman, T. A., Shapiro, I. M., et al. (2009). Controlled release of vancomycin from thin sol-gel films on implant surfaces successfully controls osteomyelitis. J. Orthopaedic Res. 27, 701-709. doi: 10.1002/jor.20815

Aframian, D., Redman, R., Yamano, S., Nikolovski, J., Cukierman, E., Yamada, K., et al. (2002). Tissue compatibility of two biodegradable tubular scaffolds implanted adjacent to skin or buccal mucosa in mice. Tissue Eng. 8, 649-659. doi: 10.1089/107632702760240562

Akman, A. C., Tığlı, R. S., Gümüşderelioğlu, M., and Nohutcu, R. M. (2010). bFGF-loaded HA-chitosan: a promising scaffold for periodontal tissue engineering. J. Biomed. Mater. Res. Part A 92, 953-962.

Alarifi, S., Ali, D., Alkahtani, S., and Alhader, M. S. (2014). Iron oxide nanoparticles induce oxidative stress, DNA damage, and caspase activation in the human breast cancer cell line. Biol. Trace Elem. Res. 159, 416-424. doi: 10.1007/s12011014-9972-0

Alcantar, N. A., Aydil, E. S., and Israelachvili, J. N. (2000). Polyethylene glycolcoated biocompatible surfaces. J. Biomed. Mater. Res. 51, 343-351. doi: 10.1002/ 1097-4636(20000905)51:3<343::AID-JBM7>3.0.CO;2-D

Alehosseini, M., Golafshan, N., Kharaziha, M., Fathi, M., and Edris, H. (2018). Hemocompatible and bioactive heparin-loaded PCL- $\alpha$-TCP fibrous membranes for bone tissue engineering. Macromol. Biosci. 18:1800020. doi: 10.1002/mabi.201800020

Alizadeh-Osgouei, M., Li, Y., and Wen, C. (2019). A comprehensive review of biodegradable synthetic polymer-ceramic composites and their manufacture for biomedical applications. Bioactive Mater. 4, 22-36. doi: 10.1016/j.bioactmat. 2018.11.003

Almubarak, S., Nethercott, H., Freeberg, M., Beaudon, C., Jha, A., Jackson, W., et al. (2016). Tissue engineering strategies for promoting vascularized bone regeneration. Bone 83, 197-209. doi: 10.1016/j.bone.2015.11.011

Amjadian, S., Seyedjafari, E., Zeynali, B., and Shabani, I. (2016). The synergistic effect of nano-hydroxyapatite and dexamethasone in the fibrous delivery system of gelatin and poly (l-lactide) on the osteogenesis of mesenchymal stem cells. Int. J. Pharm. 507, 1-11. doi: 10.1016/j.ijpharm.2016.04.032

Anderson, J. M., and Shive, M. S. (2012). Biodegradation and biocompatibility of PLA and PLGA microspheres. Adv. Drug Deliv. Rev. 64, 72-82. doi: 10.1016/j. addr.2012.09.004

Andrzejowski, P., and Giannoudis, P. V. (2019). The 'diamond concept' for long bone non-union management. J. Orthop. Traumatol. 20:21. doi: 10.1186/ s10195-019-0528-0

Angevine, P. D., Zivin, J. G., and McCormick, P. C. (2005). Cost-effectiveness of single-level anterior cervical discectomy and fusion for cervical spondylosis. Spine (Phila Pa 1976) 30, 1989-1997. doi: 10.1097/01.brs.0000176332.67849.ea

Anjaneyulu, U., Priyadarshini, B., Nirmala Grace, A., and Vijayalakshmi, U. (2017). Fabrication and characterization of Ag doped hydroxyapatite-polyvinyl alcohol composite nanofibers and its in vitro biological evaluations for bone tissue engineering applications. J. Sol-Gel Sci. Technol. 81, 750-761. doi: 10.1007/ s10971-016-4243-5

Arinzeh, T. L., Tran, T., Mcalary, J., and Daculsi, G. (2005). A comparative study of biphasic calcium phosphate ceramics for human mesenchymal stemcell-induced bone formation. Biomaterials 26, 3631-3638. doi: 10.1016/j. biomaterials.2004.09.035

Assaf, K., Leal, C. V., Derami, M. S., de Rezende Duek, E. A., Ceragioli, H. J., and de Oliveira, A. L. R. (2017). Sciatic nerve repair using poly(epsilon-caprolactone) tubular prosthesis associated with nanoparticles of carbon and graphene. Brain Behav. 7:e00755. doi: 10.1002/brb3.755

Assiotis, A., Sachinis, N. P., and Chalidis, B. E. (2012). Pulsed electromagnetic fields for the treatment of tibial delayed unions and nonunions. A prospective clinical study and review of the literature. J. Orthop. Surg. Res. 7:24. doi: 10.1186/1749799X-7-24

Babilotte, J., Guduric, V., Le Nihouannen, D., Naveau, A., Fricain, J. C., and Catros, S. (2019). 3D printed polymer-mineral composite biomaterials for bone tissue engineering: fabrication and characterization. J. Biomed. Mater. Res. 107, 2579-2595. doi: 10.1002/jbm.b.34348
Badami, A. S., Kreke, M. R., Thompson, M. S., Riffle, J. S., and Goldstein, A. S. (2006). Effect of fiber diameter on spreading, proliferation, and differentiation of osteoblastic cells on electrospun poly(lactic acid) substrates. Biomaterials 27, 596-606. doi: 10.1016/j.biomaterials.2005.05.084

Baino, F., Fiorilli, S., and Vitale-Brovarone, C. (2017). Composite biomaterials based on sol-gel mesoporous silicate glasses: a review. Bioengineering 4:15. doi: 10.3390/bioengineering4010015

Balasubramanian, P., Buettner, T., Pacheco, V. M., and Boccaccini, A. R. (2018). Boron-containing bioactive glasses in bone and soft tissue engineering. J. Eur. Ceramic Soc. 38, 855-869. doi: 10.1016/j.jeurceramsoc.2017.11.001

Balavijayalakshmi, J., Suriyanarayanan, N., and Jayaprakash, R. (2014). Effects of sintering on structural and magnetic properties of $\mathrm{Cu}$ substituted cobalt-nickel mixed ferrite nano particles. J. Magn. Magn. Mater. 362, 135-140. doi: 10.1016/ j.jmmm.2014.03.005

Balint, R., Cassidy, N. J., and Cartmell, S. H. (2013). Electrical stimulation: a novel tool for tissue engineering. Tissue Eng. Part B Rev. 19, 48-57. doi: 10.1089/ten. TEB.2012.0183

Barber, F. A., Elrod, B. F., McGuire, D. A., and Paulos, L. E. (1995). Preliminary results of an absorbable interference screw. Arthroscopy 11, 537-548. doi: 10. 1016/0749-8063(95)90129-9

Bari, A., Bloise, N., Fiorilli, S., Novajra, G., Vallet-Regí, M., Bruni, G., et al. (2017). Copper-containing mesoporous bioactive glass nanoparticles as multifunctional agent for bone regeneration. Acta Biomater. 55, 493-504. doi: 10.1016/j.actbio.2017.04.012

Bauer, T. W., and Muschler, G. F. (2000). Bone graft materials. An overview of the basic science. Clin. Orthop. Relat. Res. 371, 10-27. doi: 10.1097/00003086200002000-00003

Baxter, F. R., Turner, I. G., Bowen, C. R., Gittings, J. P., and Chaudhuri, J. B. (2009). An in vitro study of electrically active hydroxyapatite-barium titanate ceramics using Saos-2 cells. J. Mater. Sci. 20, 1697-1708. doi: 10.1007/s10856-0093734-0

Benoit, D. S., and Anseth, K. S. (2005). The effect on osteoblast function of colocalized RGD and PHSRN epitopes on PEG surfaces. Biomaterials 26, 5209-5220. doi: 10.1016/j.biomaterials.2005.01.045

Ber, S., Torun Kose, G., and Hasirci, V. (2005). Bone tissue engineering on patterned collagen films: an in vitro study. Biomaterials 26, 1977-1986. doi: 10.1016/j.biomaterials.2004.07.007

Berner, A., Reichert, J. C., Müller, M. B., Zellner, J., Pfeifer, C., Dienstknecht, T., et al. (2012). Treatment of long bone defects and non-unions: from research to clinical practice. Cell Tissue Res. 347, 501-519. doi: 10.1007/s00441-0111184-8

Bernstein, M., Gotman, I., Makarov, C., Phadke, A., Radin, S., Ducheyne, P., et al. (2010). Low temperature fabrication of $\beta$-TCP-PCL nanocomposites for bone implants. Adv. Eng. Mater. 12, B341-B347. doi: 10.1002/adem.201080027

Bhumiratana, S., Grayson, W. L., Castaneda, A., Rockwood, D. N., Gil, E. S., Kaplan, D. L., et al. (2011). Nucleation and growth of mineralized bone matrix on silk-hydroxyapatite composite scaffolds. Biomaterials 32, 2812-2820. doi: 10.1016/j.biomaterials.2010.12.058

Bian, T., Zhao, K., Meng, Q., Tang, Y., Jiao, H., and Luo, J. (2019). The construction and performance of multi-level hierarchical hydroxyapatite (HA)/collagen composite implant based on biomimetic bone Haversian motif. Mater. Design 162, 60-69. doi: 10.1016/j.matdes.2018.11.040

Bianco, A., Cacciotti, I., Lombardi, M., Montanaro, L., Bemporad, E., and Sebastiani, M. (2010). F-substituted hydroxyapatite nanopowders: thermal stability, sintering behaviour and mechanical properties. Ceram. Int. 36, 313322. doi: 10.1016/j.ceramint.2009.09.007

Bigoni, D., Cavuoto, R., Misseroni, D., Paggi, M., Ruffini, A., Sprio, S., et al. (2020). Ceramics with the signature of wood: a mechanical insight. Mater. Today Bio 5:100032. doi: 10.1016/j.mtbio.2019.100032

Bitounis, D., Ali-Boucetta, H., Hong, B. H., Min, D. H., and Kostarelos, K. (2013). Prospects and challenges of graphene in biomedical applications. Adv. Mater. 25, 2258-2268. doi: 10.1002/adma.201203700

Boanini, E., Gazzano, M., and Bigi, A. (2010). Ionic substitutions in calcium phosphates synthesized at low temperature. Acta Biomater. 6, 1882-1894. doi: 10.1016/j.actbio.2009.12.041

Boccaccini, A. R., and Blaker, J. J. (2005). Bioactive composite materials for tissue engineering scaffolds. Expert Rev. Med. Devices 2, 303-317. doi: 10.1586/ 17434440.2.3.303 
Bock, N., Riminucci, A., Dionigi, C., Russo, A., Tampieri, A., Landi, E., et al. (2010). A novel route in bone tissue engineering: magnetic biomimetic scaffolds. Acta Biomater. 6, 786-796. doi: 10.1016/j.actbio.2009.09.017

Bodkhe, S., Turcot, G., Gosselin, F. P., and Therriault, D. (2017). One-step solvent evaporation-assisted 3D printing of piezoelectric PVDF nanocomposite structures. ACS Appl. Mater. Interf. 9, 20833-20842. doi: 10.1021/acsami. $7 \mathrm{~b} 04095$

Bolbasov, E. N., Anissimov, Y. G., Pustovoytov, A. V., Khlusov, I. A., Zaitsev, A. A., Zaitsev, K. V., et al. (2014). Ferroelectric polymer scaffolds based on a copolymer of tetrafluoroethylene with vinylidene fluoride: fabrication and properties. Mater. Sci. Eng. 40, 32-41. doi: 10.1016/j.msec.2014.03.038

Bolbasov, E. N., Stankevich, K. S., Sudarev, E. A., Bouznik, V. M., Kudryavtseva, V. L., Antonova, L. V., et al. (2016). The investigation of the production method influence on the structure and properties of the ferroelectric nonwoven materials based on vinylidene fluoride - tetrafluoroethylene copolymer. Mater. Chem. Phys. 182, 338-346. doi: 10.1016/j.matchemphys.2016.07.041

Bose, S., and Tarafder, S. (2012). Calcium phosphate ceramic systems in growth factor and drug delivery for bone tissue engineering: a review. Acta Biomater. 8, 1401-1421. doi: 10.1016/j.actbio.2011.11.017

Bose, S., Tarafder, S., Banerjee, S. S., Davies, N. M., and Bandyopadhyay, A. (2011). Understanding in vivo response and mechanical property variation in $\mathrm{MgO}$, SrO and SiO2 doped $\beta$-TCP. Bone 48, 1282-1290. doi: 10.1016/j.bone.2011.03. 685

Boyan, B. (1996). Role of material surfaces in regulating bone and cartilage cell response. Biomaterials 17, 137-146. doi: 10.1016/0142-9612(96)85758-9

Boyan, B. D., Bonewald, L. F., Paschalis, E. P., Lohmann, C. H., Rosser, J., Cochran, D. L., et al. (2002). Osteoblast-mediated mineral deposition in culture is dependent on surface microtopography. Calcified Tissue Int. 71, 519-529. doi: 10.1007/s00223-001-1114-y

Bracaglia, L. G., Smith, B. T., Watson, E., Arumugasaamy, N., Mikos, A. G., and Fisher, J. P. (2017). 3D printing for the design and fabrication of polymer-based gradient scaffolds. Acta Biomater. 56, 3-13. doi: 10.1016/j.actbio.2017.03.030

Bramhill, J., Ross, S., and Ross, G. (2017). Bioactive nanocomposites for tissue repair and regeneration: a review. Int. J. Environ. Res. Public Health 14:66. doi: 10.3390/ijerph14010066

Bressan, E., Ferroni, L., Gardin, C., Sbricoli, L., Gobbato, L., Ludovichetti, F. S., et al. (2014). Graphene based scaffolds effects on stem cells commitment. J. Transl. Med. 12:296. doi: 10.1186/s12967-014-0296-9

Bucholz, R. W., Henry, S., and Henley, M. B. (1994). Fixation with bioabsorbable screws for the treatment of fractures of the ankle. J. Bone Joint Surg. Am. 76, 319-324. doi: 10.2106/00004623-199403000-00001

Burdick, J. A., and Anseth, K. S. (2002). Photoencapsulation of osteoblasts in injectable RGD-modified PEG hydrogels for bone tissue engineering. Biomaterials 23, 4315-4323. doi: 10.1016/s0142-9612(02)00176- $\mathrm{x}$

Burkus, J. K., Gornet, M. F., Dickman, C. A., and Zdeblick, T. A. (2002). Anterior lumbar interbody fusion using rhBMP-2 with tapered interbody cages. J. Spinal Disord. Tech. 15, 337-349. doi: 10.1097/00024720-200210000-00001

Burkus, J. K., Heim, S. E., Gornet, M. F., and Zdeblick, T. A. (2003). Is INFUSE bone graft superior to autograft bone? An integrated analysis of clinical trials using the LT-CAGE lumbar tapered fusion device. J. Spinal Disord. Tech. 16, 113-122. doi: 10.1097/00024720-200304000-00001

Cai, Y., Yu, J., Kundu, S. C., and Yao, J. (2016). Multifunctional nanohydroxyapatite and alginate/gelatin based sticky gel composites for potential bone regeneration. Mater. Chem. Phys. 181, 227-233. doi: 10.1016/j. matchemphys.2016.06.053

Campana, V., Milano, G., Pagano, E., Barba, M., Cicione, C., Salonna, G., et al. (2014). Bone substitutes in orthopaedic surgery: from basic science to clinical practice. J. Mater. Sci. Mater. Med. 25, 2445-2461. doi: 10.1007/s10856-0145240-2

Capuccini, C., Torricelli, P., Sima, F., Boanini, E., Ristoscu, C., Bracci, B., et al. (2008). Strontium-substituted hydroxyapatite coatings synthesized by pulsedlaser deposition: in vitro osteoblast and osteoclast response. Acta Biomater. 4, 1885-1893. doi: 10.1016/j.actbio.2008.05.005

Carragee, E. J., Hurwitz, E. L., and Weiner, B. K. (2011). A critical review of recombinant human bone morphogenetic protein-2 trials in spinal surgery: emerging safety concerns and lessons learned. Spine J. 11, 471-491. doi: 10. 1016/j.spinee.2011.04.023
Chan, E. W. C., Bennet, D., Baek, P., Barker, D., Kim, S., and TravasSejdic, J. (2018). Electrospun polythiophene phenylenes for tissue engineering. Biomacromolecules 19, 1456-1468. doi: 10.1021/acs.biomac.8b00341

Chen, C., Bai, X., Ding, Y., and Lee, I. S. (2019). Electrical stimulation as a novel tool for regulating cell behavior in tissue engineering. Biomater. Res. 23:25. doi: 10.1186/s40824-019-0176-8

Chen, D., Zhao, M., and Mundy, G. R. (2004). Bone morphogenetic proteins. Growth Factors 22, 233-241. doi: 10.1080/08977190412331279890

Chen, J., Yu, M., Guo, B., Ma, P. X., and Yin, Z. (2018). Conductive nanofibrous composite scaffolds based on in-situ formed polyaniline nanoparticle and polylactide for bone regeneration. J. Colloid Interface Sci. 514, 517-527. doi: 10.1016/j.jcis.2017.12.062

Chen, J. H., Liu, C., You, L., and Simmons, C. A. (2010). Boning up on Wolff's Law: mechanical regulation of the cells that make and maintain bone. J. Biomech. 43, 108-118. doi: 10.1016/j.jbiomech.2009.09.016

Chen, P. Y., Lin, A. Y., Lin, Y. S., Seki, Y., Stokes, A. G., Peyras, J., et al. (2008). Structure and mechanical properties of selected biological materials. J. Mech. Behav. Biomed. Mater. 1, 208-226. doi: 10.1016/j.jmbbm.2008.02.003

Cheng, L.-C., Jiang, X., Wang, J., Chen, C., and Liu, R.-S. (2013). Nano-bio effects: interaction of nanomaterials with cells. Nanoscale 5, 3547-3569. doi: 10.1039/ c3nr34276j

Cheng, X., Wan, Q., and Pei, X. (2018). Graphene family materials in bone tissue regeneration: perspectives and challenges. Nanoscale Res. Lett. 13:289. doi: 10. 1186/s11671-018-2694-z

Chorsi, M. T., Curry, E. J., Chorsi, H. T., Das, R., Baroody, J., Purohit, P. K., et al. (2019). Piezoelectric biomaterials for sensors and actuators. Adv. Mater. 31:e1802084. doi: 10.1002/adma.201802084

Christenson, E. M., Anseth, K. S., van den Beucken, J. J., Chan, C. K., Ercan, B., Jansen, J. A., et al. (2007). Nanobiomaterial applications in orthopedics. J. Orthop. Res. 25, 11-22. doi: 10.1002/jor.20305

Corradetti, B., Taraballi, F., Powell, S., Sung, D., Minardi, S., Ferrari, M., et al. (2015). Osteoprogenitor cells from bone marrow and cortical bone: understanding how the environment affects their fate. Stem Cells Dev. 24, 1112-1123. doi: 10.1089/scd.2014.0351

Cox, S. C., Thornby, J. A., Gibbons, G. J., Williams, M. A., and Mallick, K. K. (2015). 3D printing of porous hydroxyapatite scaffolds intended for use in bone tissue engineering applications. Mater. Sci. Eng. 47, 237-247. doi: 10.1016/j. msec.2014.11.024

Cruz, F. (2010). Fabrication of HA/PLLA composite scaffolds for bone tissue engineering using additive manufacturing technologies. Biopolymers 11, 227242. doi: $10.5772 / 10264$

Cui, H., Liu, Y., Deng, M., Pang, X., Zhang, P., Wang, X., et al. (2012). Synthesis of biodegradable and electroactive tetraaniline grafted poly(ester amide) copolymers for bone tissue engineering. Biomacromolecules 13, 2881 2889. doi: $10.1021 / \mathrm{bm} 300897 \mathrm{j}$

Cui, W., Liu, Q., Yang, L., Wang, K., Sun, T., Ji, Y., et al. (2018). Sustained delivery of BMP-2-related peptide from the true bone ceramics/hollow mesoporous silica nanoparticles scaffold for bone tissue regeneration. ACS Biomater. Sci. Eng. 4, 211-221. doi: 10.1021/acsbiomaterials.7b00506

D’Amora, U., Russo, T., De Santis, R., Gloria, A., and Ambrosio, L. (2016). "Hybrid nanocomposites with magnetic activation for advanced bone tissue engineering," in Bio-Inspired Regenerative Medicine: Materials, Processes, and Clinical Applications, ed. A. Tampieri (New York, NY: Pan Stanford publishing), 179. doi: 10.1201/b19914-8

Daculsi, G. (1998). Biphasic calcium phosphate concept applied to artificial bone, implant coating and injectable bone substitute. Biomaterials 19, 1473-1478. doi: 10.1016/S0142-9612(98)00061-1

Dalby, M. J., Gadegaard, N., Tare, R., Andar, A., Riehle, M. O., Herzyk, P., et al. (2007). The control of human mesenchymal cell differentiation using nanoscale symmetry and disorder. Nat. Mater. 6, 997-1003. doi: 10.1038/nmat2013

Damaraju, S. M., Shen, Y., Elele, E., Khusid, B., Eshghinejad, A., Li, J., et al. (2017). Three-dimensional piezoelectric fibrous scaffolds selectively promote mesenchymal stem cell differentiation. Biomaterials 149, 51-62. doi: 10.1016/ j.biomaterials.2017.09.024

Damaraju, S. M., Wu, S., Jaffe, M., and Arinzeh, T. L. (2013). Structural changes in PVDF fibers due to electrospinning and its effect on biological function. Biomed. Mater. 8:045007. doi: 10.1088/1748-6041/8/4/045007 
Daristotle, J. L., Behrens, A. M., Sandler, A. D., and Kofinas, P. (2016). A review of the fundamental principles and applications of solution blow spinning. ACS Appl. Mater. Interfaces 8, 34951-34963. doi: 10.1021/acsami.6b12994

David Roodman, G. (2003). Role of stromal-derived cytokines and growth factors in bone metastasis. Cancer 97, 733-738. doi: 10.1002/cncr.11148

De Bruijn, J., Klein, C., De Groot, K., and Van Blitterswijk, C. (1992). The ultrastructure of the bone-hydroxyapatite interface in vitro. J. Biomed. Mater. Res. 26, 1365-1382. doi: 10.1002/jbm.820261008

De la Riva, B., Sánchez, E., Hernández, A., Reyes, R., Tamimi, F., López-Cabarcos, E., et al. (2010). Local controlled release of VEGF and PDGF from a combined brushite-chitosan system enhances bone regeneration. J. Controlled Release 143, 45-52. doi: 10.1016/j.jconrel.2009.11.026

Diaz-Gomez, L., García-González, C. A., Wang, J., Yang, F., Aznar-Cervantes, S., Cenis, J. L., et al. (2017). Biodegradable PCL/fibroin/hydroxyapatite porous scaffolds prepared by supercritical foaming for bone regeneration. Int. J. Pharma. 527, 115-125. doi: 10.1016/j.ijpharm.2017.05.038

Dimitriou, R., Jones, E., McGonagle, D., and Giannoudis, P. V. (2011). Bone regeneration: current concepts and future directions. BMC Med. 9:66. doi: 10.1186/1741-7015-9-66

Ding, Z., Fan, Z., Huang, X., Lu, Q., Xu, W., and Kaplan, D. L. (2016). Silkhydroxyapatite nanoscale scaffolds with programmable growth factor delivery for bone repair. ACS Appl. Mater. Interf. 8, 24463-24470. doi: 10.1021/acsami. $6 \mathrm{~b} 08180$

Dong, X., Wang, Q., Wu, T., and Pan, H. (2007). Understanding adsorptiondesorption dynamics of BMP-2 on hydroxyapatite (001) surface. Biophys. J. 93, 750-759. doi: 10.1529/biophysj.106.103168

Du, Y., Guo, J. L., Wang, J., Mikos, A. G., and Zhang, S. (2019). Hierarchically designed bone scaffolds: from internal cues to external stimuli. Biomaterials 218:119334. doi: 10.1016/j.biomaterials.2019.119334

Duan, B., Cheung, W. L., and Wang, M. (2011). Optimized fabrication of Ca$\mathrm{P} / \mathrm{PHBV}$ nanocomposite scaffolds via selective laser sintering for bone tissue engineering. Biofabrication 3:015001. doi: 10.1088/1758-5082/3/1/015001

Dubey, A. K., Basu, B., and Bandyopadhyay, A. (2014). Pulsed electrical stimulation and surface charge induced cell growth on multistage spark plasma sintered hydroxyapatite-barium titanate piezobiocomposite. J. Am. Ceram. Soc. 97, 481-489. doi: 10.1111/jace.12647

Dubey, A. K., Ea, A., Balani, K., Basu, B., and Bandyopadhyay, A. (2013). Multifunctional properties of multistage spark plasma sintered HA-BaTiO 3 based piezobiocomposites for bone replacement applications. J. Am. Ceramic Soc. 96, 3753-3759. doi: 10.1111/jace.12566

Dubey, A. K., Gupta, S. D., and Basu, B. (2011). Optimization of electrical stimulation parameters for enhanced cell proliferation on biomaterial surfaces. J. Biomed. Mater. Res. 98, 18-29. doi: 10.1002/jbm.b.31827

Dubey, A. K., Kinoshita, R., and Kakimoto, K.-I. (2015). Piezoelectric sodium potassium niobate mediated improved polarization and in vitro bioactivity of hydroxyapatite. RSC Adv. 5, 19638-19646. doi: 10.1039/C5RA00771B

Ducheyne, P. (2015). Comprehensive Biomaterials. Amsterdam: Elsevier.

Dziadek, M., Stodolak-Zych, E., and Cholewa-Kowalska, K. (2017). Biodegradable ceramic-polymer composites for biomedical applications: a review. Mater. Sci. Eng. C 71, 1175-1191. doi: 10.1016/j.msec.2016.10.014

Ehterami, A., Kazemi, M., Nazari, B., Saraeian, P., and Azami, M. (2018). Fabrication and characterization of highly porous barium titanate based scaffold coated by Gel/HA nanocomposite with high piezoelectric coefficient for bone tissue engineering applications. J. Mech. Behav. Biomed. Mater. 79, 195-202. doi: 10.1016/j.jmbbm.2017.12.034

Einhorn, T. A., and Gerstenfeld, L. C. (2015). Fracture healing: mechanisms and interventions. Nat. Rev. Rheumatol. 11, 45-54. doi: 10.1038/nrrheum.2014.164

Fadeev, I. V., Shvorneva, L. I., Barinov, S. M., and Orlovskii, V. P. (2003). Synthesis and structure of magnesium-substituted hydroxyapatite. Inorganic Mater. 39, 947-950. doi: 10.1023/A:1025509305805

Fan, D., De Rosa, E., Murphy, M. B., Peng, Y., Smid, C. A., Chiappini, C., et al. (2012). Mesoporous silicon-PLGA composite microspheres for the double controlled release of biomolecules for orthopedic tissue engineering. $A d v$. Funct. Mater. 22, 282-293. doi: 10.1002/adfm.201100403

Fan, R., Deng, X., Zhou, L., Gao, X., Fan, M., Wang, Y., et al. (2014). Injectable thermosensitive hydrogel composite with surface-functionalized calcium phosphate as raw materials. Int. J. Nanomed. 9:615. doi: 10.2147/IJN. S52689
Farokhi, M., Mottaghitalab, F., Shokrgozar, M. A., Ai, J., Hadjati, J., and Azami, M. (2014). Bio-hybrid silk fibroin/calcium phosphate/PLGA nanocomposite scaffold to control the delivery of vascular endothelial growth factor. Mater. Sci. Eng. C 35, 401-410. doi: 10.1016/j.msec.2013.11.023

Farshid, B., Lalwani, G., Shir Mohammadi, M., Simonsen, J., and Sitharaman, B. (2017). Boron nitride nanotubes and nanoplatelets as reinforcing agents of polymeric matrices for bone tissue engineering. J. Biomed. Mater. Res. B Appl. Biomater. 105, 406-419. doi: 10.1002/jbm.b.33565

Feng, P., Wei, P., Shuai, C., and Peng, S. (2014). Characterization of mechanical and biological properties of 3-D scaffolds reinforced with zinc oxide for bone tissue engineering. PLoS One 9:e87755. doi: 10.1371/journal.pone.008 7755

Fernandes, J. S., Gentile, P., Martins, M., Neves, N. M., Miller, C., Crawford, A., et al. (2016). Reinforcement of poly-l-lactic acid electrospun membranes with strontium borosilicate bioactive glasses for bone tissue engineering. Acta Biomater. 44, 168-177. doi: 10.1016/j.actbio.2016.08.042

Fernandez de Grado, G., Keller, L., Idoux-Gillet, Y., Wagner, Q., Musset, A.-M., Benkirane-Jessel, N., et al. (2018). Bone substitutes: a review of their characteristics, clinical use, and perspectives for large bone defects management. J. Tissue Eng. 9:204173141877681. doi: 10.1177/2041731 418776819

Fernandez, F., Babu, S. S., Komath, M., and Varma, H. (2020). "Biointegration of bone graft substiutes from osteointegration to osteotranduction," in Biointegration of Medical Implant Materials, ed. C. P. Sharma (Amsterdam: Elsevier), 245-261. doi: 10.1016/B978-0-08-102680-9.00010-X

Fielding, G., and Bose, S. (2013). SiO2 and $\mathrm{ZnO}$ dopants in three-dimensionally printed tricalcium phosphate bone tissue engineering scaffolds enhance osteogenesis and angiogenesis in vivo. Acta Biomater. 9, 9137-9148. doi: 10. 1016/j.actbio.2013.07.009

Filardo, G., Kon, E., Tampieri, A., Cabezas-Rodríguez, R., Di Martino, A., Fini, M., et al. (2014). New bio-ceramization processes applied to vegetable hierarchical structures for bone regeneration: an experimental model in sheep. Tissue Eng. Part A 20, 763-773. doi: 10.1089/ten.TEA.2013.0108

Filardo, G., Roffi, A., Fey, T., Fini, M., Giavaresi, G., Marcacci, M., et al. (2019). Vegetable hierarchical structures as template for bone regeneration: new bio-ceramization process for the development of a bone scaffold applied to an experimental sheep model. J. Biomed. Mater. Res. Part B 108, 600-611. doi: $10.1002 /$ jbm.b.34414

Fiorilli, S., Molino, G., Pontremoli, C., Iviglia, G., Torre, E., Cassinelli, C., et al. (2018). The incorporation of strontium to improve bone-regeneration ability of mesoporous bioactive glasses. Materials 11:678. doi: 10.3390/ma11050678

Franz, S., Rammelt, S., Scharnweber, D., and Simon, J. C. (2011). Immune responses to implants-a review of the implications for the design of immunomodulatory biomaterials. Biomaterials 32, 6692-6709. doi: 10.1016/ j.biomaterials.2011.05.078

Frasnelli, M., Cristofaro, F., Sglavo, V. M., Dirè, S., Callone, E., Ceccato, R., et al. (2017). Synthesis and characterization of strontium-substituted hydroxyapatite nanoparticles for bone regeneration. Mater. Sci. Eng. C 71, 653-662. doi: 10.1016/j.msec.2016.10.047

Fratzl, P., and Weinkamer, R. (2007). Nature's hierarchical materials. Prog. Mater. Sci. 52, 1263-1334. doi: 10.1016/j.pmatsci.2007.06.001

Fredericks, D. C., Nepola, J. V., Baker, J. T., Abbott, J., and Simon, B. (2000). Effects of pulsed electromagnetic fields on bone healing in a rabbit tibial osteotomy model. J. Orthop. Trauma 14, 93-100. doi: 10.1097/00005131-20000200000004

Friess, W. (1998). Collagen-biomaterial for drug delivery. Eur. J. Pharm. Biopharm. 45, 113-136. doi: 10.1016/S0939-6411(98)00017-4

Fukada, E., and Yasuda, I. (1957). On the piezoelectric effect of bone. J. Phys. Soc. Japan 12, 1158-1162. doi: 10.1143/JPSJ.12.1158

Funk, R. H. W. (2015). Endogenous electric fields as guiding cue for cell migration. Front. Physiol. 6:143. doi: 10.3389/fphys.2015.00143

Furlan, R. G., Correr, W. R., Russi, A. F. C., da Costa Iemma, M. R., Trovatti, E., and Pecoraro, É. (2018). Preparation and characterization of boron-based bioglass by sol- gel process. J. Sol-Gel Sci. Technol. 88, 181-191. doi: 10.1007/s10971018-4806-8

Gan, J. C., and Glazer, P. A. (2006). Electrical stimulation therapies for spinal fusions: current concepts. Eur. Spine J. 15, 1301-1311. doi: 10.1007/s00586-0060087-y 
Gan, Q., Zhu, J., Yuan, Y., Liu, H., Qian, J., Li, Y., et al. (2015). A dual-delivery system of $\mathrm{pH}$-responsive chitosan-functionalized mesoporous silica nanoparticles bearing BMP-2 and dexamethasone for enhanced bone regeneration. J. Mater. Chem. B 3, 2056-2066. doi: 10.1039/C4TB01897D

Ghanaati, S., Barbeck, M., Orth, C., Willershausen, I., Thimm, B. W., Hoffmann, C., et al. (2010). Influence of $\beta$-tricalcium phosphate granule size and morphology on tissue reaction in vivo. Acta Biomater. 6, 4476-4487. doi: 10.1016/j.actbio. 2010.07.006

Giannoudis, P. V., Dinopoulos, H., and Tsiridis, E. (2005). Bone substitutes: an update. Injury 36, S20-S27. doi: 10.1016/j.injury.2005.07.029

Gibbs, D. M., Black, C. R., Dawson, J. I., and Oreffo, R. O. (2016). A review of hydrogel use in fracture healing and bone regeneration. J. Tissue Eng. Regen. Med. 10, 187-198. doi: 10.1002/term.1968

Gimenes, R., Bar-Cohen, Y., Zaghete, M. A., Bertolini, M., Varela, J. A., Coelho, L. O., et al. (2004). "Composites PVDF-TrFE/BT used as bioactive membranes for enhancing bone regeneration," in Proceedings of the Smart Structures and Materials 2004: Electroactive Polymer Actuators and Devices (EAPAD) 5385, San Diego, CA, 539. doi: 10.1117/12.548647

Gkiokas, A., Morassi, L. G., Kohl, S., Zampakides, C., Megremis, P., and Evangelopoulos, D. S. (2012). Bioabsorbable pins for treatment of osteochondral fractures of the knee after acute patella dislocation in children and young adolescents. Adv. Orthop. 2012:249687. doi: 10.1155/2012/249687

Goldstein, C., Sprague, S., and Petrisor, B. A. (2010). Electrical stimulation for fracture healing: current evidence. J. Orthop. Trauma 24(Suppl. 1), S62-S65. doi: 10.1097/BOT.0b013e3181cddelb

Gong, T. (2015). Nanomaterials and Regenrative Medicine, Vol. 10. Zagreb: IAPC Publishing.

Grabowski, G., and Cornett, C. A. (2013). Bone graft and bone graft substitutes in spine surgery: current concepts and controversies. J. Am. Acad. Orthop. Surg. 21, 51-60. doi: 10.5435/JAAOS-21-01-51

Gruskay, J. A., Basques, B. A., Bohl, D. D., Webb, M. L., and Grauer, J. N. (2014). Short-term adverse events, length of stay, and readmission after iliac crest bone graft for spinal fusion. Spine (Phila Pa 1976) 39, 1718-1724. doi: 10.1097/BRS. 0000000000000476

Gu, W., Wu, C., Chen, J., and Xiao, Y. (2013). Nanotechnology in the targeted drug delivery for bone diseases and bone regeneration. Int. J. Nanomedicine 8 , 2305-2317. doi: 10.2147/IJN.S44393

Guex, A. G., Puetzer, J. L., Armgarth, A., Littmann, E., Stavrinidou, E., Giannelis, E. P., et al. (2017). Highly porous scaffolds of PEDOT:PSS for bone tissue engineering. Acta Biomater. 62, 91-101. doi: 10.1016/j.actbio.2017.08.045

Guihard, P., Boutet, M.-A., Brounais-Le Royer, B., Gamblin, A.-L., Amiaud, J., Renaud, A., et al. (2015). Oncostatin m, an inflammatory cytokine produced by macrophages, supports intramembranous bone healing in a mouse model of tibia injury. Am. J. Pathol. 185, 765-775. doi: 10.1016/j.ajpath.2014.11.008

Guihard, P., Danger, Y., Brounais, B., David, E., Brion, R., Delecrin, J., et al. (2012). Induction of osteogenesis in mesenchymal stem cells by activated monocytes/macrophages depends on oncostatin M signaling. Stem Cells 30, 762-772. doi: 10.1002/stem.1040

Gupta, A., Kukkar, N., Sharif, K., Main, B. J., Albers, C. E., and El-Amin Iii, S. F. (2015). Bone graft substitutes for spine fusion: a brief review. World J. Orthop. 6, 449-456. doi: 10.5312/wjo.v6.i6.449

Gupta, H. S., Wagermaier, W., Zickler, G. A., Raz-Ben Aroush, D., Funari, S. S., Roschger, P., et al. (2005). Nanoscale deformation mechanisms in bone. Nano Lett. 5, 2108-2111. doi: 10.1021/nl051584b

Gusic, N., Ivkovic, A., VaFaye, J., Vukasovic, A., Ivkovic, J., Hudetz, D., et al. (2014). Nanobiotechnology and bone regeneration: a mini-review. Int. Orthop. 38, 1877-1884. doi: 10.1007/s00264-014-2412-0

Habraken, W., Wolke, J., and Jansen, J. (2007). Ceramic composites as matrices and scaffolds for drug delivery in tissue engineering. Adv. Drug Deliv. Rev. 59, 234-248. doi: 10.1016/j.addr.2007.03.011

Hadley, K. B., Newman, S. M., and Hunt, J. R. (2010). Dietary zinc reduces osteoclast resorption activities and increases markers of osteoblast differentiation, matrix maturation, and mineralization in the long bones of growing rats. J. Nutr. Biochem. 21, 297-303. doi: 10.1016/j.jnutbio.2009.01.002

Häfeli, U. O., Riffle, J. S., Harris-Shekhawat, L., Carmichael-Baranauskas, A., Mark, F., Dailey, J. P., et al. (2009). Cell uptake and in vitro toxicity of magnetic nanoparticles suitable for drug delivery. Mol. Pharma. 6, 1417-1428. doi: 10. $1021 / \mathrm{mp} 900083 \mathrm{~m}$
Haider, A., Haider, S., and Kang, I.-K. (2018). A comprehensive review summarizing the effect of electrospinning parameters and potential applications of nanofibers in biomedical and biotechnology. Arabian $\mathrm{J}$. Chem. 11, 1165-1188. doi: 10.1016/j.arabjc.2015.11.015

Halperin, C., Mutchnik, S., Agronin, A., Molotskii, M., Urenski, P., Salai, M., et al. (2004). Piezoelectric effect in human bones studied in nanometer scale. Nano Lett. 4, 1253-1256. doi: 10.1021/nl049453i

He, Q., Zhao, Y., Chen, B., Xiao, Z., Zhang, J., Chen, L., et al. (2011). Improved cellularization and angiogenesis using collagen scaffolds chemically conjugated with vascular endothelial growth factor. Acta Biomater. 7, 1084-1093. doi: 10.1016/j.actbio.2010.10.022

Hench, L. L., Roki, N., and Fenn, M. B. (2014). Bioactive glasses: importance of structure and properties in bone regeneration. J. Mol. Struct. 1073, 24-30. doi: 10.1016/j.molstruc.2014.03.066

Henkel, J., Woodruff, M. A., Epari, D. R., Steck, R., Glatt, V., Dickinson, I. C., et al. (2013). Bone regeneration based on tissue engineering conceptions-A 21st century perspective. Bone Res. 1, 216-248. doi: 10.4248/BR201303002

Heo, S. J., Kim, S. E., Wei, J., Hyun, Y. T., Yun, H. S., Kim, D. H., et al. (2009). Fabrication and characterization of novel nano-and micro-HA/PCL composite scaffolds using a modified rapid prototyping process. J. Biomed. Mater. Res. Part A 89, 108-116. doi: 10.1002/jbm.a.31726

Ho-Shui-Ling, A., Bolander, J., Rustom, L. E., Johnson, A. W., Luyten, F. P., and Picart, C. (2018). Bone regeneration strategies: engineered scaffolds, bioactive molecules and stem cells current stage and future perspectives. Biomaterials 180, 143-162. doi: 10.1016/j.biomaterials.2018.07.017

Hoare, T. R., and Kohane, D. S. (2008). Hydrogels in drug delivery: progress and challenges. Polymer 49, 1993-2007. doi: 10.1016/j.polymer.2008.01.027

Hoffman, A. S. (2012). Hydrogels for biomedical applications. Adv. Drug Deliv. Rev. 64, 18-23. doi: 10.1016/j.addr.2012.09.010

Holzapfel, B. M., Wagner, F., Martine, L. C., Reppenhagen, S., Rudert, M., Schuetz, M., et al. (2016). Tissue engineering and regenerative medicine in musculoskeletal oncology. Cancer Metastasis Rev. 35, 475-487. doi: 10.1007/ s10555-016-9635-Z

Hu, Y., Cai, K., Luo, Z., Xu, D., Xie, D., Huang, Y., et al. (2012). TiO2 nanotubes as drug nanoreservoirs for the regulation of mobility and differentiation of mesenchymal stem cells. Acta Biomater. 8, 439-448. doi: 10.1016/j.actbio.2011. 10.021

Huang, D. M., Hsiao, J. K., Chen, Y. C., Chien, L. Y., Yao, M., Chen, Y. K., et al. (2009). The promotion of human mesenchymal stem cell proliferation by superparamagnetic iron oxide nanoparticles. Biomaterials 30, 3645-3651. doi: 10.1016/j.biomaterials.2009.03.032

Huang, P., Wang, J., Lai, S., Liu, F., Ni, N., Cao, Q., et al. (2014). Surface modified titania nanotubes containing anti-bacterial drugs for controlled delivery nanosystems with high bioactivity. J. Mater. Chem. B 2, 8616-8625. doi: 10.1039/C4TB01281J

Ikada, Y., Shikinami, Y., Hara, Y., Tagawa, M., and Fukada, E. (1996). Enhancement of bone formation by drawn poly(L-lactide). J. Biomed. Mater. Res. 30, 553-558. doi: 10.1002/(SICI)1097-4636(199604)30:4<553::AID-JBM14<3.0.CO;2-I

Ikeda, R., Fujioka, H., Nagura, I., Kokubu, T., Toyokawa, N., Inui, A., et al. (2009). The effect of porosity and mechanical property of a synthetic polymer scaffold on repair of osteochondral defects. Int. Orthop. 33, 821-828. doi: 10.1007/ s00264-008-0532-0

Islam, M. T., Felfel, R. M., Abou Neel, E. A., Grant, D. M., Ahmed, I., and Hossain, K. M. Z. (2017). Bioactive calcium phosphate-based glasses and ceramics and their biomedical applications: a review. J. Tissue Eng. 8:2041731417719170. doi: $10.1177 / 2041731417719170$

Izquierdo-Barba, I., Salinas, A. J., and Vallet-Regí, M. (2013). Bioactive glasses: from macro to nano. Int. J. App. Glass Sci. 4, 149-161. doi: 10.1111/ijag.12028

Jacob, J., Haponiuk, J. T., Thomas, S., and Gopi, S. (2018). Biopolymer based nanomaterials in drug delivery systems: a review. Mater. Today Chem. 9, 43-55. doi: 10.1016/j.mtchem.2018.05.002

Jansen, J. H., van der Jagt, O. P., Punt, B. J., Verhaar, J. A., van Leeuwen, J. P., Weinans, H., et al. (2010). Stimulation of osteogenic differentiation in human osteoprogenitor cells by pulsed electromagnetic fields: an in vitro study. BMC Musculoskelet Disord. 11:188. doi: 10.1186/1471-2474-11-188

Jeon, B. J., Jeong, S. Y., Koo, A. N., Kim, B.-C., Hwang, Y.-S., and Lee, S. C. (2012). Fabrication of porous PLGA microspheres with BMP-2 releasing polyphosphate-functionalized nano-hydroxyapatite for enhanced 
bone regeneration. Macromol. Res. 20, 715-724. doi: 10.1007/s13233-0120103-5

Jianqing, F., Huipin, Y., and Xingdong, Z. (1997). Promotion of osteogenesis by a piezoelectric biological ceramic. Biomaterials 18, 1531-1534. doi: 10.1016/ S0142-9612(97)80004-X

Jiao, H., Zhao, K., Ma, L., Tang, Y., Liu, X., and Bian, T. (2017). Preparation and characterization of $\mathrm{BaTiO} / \mathrm{HA}$ nanocomposite materials by hydrothermal synthesis. J. Alloys Compounds 693, 221-225. doi: 10.1016/j.jallcom.2016.09. 175

Jones, J. R., Brauer, D. S., Hupa, L., and Greenspan, D. C. (2016). Bioglass and bioactive glasses and their impact on healthcare. Int. J. Appl. Glass Sci. 7, 423-434. doi: 10.1111/ijag.12252

Jose, M., Thomas, V., Johnson, K., Dean, D., and Nyairo, E. (2009). Aligned PLGA/HA nanofibrous nanocomposite scaffolds for bone tissue engineering. Acta Biomater. 5, 305-315. doi: 10.1016/j.actbio.2008.07.019

Kaigler, D., Wang, Z., Horger, K., Mooney, D. J., and Krebsbach, P. H. (2006). VEGF scaffolds enhance angiogenesis and bone regeneration in irradiated osseous defects. J. Bone Mineral Res. 21, 735-744. doi: 10.1359/jbmr.060120

Kalbacova, M., Broz, A., Kong, J., and Kalbac, M. (2010). Graphene substrates promote adherence of human osteoblasts and mesenchymal stromal cells. Carbon 48, 4323-4329. doi: 10.1016/j.carbon.2010.07.045

Kalita, S. J., and Bhatt, H. A. (2007). Nanocrystalline hydroxyapatite doped with magnesium and zinc: synthesis and characterization. Mater. Sci. Eng. C 27, 837-848. doi: 10.1016/j.msec.2006.09.036

Kalita, S. J., and Verma, S. (2010). Nanocrystalline hydroxyapatite bioceramic using microwave radiation: synthesis and characterization. Mater. Sci. Eng. C 30, 295-303. doi: 10.1016/j.msec.2009.11.007

Kamitakahara, M., Ohtsuki, C., and Miyazaki, T. (2008). Behavior of ceramic biomaterials derived from tricalcium phosphate in physiological condition. J. Biomater. Appl. 23, 197-212. doi: 10.1177/0885328208096798

Kang, K. S., Hong, J. M., Jeong, Y. H., Seol, Y. J., Yong, W. J., Rhie, J. W., et al. (2014). Combined effect of three types of biophysical stimuli for bone regeneration. Tissue Eng. Part A 20, 1767-1777. doi: 10.1089/ten.TEA.2013. 0157

Kang, M. S., Kim, J.-H., Singh, R. K., Jang, J.-H., and Kim, H.-W. (2015). Therapeutic-designed electrospun bone scaffolds: mesoporous bioactive nanocarriers in hollow fiber composites to sequentially deliver dual growth factors. Acta Biomater. 16, 103-116. doi: 10.1016/j.actbio.2014.12.028

Kao, F. C., Chiu, P. Y., Tsai, T. T., and Lin, Z. H. (2019). The application of nanogenerators and piezoelectricity in osteogenesis. Sci. Technol. Adv. Mater. 20, 1103-1117. doi: 10.1080/14686996.2019.1693880

Kaplan, F., Hayes, W., Keaveny, T., Boskey, A., Einhorn, T., and Iannotti, J. (1994). Orthopedic basic science. Am. Acad. Orthop. Surg. 1, 127-145.

Kargozar, S., Baino, F., Hamzehlou, S., Hill, R. G., and Mozafari, M. (2018). Bioactive glasses: sprouting angiogenesis in tissue engineering. Trends Biotechnol. 36, 430-444. doi: 10.1016/j.tibtech.2017.12.003

Kaur, G., Adhikari, R., Cass, P., Bown, M., and Gunatillake, P. (2015). Electrically conductive polymers and composites for biomedical applications. RSC Adv. 5, 37553-37567. doi: 10.1039/C5RA01851J

Kaya, S., Cresswell, M., and Boccaccini, A. R. (2018). Mesoporous silica-based bioactive glasses for antibiotic-free antibacterial applications. Mater. Sci. Eng. C 83, 99-107. doi: 10.1016/j.msec.2017.11.003

Kempen, D. H., Lu, L., Heijink, A., Hefferan, T. E., Creemers, L. B., Maran, A., et al. (2009). Effect of local sequential VEGF and BMP-2 delivery on ectopic and orthotopic bone regeneration. Biomaterials 30, 2816-2825. doi: 10.1016/j. biomaterials.2009.01.031

Kenar, H., Kose, G., and Hasirci, V. (2006). Tissue engineering of bone on micropatterned biodegradable polyester films. Biomaterials 27, 885-895. doi: 10.1016/j.biomaterials.2005.07.001

Kim, B.-S., Yang, S.-S., and Kim, C. S. (2018). Incorporation of BMP-2 nanoparticles on the surface of a $3 \mathrm{D}$-printed hydroxyapatite scaffold using an $\varepsilon$-polycaprolactone polymer emulsion coating method for bone tissue engineering. Colloids Surf. B Biointerf. 170, 421-429. doi: 10.1016/j.colsurfb. 2018.06.043

Kim, D., Lee, B., Thomopoulos, S., and Jun, Y.-S. (2018). The role of confined collagen geometry in decreasing nucleation energy barriers to intrafibrillar mineralization. Nat. Commun. 9, 1-9. doi: 10.1038/s41467-018-03041-1
Kim, H. W., Li, L. H., Koh, Y. H., Knowles, J. C., and Kim, H. E. (2004). Sol-Gel preparation and properties of fluoride-substituted hydroxyapatite powders. J. Am. Ceramic Soc. 87, 1939-1944. doi: 10.1111/j.1151-2916.2004.tb06344.x

Kim, H. W., Song, J. H., and Kim, H. E. (2005). Nanofiber generation of gelatinhydroxyapatite biomimetics for guided tissue regeneration. Adv. Funct. Mater. 15, 1988-1994. doi: 10.1002/adfm.200500116

Kim, J.-J., El-Fiqi, A., and Kim, H.-W. (2017). Synergetic cues of bioactive nanoparticles and nanofibrous structure in bone scaffolds to stimulate osteogenesis and angiogenesis. ACS Appl. Mater. Interf. 9, 2059-2073. doi: 10.1021/acsami.6b12089

Kim, J. W., Shin, Y. C., Lee, J. J., Bae, E. B., Jeon, Y. C., Jeong, C. M., et al. (2017). The effect of reduced graphene oxide-coated biphasic calcium phosphate bone graft material on osteogenesis. Int. J. Mol. Sci. 18:1725. doi: 10.3390/ ijms18081725

Kim, K., Zhu, W., Qu, X., Aaronson, C., McCall, W. R., Chen, S., et al. (2014). $3 \mathrm{D}$ optical printing of piezoelectric nanoparticle-polymer composite materials. ACS Nano 8, 9799-9806. doi: 10.1021/nn503268f

Kim, S., Ku, S. H., Lim, S. Y., Kim, J. H., and Park, C. B. (2011). Graphenebiomineral hybrid materials. Adv. Mater. 23, 2009-2014. doi: 10.1002/adma. 201100010

Kim, S. E., Song, S.-H., Yun, Y. P., Choi, B.-J., Kwon, I. K., Bae, M. S., et al. (2011). The effect of immobilization of heparin and bone morphogenic protein2 (BMP-2) to titanium surfaces on inflammation and osteoblast function. Biomaterials 32, 366-373. doi: 10.1016/j.biomaterials.2010.09.008

Kong, C. H., Steffi, C., Shi, Z., and Wang, W. (2018). Development of mesoporous bioactive glass nanoparticles and its use in bone tissue engineering. J. Biomed. Mater. Res. Part B 106, 2878-2887. doi: 10.1002/jbm.b.34143

Kumar, A., Kargozar, S., Baino, F., and Han, S. S. (2019). Additive manufacturing methods for producing hydroxyapatite and hydroxyapatite-based composite scaffolds: a review. Front. Mater. 6:313. doi: 10.3389/fmats

Kwon, D. H., Lee, S. J., Wikesjö, U. M., Johansson, P. H., Johansson, C. B., and Sul, Y. T. (2017). Bone tissue response following local drug delivery of bisphosphonate through titanium oxide nanotube implants in a rabbit model. J. Clin. Periodontol. 44, 941-949. doi: 10.1111/jcpe.12776

Lai, M., Cai, K., Zhao, L., Chen, X., Hou, Y., and Yang, Z. (2011). Surface functionalization of $\mathrm{TiO} 2$ nanotubes with bone morphogenetic protein 2 and its synergistic effect on the differentiation of mesenchymal stem cells. Biomacromolecules 12, 1097-1105. doi: 10.1021/bm1014365

Lalegul-Ulker, O., Elcin, A. E., and Elcin, Y. M. (2018). Intrinsically conductive polymer nanocomposites for cellular applications. Adv. Exp. Med. Biol. 1078, 135-153. doi: 10.1007/978-981-13-0950-2_8

Lallana, E., Sousa-Herves, A., Fernandez-Trillo, F., Riguera, R., and FernandezMegia, E. (2012). Click chemistry for drug delivery nanosystems. Pharm. Res. 29, 1-34. doi: 10.1007/s11095-011-0568-5

Lalzawmliana, V., Anand, A., Kumar, V., Das, P., Devi, K. B., Mukherjee, J., et al. (2019). Potential of growth factor incorporated mesoporous bioactive glass for in vivo bone regeneration. J. Mech. Behav. Biomed. Mater. 91, 182-192. doi: 10.1016/j.jmbbm.2018.12.012

Lalzawmliana, V., Anand, A., Roy, M., Kundu, B., and Nandi, S. K. (2020). Mesoporous bioactive glasses for bone healing and biomolecules delivery. Mater. Sci. Eng. C 106:110180. doi: 10.1016/j.msec.2019.110180

Landi, E., Tampieri, A., Mattioli-Belmonte, M., Celotti, G., Sandri, M., Gigante, A., et al. (2006). Biomimetic Mg- and Mg,CO3-substituted hydroxyapatites: synthesis characterization and in vitro behaviour. J. Eur. Ceramic Soc. 26, 2593-2601. doi: 10.1016/j.jeurceramsoc.2005.06.040

Landi, E., Valentini, F., and Tampieri, A. (2008). Porous hydroxyapatite/gelatine scaffolds with ice-designed channel-like porosity for biomedical applications. Acta Biomater. 4, 1620-1626. doi: 10.1016/j.actbio.2008.05.023

Lee, E. J., Kasper, F. K., and Mikos, A. G. (2014). Biomaterials for tissue engineering. Ann. Biomed. Eng. 42, 323-337. doi: 10.1007/s10439-013-0859-6

Lee, J.-H., Mandakhbayar, N., El-Fiqi, A., and Kim, H.-W. (2017). Intracellular codelivery of Sr ion and phenamil drug through mesoporous bioglass nanocarriers synergizes BMP signaling and tissue mineralization. Acta Biomater. 60, 93-108. doi: 10.1016/j.actbio.2017.07.021

Lee, J., Byun, H., Madhurakkat Perikamana, S. K., Lee, S., and Shin, H. (2019). Current advances in immunomodulatory biomaterials for bone regeneration. Adv. Healthcare Mater. 8:1801106. doi: 10.1002/adhm.201801106 
Lee, J., Yoo, J. J., Atala, A., and Lee, S. J. (2012). The effect of controlled release of PDGF-BB from heparin-conjugated electrospun PCL/gelatin scaffolds on cellular bioactivity and infiltration. Biomaterials 33, 6709-6720. doi: 10.1016/j. biomaterials.2012.06.017

Lee, S. S., Fyrner, T., Chen, F., Álvarez, Z., Sleep, E., Chun, D. S., et al. (2017). Sulfated glycopeptide nanostructures for multipotent protein activation. Nature Nanotechnol. 12, 821-829. doi: 10.1038/nnano.2017.109

Lee, S. S., Hsu, E. L., Mendoza, M., Ghodasra, J., Nickoli, M. S., Ashtekar, A., et al. (2015). Gel scaffolds of BMP-2-binding peptide amphiphile nanofibers for spinal arthrodesis. Adv. Healthcare Mater. 4, 131-141. doi: 10.1002/adhm. 201400129

Lee, S. S., Huang, B. J., Kaltz, S. R., Sur, S., Newcomb, C. J., Stock, S. R., et al. (2013). Bone regeneration with low dose BMP-2 amplified by biomimetic supramolecular nanofibers within collagen scaffolds. Biomaterials 34, 452-459. doi: 10.1016/j.biomaterials.2012.10.005

Lee, W. C., Lim, C. H., Shi, H., Tang, L. A., Wang, Y., Lim, C. T., et al. (2011). Origin of enhanced stem cell growth and differentiation on graphene and graphene oxide. ACS Nano 5, 7334-7341. doi: 10.1021/nn202190c

LeGeros, R. Z. (2008). Calcium phosphate-based osteoinductive materials. Chem. Rev. 108, 4742-4753. doi: 10.1021/cr800427g

Leite, A. I. J., Gonçalves, A. I., Rodrigues, M. R. T., Gomes, M. E., and Mano, J. O. F. (2018). Strontium-doped bioactive glass nanoparticles in osteogenic commitment. ACS Appl. Mater. Interf. 10, 23311-23320. doi: 10.1021/acsami. 8 b06154

Leung, V., and Ko, F. (2011). Biomedical applications of nanofibers. Polym. Adv. Technol. 22, 350-365. doi: 10.1002/pat.1813

Li, C., Vepari, C., Jin, H.-J., Kim, H. J., and Kaplan, D. L. (2006). Electrospun silk-BMP-2 scaffolds for bone tissue engineering. Biomaterials 27, 3115-3124. doi: 10.1016/j.biomaterials.2006.01.022

Li, L., Yu, M., Ma, P. X., and Guo, B. (2016). Electroactive degradable copolymers enhancing osteogenic differentiation from bone marrow derived mesenchymal stem cells. J. Mater. Chem. 4, 471-481. doi: 10.1039/C5TB01899D

Li, L., Zhou, G., Wang, Y., Yang, G., Ding, S., and Zhou, S. (2015). Controlled dual delivery of BMP-2 and dexamethasone by nanoparticle-embedded electrospun nanofibers for the efficient repair of critical-sized rat calvarial defect. Biomaterials 37, 218-229. doi: 10.1016/j.biomaterials.2014.10.015

Li, W.-J., Mauck, R. L., Cooper, J. A., Yuan, X., and Tuan, R. S. (2007). Engineering controllable anisotropy in electrospun biodegradable nanofibrous scaffolds for musculoskeletal tissue engineering. J. Biomech. 40, 1686-1693. doi: 10.1016/j. jbiomech.2006.09.004

Li, X., Wang, X., Jiang, X., Yamaguchi, M., Ito, A., Bando, Y., et al. (2016). Boron nitride nanotube-enhanced osteogenic differentiation of mesenchymal stem cells. J. Biomed. Mater. Res. B Appl. Biomater. 104, 323-329. doi: 10.1002/jbm.b. 33391

Li, Z., Lu, W. W., Chiu, P. K. Y., Lam, R. W. M., Xu, B., Cheung, K. M. C., et al. (2009). Strontium-calcium coadministration stimulates bone matrix osteogenic factor expression and new bone formation in a large animal model. J. Orthopaedic Res. 27, 758-762. doi: 10.1002/jor.20818

Liang, P., Zheng, J., Zhang, Z., Hou, Y., Wang, J., Zhang, C., et al. (2019). Bioactive 3D scaffolds self-assembled from phosphorylated mimicking peptide amphiphiles to enhance osteogenesis. J. Biomater. Sci. Polym. Ed. 30, 34-48. doi: 10.1080/09205063.2018.1505264

Liang, Y., and Kiick, K. L. (2014). Heparin-functionalized polymeric biomaterials in tissue engineering and drug delivery applications. Acta Biomater. 10, 15881600. doi: 10.1016/j.actbio.2013.07.031

Lim, J. Y., Hansen, J. C., Siedlecki, C. A., Runt, J., and Donahue, H. J. (2005). Human foetal osteoblastic cell response to polymer-demixed nanotopographic interfaces. J. R. Soc. Interface 2, 97-108. doi: 10.1098/rsif.2004. 0019

Liou, S.-C., Chen, S.-Y., Lee, H.-Y., and Bow, J.-S. (2004). Structural characterization of nano-sized calcium deficient apatite powders. Biomaterials 25, 189-196. doi: 10.1016/S0142-9612(03)00479-4

Liu, B., Chen, L., Shao, C., Zhang, F., Zhou, K., Cao, J., et al. (2016). Improved osteoblasts growth on osteomimetic hydroxyapatite/BaTiO3 composites with aligned lamellar porous structure. Mater. Sci. Eng. C Mater. Biol. Appl. 61, 8-14. doi: 10.1016/j.msec.2015.12.009

Liu, H., Slamovich, E. B., and Webster, T. J. (2006). Increased osteoblast functions among nanophase titania/poly(lactide-co-glycolide) composites of the highest nanometer surface roughness. J. Biomed. Mater. Res. A 78, 798-807. doi: 10. 1002/jbm.a.30734

Liu, J. M., Zhang, X., Joe, S., Luo, X., and Shea, L. D. (2018). Evaluation of biomaterial scaffold delivery of IL-33 as a localized immunomodulatory agent to support cell transplantation in adipose tissue. J. Immunol. Regen. Med. 1, 1-12. doi: 10.1016/j.regen.2018.01.003

Liu, L., Bhatia, R., and Webster, T. J. (2017). Atomic layer deposition of nano$\mathrm{TiO} 2$ thin films with enhanced biocompatibility and antimicrobial activity for orthopedic implants. Int. J. Nanomed. 12:8711. doi: 10.2147/IJN.S148065

Liu, L., Li, P., Zhou, G., Wang, M., Jia, X., Liu, M., et al. (2013). Increased proliferation and differentiation of pre-osteoblasts MC3T3-E1 cells on nanostructured polypyrrole membrane under combined electrical and mechanical stimulation. J. Biomed. Nanotechnol. 9, 1532-1539. doi: 10.1166/ jbn.2013.1650

Liu, X.-Y., Qiu, G.-X., Weng, X.-S., Yu, B., and Wang, Y.-P. (2014). What is the optimum fusion technique for adult spondylolisthesis-PLIF or PLF or PLIF Plus PLF? A meta-analysis from 17 comparative studies. Spine 39, 1887-1898. doi: 10.1097/BRS.0000000000000549

Liu, Y., Lu, Y., Tian, X., Cui, G., Zhao, Y., Yang, Q., et al. (2009). Segmental bone regeneration using an rhBMP-2-loaded gelatin/nanohydroxyapatite/fibrin scaffold in a rabbit model. Biomaterials 30, 6276-6285. doi: 10.1016/j. biomaterials.2009.08.003

Lode, A., Reinstorf, A., Bernhardt, A., Wolf-Brandstetter, C., König, U., and Gelinsky, M. (2008). Heparin modification of calcium phosphate bone cements for VEGF functionalization. J. Biomed. Mater. Res. Part A 86, 749-759. doi: 10.1002/jbm.a.31581

Lü, J.-M., Wang, X., Marin-Muller, C., Wang, H., Lin, P. H., Yao, Q., et al. (2009). Current advances in research and clinical applications of PLGA-based nanotechnology. Expert Rev. Mol. Diagnost. 9, 325-341. doi: 10.1586/erm.09.15

Lucke, M., Schmidmaier, G., Sadoni, S., Wildemann, B., Schiller, R., Haas, N., et al. (2003). Gentamicin coating of metallic implants reduces implant-related osteomyelitis in rats. Bone 32, 521-531. doi: 10.1016/S8756-3282(03)00050-4

Madl, C. M., Mehta, M., Duda, G. N., Heilshorn, S. C., and Mooney, D. J. (2014). Presentation of BMP-2 mimicking peptides in 3D hydrogels directs cell fate commitment in osteoblasts and mesenchymal stem cells. Biomacromolecules 15 , 445-455. doi: 10.1021/bm401726u

Maeder, M. D., Damjanovic, D., and Setter, N. (2004). Lead free piezoelectric materials. J. Electroceram. 13, 385-392. doi: 10.1007/s10832-004-5130-y

Magrez, A., Horváth, L., Smajda, R., Salicio, V., Pasquier, N., Forro, L., et al. (2009). Cellular toxicity of TiO2-based nanofilaments. ACS Nano 3, 2274-2280. doi: $10.1021 / \mathrm{nn} 9002067$

Maier, J. A., Bernardini, D., Rayssiguier, Y., and Mazur, A. (2004). High concentrations of magnesium modulate vascular endothelial cell behaviour in vitro. Biochim. Biophys. Acta (BBA) 1689, 6-12. doi: 10.1016/j.bbadis.2004. 02.004

Makadia, H. K., and Siegel, S. J. (2011). Poly lactic-co-glycolic acid (PLGA) as biodegradable controlled drug delivery carrier. Polymers 3, 1377-1397. doi: 10.3390/polym 3031377

Malafaya, P. B., Silva, G. A., and Reis, R. L. (2007). Natural-origin polymers as carriers and scaffolds for biomolecules and cell delivery in tissue engineering applications. Adv. Drug Deliv. Rev. 59, 207-233. doi: 10.1016/j.addr.2007.03. 012

Malikmammadov, E., Tanir, T. E., Kiziltay, A., Hasirci, V., and Hasirci, N. (2018). PCL-TCP wet spun scaffolds carrying antibiotic-loaded microspheres for bone tissue engineering. J. Biomater. Sci. Polym. Ed. 29, 805-824. doi: 10.1080/ 09205063.2017.1354671

Mancuso, E., Bretcanu, O. A., Marshall, M., Birch, M. A., McCaskie, A. W., and Dalgarno, K. W. (2017). Novel bioglasses for bone tissue repair and regeneration: effect of glass design on sintering ability, ion release and biocompatibility. Mater. Design 129, 239-248. doi: 10.1016/j.matdes.2017.05. 037

Marędziak, M., Śmieszek, A., Tomaszewski, K. A., Lewandowski, D., and Marycz, K. (2016). The effect of low static magnetic field on osteogenic and adipogenic differentiation potential of human adipose stromal/stem cells. J. Magn. Magn. Mater. 398, 235-245. doi: 10.1016/j.jmmm.2015.09.004

Marino, A., Arai, S., Hou, Y., Sinibaldi, E., Pellegrino, M., Chang, Y.-T., et al. (2015). Piezoelectric nanoparticle-assisted wireless neuronal stimulation. ACS Nano 9, 7678-7689. doi: 10.1021/acsnano.5b03162 
Marino, A., Genchi, G. G., Mattoli, V., and Ciofani, G. (2017). Piezoelectric nanotransducers: the future of neural stimulation. Nano Today 14, 9-12. doi: 10.1016/j.nantod.2016.12.005

Marsell, R., and Einhorn, T. A. (2011). The biology of fracture healing. Injury 42, 551-555. doi: 10.1016/j.injury.2011.03.031

Masquelet, A. C., Fitoussi, F., Begue, T., and Muller, G. P. (2000). [Reconstruction of the long bones by the induced membrane and spongy autograft]. Ann. Chir. Plast. Esthet. 45, 346-353.

Mastrogiacomo, M., Scaglione, S., Martinetti, R., Dolcini, L., Beltrame, F., Cancedda, R., et al. (2006). Role of scaffold internal structure on in vivo bone formation in macroporous calcium phosphate bioceramics. Biomaterials 27, 3230-3237. doi: 10.1016/j.biomaterials.2006.01.031

Matesanz, M. C., Linares, J., Lilue, I., Sánchez-Salcedo, S., Feito, M. J., Arcos, D., et al. (2014). Nanocrystalline silicon substituted hydroxyapatite effects on osteoclast differentiation and resorptive activity. J. Mater. Chem. B 2, 29102919. doi: $10.1039 / \mathrm{c} 3$ tb21697g

Matsumoto, T., Okazaki, M., Inoue, M., Yamaguchi, S., Kusunose, T., Toyonaga, T., et al. (2004). Hydroxyapatite particles as a controlled release carrier of protein. Biomaterials 25, 3807-3812. doi: 10.1016/j.biomaterials.2003.10.081

McCaig, C. D., Rajnicek, A. M., Song, B., and Zhao, M. (2005). Controlling cell behavior electrically: current views and future potential. Physiol. Rev. 85, 943-978. doi: 10.1152/physrev.00020.2004

McKay, W. F., Peckham, S. M., and Badura, J. M. (2007). A comprehensive clinical review of recombinant human bone morphogenetic protein-2 (INFUSE ${ }^{\circledR}$ Bone Graft). Int. Orthop. 31, 729-734. doi: 10.1007/s00264-007-0418-6

Mehta, M., Schmidt-Bleek, K., Duda, G. N., and Mooney, D. J. (2012). Biomaterial delivery of morphogens to mimic the natural healing cascade in bone. Adv. Drug Deliv. Rev. 64, 1257-1276. doi: 10.1016/j.addr.2012.05.006

Miao, X., Lim, W.-K., Huang, X., and Chen, Y. (2005). Preparation and characterization of interpenetrating phased TCP/HA/PLGA composites. Materials Lett. 59, 4000-4005. doi: 10.1016/j.matlet.2005.07.062

Michalski, M. N., and McCauley, L. K. (2017). Macrophages and skeletal health. Pharmacol. Ther. 174, 43-54. doi: 10.1016/j.pharmthera.2017.02.017

Minardi, S., Corradetti, B., Taraballi, F., Byun, J. H., Cabrera, F., Liu, X., et al. (2016a). IL-4 release from a biomimetic scaffold for the temporally controlled modulation of macrophage response. Ann. Biomed. Eng. 44, 2008-2019. doi: 10.1007/s10439-016-1580-z

Minardi, S., Corradetti, B., Taraballi, F., Sandri, M., Van Eps, J., Cabrera, F. J., et al. (2015a). Evaluation of the osteoinductive potential of a bio-inspired scaffold mimicking the osteogenic niche for bone augmentation. Biomaterials 62, 128-137. doi: 10.1016/j.biomaterials.2015.05.011

Minardi, S., Fernandez-Moure, J. S., Fan, D., Murphy, M. B., Yazdi, I. K., Liu, X., et al. (2020). Biocompatible PLGA-mesoporous silicon microspheres for the controlled release of BMP-2 for bone augmentation. Pharmaceutics 12:118. doi: 10.3390/pharmaceutics 12020118

Minardi, S., Pandolfi, L., Taraballi, F., De Rosa, E., Yazdi, I. K., Liu, X., et al. (2015b). PLGA-mesoporous silicon microspheres for the in vivo controlled temporospatial delivery of proteins. ACS Appl. Mater. Interf. 7, 16364-16373. doi: 10.1021/acsami.5b03464

Minardi, S., Sandri, M., Martinez, J. O., Yazdi, I. K., Liu, X., Ferrari, M., et al. (2014). Multiscale patterning of a biomimetic scaffold integrated with composite microspheres. Small 10, 3943-3953. doi: 10.1002/smll.201401211

Minardi, S., Taraballi, F., Cabrera, F., Van Eps, J., Wang, X., Gazze, S., et al. (2019). Biomimetic hydroxyapatite/collagen composite drives bone niche recapitulation in a rabbit orthotopic model. Materials Today Bio 2:100005. doi: 10.1016/j.mtbio.2019.100005

Minardi, S., Taraballi, F., Pandolfi, L., and Tasciotti, E. (2016b). Patterning biomaterials for the spatiotemporal delivery of bioactive molecules. Front. Bioeng. Biotechnol. 4:45. doi: 10.3389/fbioe.2016. 00045

Mohammadi, M., Alibolandi, M., Abnous, K., Salmasi, Z., Jaafari, M. R., and Ramezani, M. (2018). Fabrication of hybrid scaffold based on hydroxyapatitebiodegradable nanofibers incorporated with liposomal formulation of BMP-2 peptide for bone tissue engineering. Nanomed. Nanotechnol. Biol. Med. 14, 1987-1997. doi: 10.1016/j.nano.2018.06.001

Monmaturapoj, N., and Yatongchai, C. (2011). Influence of preparation method on hydroxyapatite porous scaffolds. Bull. Mater. Sci. 34, 1733-1737. doi: 10.1007/ s12034-011-0384-x
Mouriño, V., Vidotto, R., Cattalini, J., and Boccaccini, A. (2019). Enhancing biological activity of bioactive glass scaffolds by inorganic ion delivery for bone tissue engineering. Curr. Opin. Biomed. Eng. 10, 23-34. doi: 10.1016/j.cobme. 2019.02.002

Murphy, C. M., Haugh, M. G., and O'Brien, F. J. (2010). The effect of mean pore size on cell attachment, proliferation and migration in collagen-glycosaminoglycan scaffolds for bone tissue engineering. Biomaterials 31, 461-466. doi: 10.1016/j. biomaterials.2009.09.063

Murphy, S. V., and Atala, A. (2014). 3D bioprinting of tissues and organs. Nat. Biotechnol. 32, 773-785. doi: 10.1038/nbt.2958

Murugan, R., and Ramakrishna, S. (2005). Development of nanocomposites for bone grafting. Composites Sci. Technol. 65, 2385-2406. doi: 10.1016/j. compscitech.2005.07.022

Nadeem, D., Smith, C.-A., Dalby, M. J., Dominic Meek, R. M., Lin, S., Li, G., et al. (2015). Three-dimensional CaP/gelatin lattice scaffolds with integrated osteoinductive surface topographies for bone tissue engineering. Biofabrication 7:015005. doi: 10.1088/1758-5090/7/1/015005

Nair, A. K., Gautieri, A., and Buehler, M. J. (2014). Role of intrafibrillar collagen mineralization in defining the compressive properties of nascent bone. Biomacromolecules 15, 2494-2500. doi: 10.1021/bm5003416

Nandakumar, A., Cruz, C., Mentink, A., Birgani, Z. T., Moroni, L., van Blitterswijk, C., et al. (2013). Monolithic and assembled polymer-ceramic composites for bone regeneration. Acta Biomater. 9, 5708-5717. doi: 10.1016/j.actbio.2012.10. 044

Nawaz, Q., Rehman, M. A. U., Burkovski, A., Schmidt, J., Beltrán, A. M., Shahid, A., et al. (2018). Synthesis and characterization of manganese containing mesoporous bioactive glass nanoparticles for biomedical applications. J. Mater. Sci. Mater. Med. 29:64. doi: 10.1007/s10856-018-6070-4

Nayak, T. R., Andersen, H., Makam, V. S., Khaw, C., Bae, S., Xu, X., et al. (2011). Graphene for controlled and accelerated osteogenic differentiation of human mesenchymal stem cells. ACS Nano 5, 4670-4678. doi: 10.1021/nn200500h

Neves, N., Linhares, D., Costa, G., Ribeiro, C., and Barbosa, M. (2017). In vivo and clinical application of strontium-enriched biomaterials for bone regeneration: a systematic review. Bone Joint Res. 6, 366-375. doi: 10.1302/2046-3758.66.BJR2016-0311.R1

Nguyen, K. T., and West, J. L. (2002). Photopolymerizable hydrogels for tissue engineering applications. Biomaterials 23, 4307-4314. doi: 10.1016/S01429612(02)00175-8

Nie, T., Baldwin, A., Yamaguchi, N., and Kiick, K. L. (2007). Production of heparinfunctionalized hydrogels for the development of responsive and controlled growth factor delivery systems. J. Controlled Release 122, 287-296. doi: 10.1016/ j.jconrel.2007.04.019

Niskanen, J., Zhang, I., Xue, Y., Golberg, D., Maysinger, D., and Winnik, F. M. (2016). Boron nitride nanotubes as vehicles for intracellular delivery of fluorescent drugs and probes. Nanomedicine 11, 447-463. doi: 10.2217/nnm.15. 214

Niu, X., Feng, Q., Wang, M., Guo, X., and Zheng, Q. (2009). Porous nanoHA/collagen/PLLA scaffold containing chitosan microspheres for controlled delivery of synthetic peptide derived from BMP-2. J. Controlled Release 134, 111-117. doi: 10.1016/j.jconrel.2008.11.020

Noris-Suarez, K., Lira-Olivares, J., Ferreira, A. M., Feijoo, J. L., Suarez, N., Hernandez, M. C., et al. (2007). In vitro deposition of hydroxyapatite on cortical bone collagen stimulated by deformation-induced piezoelectricity. Biomacromolecules 8, 941-948. doi: 10.1021/bm060828z

Nunes-Pereira, J., Ribeiro, S., Ribeiro, C., Gombek, C. J., Gama, F. M., Gomes, A. C., et al. (2015). Poly(vinylidene fluoride) and copolymers as porous membranes for tissue engineering applications. Polymer Testing 44, 234-241. doi: 10.1016/j.polymertesting.2015.05.001

Nurunnabi, M., Parvez, K., Nafiujjaman, M., Revuri, V., Khan, H. A., Feng, X., et al. (2015). Bioapplication of graphene oxide derivatives: drug/gene delivery, imaging, polymeric modification, toxicology, therapeutics and challenges. RSC Adv. 5, 42141-42161. doi: 10.1039/C5RA04756K

O’Brien, F. J., Harley, B. A., Yannas, I. V., and Gibson, L. (2004). Influence of freezing rate on pore structure in freeze-dried collagen-GAG scaffolds. Biomaterials 25, 1077-1086. doi: 10.1016/S0142-9612(03)00630-6

Oh, S.-H., Finones, R. R., Daraio, C., Chen, L.-H., and Jin, S. (2005). Growth of nano-scale hydroxyapatite using chemically treated titanium oxide nanotubes. Biomaterials 26, 4938-4943. doi: 10.1016/j.biomaterials.2005.01.048 
Oliveira, P., Montembault, A., Sudre, G., Alcouffe, P., Marcon, L., Gehan, H., et al. (2019). Self-crosslinked fibrous collagen/chitosan blends: processing, properties evaluation and monitoring of degradation by bi-fluorescence imaging. Int. J. Biol. Macromol. 131, 353-367. doi: 10.1016/j.ijbiomac.2019.02.134

Opoku, C., Dahiya, A. S., Oshman, C., Cayrel, F., Poulin-Vittrant, G., Alquier, D., et al. (2015). Fabrication of $\mathrm{ZnO}$ nanowire based piezoelectric generators and related structures. Phys. Proc. 70, 858-862. doi: 10.1016/j.phpro.2015.08.176

Otero, T. F., Martinez, J. G., and Arias-Pardilla, J. (2012). Biomimetic electrochemistry from conducting polymers. A review. Electrochim. Acta 84, 112-128. doi: 10.1016/j.electacta.2012.03.097

Ozturan, K. E., Demir, B., Yucel, I., Cak $\iota c \imath$, H., Yilmaz, F., and Haberal, A. (2011). Effect of strontium ranelate on fracture healing in the osteoporotic rats. J. Orthop. Res. 29, 138-142. doi: 10.1002/jor.21204

Palazzo, B., Izzo, D., Scalera, F., Cancelli, A., and Gervaso, F. (2015). Biohybrid scaffolds for bone tissue engineering: nano-hydroxyapatite/chitosan composites. Key Eng. Mater. 631, 300-305. doi: 10.4028/www.scientific.net/ KEM.631.300

Panda, P. K., and Sahoo, B. (2015). PZT to lead free piezo ceramics: a review. Ferroelectrics 474, 128-143. doi: 10.1080/00150193.2015.997146

Pang, L., Dai, C., Bi, L., Guo, Z., and Fan, J. (2017). Biosafety and antibacterial ability of graphene and graphene oxide in vitro and in vivo. Nanoscale Res. Lett. 12:564. doi: 10.1186/s11671-017-2317-0

Panseri, S., Cunha, C., D’Alessandro, T., Sandri, M., Giavaresi, G., Marcacci, M., et al. (2012). Intrinsically superparamagnetic Fe-hydroxyapatite nanoparticles positively influence osteoblast-like cell behaviour. J. Nanobiotechnol. 10:32. doi: 10.1186/1477-3155-10-32

Pașcu, E. I., Stokes, J., and McGuinness, G. B. (2013). Electrospun composites of PHBV, silk fibroin and nano-hydroxyapatite for bone tissue engineering. Mater. Sci. Eng. 33, 4905-4916. doi: 10.1016/j.msec.2013.08.012

Perez, R. A., Seo, S.-J., Won, J.-E., Lee, E.-J., Jang, J.-H., Knowles, J. C., et al. (2015). Therapeutically relevant aspects in bone repair and regeneration. Mater. Today 18, 573-589. doi: 10.1016/j.mattod.2015.06.011

Perez, R. A., Won, J.-E., Knowles, J. C., and Kim, H.-W. (2013). Naturally and synthetic smart composite biomaterials for tissue regeneration. Adv. Drug Deliv. Rev. 65, 471-496. doi: 10.1016/j.addr.2012.03.009

Perizzolo, D., Lacefield, W. R., and Brunette, D. M. (2001). Interaction between topography and coating in the formation of bone nodules in culture for hydroxyapatite- and titanium-coated micromachined surfaces. J. Biomed. Mater. Res. 56, 494-503. doi: 10.1002/1097-4636(20010915)56:4<494::AIDJBM1121<3.0.CO2-X

Pisanic, T. R. II, Blackwell, J. D., Shubayev, V. I., Finones, R. R., and Jin, S. (2007). Nanotoxicity of iron oxide nanoparticle internalization in growing neurons. Biomaterials 28, 2572-2581. doi: 10.1016/j.biomaterials.2007.01.043

Portan, D. V., Kroustalli, A. A., Deligianni, D. D., and Papanicolaou, G. C. (2012). On the biocompatibility between $\mathrm{TiO} 2$ nanotubes layer and human osteoblasts. J. Biomed. Mater. Res. Part A 100, 2546-2553. doi: 10.1002/jbm.a.34188

Prokop, A., Jubel, A., Hahn, U., Dietershagen, M., Bleidistel, M., Peters, C., et al. (2005). A comparative radiological assessment of polylactide pins over 3 years in vivo. Biomaterials 26, 4129-4138. doi: 10.1016/j.biomaterials. 2004 . 10.031

Puertolas, J. A., and Kurtz, S. M. (2014). Evaluation of carbon nanotubes and graphene as reinforcements for UHMWPE-based composites in arthroplastic applications: a review. J. Mech. Behav. Biomed. Mater. 39, 129-145. doi: 10.1016/ j.jmbbm.2014.06.013

Puppi, D., Chiellini, F., Piras, A., and Chiellini, E. (2010). Polymeric materials for bone and cartilage repair. Prog. Polym. Sci. 35, 403-440. doi: 10.1016/j. progpolymsci.2010.01.006

Puricelli, E., Ulbrich, L. M., Ponzoni, D., and Filho, J. J. (2006). Histological analysis of the effects of a static magnetic field on bone healing process in rat femurs. Head Face Med. 2:43. doi: 10.1186/1746-160X-2-43

Rahman, C. V., Ben-David, D., Dhillon, A., Kuhn, G., Gould, T. W., Müller, R., et al. (2014). Controlled release of BMP-2 from a sintered polymer scaffold enhances bone repair in a mouse calvarial defect model. J. Tissue Eng. Regen. Med. 8, 59-66. doi: 10.1002/term.1497

Raja, K., Misra, M., and Paramguru, K. (2005). Deposition of calcium phosphate coating on nanotubular anodized titanium. Mater. Lett. 59, 2137-2141. doi: 10.1016/j.matlet.2005.01.084
Ratnayake, J. T., Mucalo, M., and Dias, G. J. (2017). Substituted hydroxyapatites for bone regeneration: a review of current trends. J. Biomed. Mater. Res. Part B Appl. Biomater. 105, 1285-1299. doi: 10.1002/jbm.b.33651

Rawat, P., Manglani, K., Gupta, S., Kalam, A., Vohora, D., Ahmad, F. J., et al. (2015). Design and development of bioceramic based functionalized PLGA nanoparticles of risedronate for bone targeting: in-vitro characterization and pharmacodynamic evaluation. Pharma. Res. 32, 3149-3158. doi: 10.1007/ s11095-015-1692-4

Reddy, L. H., Arias, J. L., Nicolas, J., and Couvreur, P. (2012). Magnetic nanoparticles: design and characterization, toxicity and biocompatibility, pharmaceutical and biomedical applications. Chem. Rev. 112, 5818-5878. doi: $10.1021 / \mathrm{cr} 300068 \mathrm{p}$

Reid, B., and Zhao, M. (2014). The electrical response to injury: molecular mechanisms and wound healing. Adv. Wound Care 3, 184-201. doi: 10.1089/ wound.2013.0442

Ren, F., Xin, R., Ge, X., and Leng, Y. (2009). Characterization and structural analysis of zinc-substituted hydroxyapatites. Acta Biomater. 5, 3141-3149. doi: 10.1016/j.actbio.2009.04.014

Reves, B. T., Jennings, J. A., Bumgardner, J. D., and Haggard, W. O. (2011). Osteoinductivity assessment of BMP-2 loaded composite chitosan-nanohydroxyapatite scaffolds in a rat muscle pouch. Materials 4, 1360-1374. doi: 10.3390/ma4081360

Rezwan, K., Chen, Q. Z., Blaker, J. J., and Boccaccini, A. R. (2006). Biodegradable and bioactive porous polymer/inorganic composite scaffolds for bone tissue engineering. Biomaterials 27, 3413-3431. doi: 10.1016/j.biomaterials.2006.01. 039

Ribeiro, C., Correia, D. M., Rodrigues, I., Guardão, L., Guimarães, S., Soares, R., et al. (2017). In vivo demonstration of the suitability of piezoelectric stimuli for bone reparation. Mater. Lett. 209, 118-121. doi: 10.1016/j.matlet.2017.07.099

Ribeiro, C., Correia, V., Martins, P., Gama, F. M., and Lanceros-Mendez, S. (2016). Proving the suitability of magnetoelectric stimuli for tissue engineering applications. Colloids Surf. 140, 430-436. doi: 10.1016/j.colsurfb.2015.12.055

Ribeiro, C., Parssinen, J., Sencadas, V., Correia, V., Miettinen, S., Hytonen, V. P., et al. (2015a). Dynamic piezoelectric stimulation enhances osteogenic differentiation of human adipose stem cells. J. Biomed. Mater. Res. A 103, 2172-2175. doi: 10.1002/jbm.a.35368

Ribeiro, C., Sencadas, V., Correia, D. M., and Lanceros-Mendez, S. (2015b). Piezoelectric polymers as biomaterials for tissue engineering applications. Colloids Surf. B Biointerf. 136, 46-55. doi: 10.1016/j.colsurfb.2015.08.043

Ridi, F., Meazzini, I., Castroflorio, B., Bonini, M., Berti, D., and Baglioni, P. (2017). Functional calcium phosphate composites in nanomedicine. Adv. Colloid Interf. Sci. 244, 281-295. doi: 10.1016/j.cis.2016.03.006

Roberts, T. T., and Rosenbaum, A. J. (2012). Bone grafts, bone substitutes and orthobiologics: the bridge between basic science and clinical advancements in fracture healing. Organogenesis 8, 114-124. doi: 10.4161/org.23306

Rocca, A., Marino, A., Rocca, V., Moscato, S., de Vito, G., Piazza, V., et al. (2015). Barium titanate nanoparticles and hypergravity stimulation improve differentiation of mesenchymal stem cells into osteoblasts. Int. J. Nanomed. 10, 433-445. doi: 10.2147/IJN.S76329

Rodell, C. B., Rai, R., Faubel, S., Burdick, J. A., and Soranno, D. E. (2015). Local immunotherapy via delivery of interleukin-10 and transforming growth factor $\beta$ antagonist for treatment of chronic kidney disease. J. Controlled Release 206, 131-139. doi: 10.1016/j.jconrel.2015.03.025

Roffi, A., Krishnakumar, G. S., Gostynska, N., Kon, E., Candrian, C., and Filardo, G. (2017). The role of three-dimensional scaffolds in treating long bone defects: evidence from preclinical and clinical literature-a systematic review. BioMed Res. Int. 2017:8074178. doi: 10.1155/2017/8074178

Sadat-Shojai, M., Khorasani, M.-T., Dinpanah-Khoshdargi, E., and Jamshidi, A. (2013). Synthesis methods for nanosized hydroxyapatite with diverse structures. Acta Biomater. 9, 7591-7621. doi: 10.1016/j.actbio.2013.04.012

Saiz, E., Zimmermann, E. A., Lee, J. S., Wegst, U. G. K., and Tomsia, A. P. (2013). Perspectives on the role of nanotechnology in bone tissue engineering. Dental Mater. 29, 103-115. doi: 10.1016/j.dental.2012.08.001

Sajesh, K. M., Jayakumar, R., Nair, S. V., and Chennazhi, K. P. (2013). Biocompatible conducting chitosan/polypyrrole-alginate composite scaffold for bone tissue engineering. Int. J. Biol. Macromol. 62, 465-471. doi: 10.1016/j. ijbiomac.2013.09.028 
Samavedi, S., Whittington, A. R., and Goldstein, A. S. (2013). Calcium phosphate ceramics in bone tissue engineering: a review of properties and their influence on cell behavior. Acta Biomater. 9, 8037-8045. doi: 10.1016/j.actbio.2013. 06.014

Sapir, Y., Cohen, S., Friedman, G., and Polyak, B. (2012). The promotion of in vitro vessel-like organization of endothelial cells in magnetically responsive alginate scaffolds. Biomaterials 33, 4100-4109. doi: 10.1016/j.biomaterials.2012.02.037

Scalize, P. H., Bombonato-Prado, K. F., de Sousa, L. G., Rosa, A. L., Beloti, M. M., Semprini, M., et al. (2016). Poly(Vinylidene Fluoride-Trifluorethylene)/barium titanate membrane promotes de novo bone formation and may modulate gene expression in osteoporotic rat model. J. Mater. Sci. 27:180. doi: 10.1007/s10856016-5799-x

Schmidt-Bleek, K., Petersen, A., Dienelt, A., Schwarz, C., and Duda, G. N. (2014). Initiation and early control of tissue regeneration - bone healing as a model system for tissue regeneration. Expert Opin. Biol. Ther. 14, 247-259. doi: 10. $1517 / 14712598.2014 .857653$

Schult, M., Buckow, E., and Seitz, H. (2016). Experimental studies on 3D printing of barium titanate ceramics for medical applications. Curr. Directions Biomed. Eng. 2, 95-99. doi: 10.1515/cdbme-2016-0024

Serakinci, N., Fahrioglu, U., and Christensen, R. (2014). Mesenchymal stem cells, cancer challenges and new directions. Eur. J. Cancer 50, 1522-1530. doi: 10. 1016/j.ejca.2014.02.011

Sergi, R., Bellucci, D., Candidato, R. T., Lusvarghi, L., Bolelli, G., Pawlowski, L., et al. (2018). Bioactive $\mathrm{Zn}$-doped hydroxyapatite coatings and their antibacterial efficacy against Escherichia coli and Staphylococcus aureus. Surf. Coa. Technol. 352, 84-91. doi: 10.1016/j.surfcoat.2018.08.017

Serra, G., Morais, L., Elias, C. N., Semenova, I. P., Valiev, R., Salimgareeva, G., et al. (2013). Nanostructured severe plastic deformation processed titanium for orthodontic mini-implants. Mater. Sci. Eng. C Mater. Biol. Appl. 33, 4197-4202. doi: 10.1016/j.msec.2013.06.012

Setyawati, M. I., Khoo, P. K. S., Eng, B. H., Xiong, S., Zhao, X., Das, G. K., et al. (2013). Cytotoxic and genotoxic characterization of titanium dioxide, gadolinium oxide, and poly (lactic-co-glycolic acid) nanoparticles in human fibroblasts. J. Biomed. Mater. Res. Part A 101, 633-640. doi: 10.1002/jbm.a. 34363

Shadjou, N., and Hasanzadeh, M. (2015). Bone tissue engineering using silica-based mesoporous nanobiomaterials: recent progress. Mater. Sci. Eng. C 55, 401-409. doi: 10.1016/j.msec.2015.05.027

Shakir, M., Jolly, R., Khan, A. A., Ahmed, S. S., Alam, S., Rauf, M. A., et al. (2018). Resol based chitosan/nano-hydroxyapatite nanoensemble for effective bone tissue engineering. Carbohydr. Polym. 179, 317-327. doi: 10.1016/j.carbpol. 2017.09.103

Shalumon, K. T., Anulekha, K. H., Nair, S. V., Nair, S. V., Chennazhi, K. P., and Jayakumar, R. (2011). Sodium alginate/poly(vinyl alcohol)/nano ZnO composite nanofibers for antibacterial wound dressings. Int. J. Biol. Macromol. 49, 247-254. doi: 10.1016/j.ijbiomac.2011.04.005

Shen, X., Zhang, Y., Gu, Y., Xu, Y., Liu, Y., Li, B., et al. (2016). Sequential and sustained release of SDF-1 and BMP-2 from silk fibroin-nanohydroxyapatite scaffold for the enhancement of bone regeneration. Biomaterials 106, 205-216. doi: 10.1016/j.biomaterials.2016.08.023

Shen, Y., Huang, Z., Liu, X., Qian, J., Xu, J., Yang, X., et al. (2015). Iron-induced myocardial injury: an alarming side effect of superparamagnetic iron oxide nanoparticles. J. Cell Mol. Med. 19, 2032-2035. doi: 10.1111/jcmm.12582

Shepherd, J. H., and Best, S. M. (2011). Calcium phosphate scaffolds for bone repair. JOM 63, 83-92. doi: 10.1007/s11837-011-0063-9

Silva, E., Vasconcellos, L. M. R., Rodrigues, B. V. M., Dos Santos, D. M., CampanaFilho, S. P., Marciano, F. R., et al. (2017). PDLLA honeycomb-like scaffolds with a high loading of superhydrophilic graphene/multi-walled carbon nanotubes promote osteoblast in vitro functions and guided in vivo bone regeneration. Mater. Sci. Eng. C Mater. Biol. Appl. 73, 31-39. doi: 10.1016/j.msec.2016. 11.075

Singh, K., Ahmadinia, K., Park, D. K., Nandyala, S. V., Marquez-Lara, A., Patel, A. A., et al. (2014). Complications of spinal fusion with utilization of bone morphogenetic protein: a systematic review of the literature. Spine (Phila $\mathrm{Pa}$ 1976) 39, 91-101. doi: 10.1097/BRS.0000000000000004

Singh, R. K., Jin, G.-Z., Mahapatra, C., Patel, K. D., Chrzanowski, W., and Kim, H.-W. (2015). Mesoporous silica-layered biopolymer hybrid nanofibrous scaffold: a novel nanobiomatrix platform for therapeutics delivery and bone regeneration. ACS Appl. Mater. Interf. 7, 8088-8098. doi: 10.1021/acsami. 5 b00692

Singh, R. K., Patel, K. D., Lee, J. H., Lee, E.-J., Kim, J.-H., Kim, T.-H., et al. (2014). Potential of magnetic nanofiber scaffolds with mechanical and biological properties applicable for bone regeneration. PLoS One 9:e91584. doi: 10.1371/ journal.pone.0091584

Singh, S., Wu, B. M., and Dunn, J. C. (2011). The enhancement of VEGF-mediated angiogenesis by polycaprolactone scaffolds with surface cross-linked heparin. Biomaterials 32, 2059-2069. doi: 10.1016/j.biomaterials.2010.11.038

Smith, W. R., Hudson, P. W., Ponce, B. A., and Rajaram Manoharan, S. R. (2018). Nanotechnology in orthopedics: a clinically oriented review. BMC Musculoskelet Disord. 19:67. doi: 10.1186/s12891-018-1990-1

Sopyan, I., Mel, M., Ramesh, S., and Khalid, K. (2007). Porous hydroxyapatite for artificial bone applications. Sci. Technol. Adv. Mater. 8:116. doi: 10.1016/j.stam. 2006.11.017

Spiller, K. L., Nassiri, S., Witherel, C. E., Anfang, R. R., Ng, J., Nakazawa, K. R., et al. (2015). Sequential delivery of immunomodulatory cytokines to facilitate the M1-to-M2 transition of macrophages and enhance vascularization of bone scaffolds. Biomaterials 37, 194-207. doi: 10.1016/j.biomaterials.2014.10.017

Sridhar, S., Venugopal, J. R., Sridhar, R., and Ramakrishna, S. (2015). Cardiogenic differentiation of mesenchymal stem cells with gold nanoparticle loaded functionalized nanofibers. Colloids Surf. 134, 346-354. doi: 10.1016/j.colsurfb. 2015.07.019

Stevenson, S., and Horowitz, M. (1992). The response to bone allografts. J. Bone Joint Surg. Am. 74, 939-950. doi: 10.2106/00004623-199274060-00017

Sultana, N., and Wang, M. (2012). PHBV/PLLA-based composite scaffolds fabricated using an emulsion freezing/freeze-drying technique for bone tissue engineering: surface modification and in vitro biological evaluation. Biofabrication 4:015003. doi: 10.1088/1758-5082/4/1/015003

Sun, T., Zhou, K., Liu, M., Guo, X., Qu, Y., Cui, W., et al. (2018). Loading of BMP-2-related peptide onto three-dimensional nano-hydroxyapatite scaffolds accelerates mineralization in critical-sized cranial bone defects. J. Tissue Eng. Regen. Med. 12, 864-877. doi: 10.1002/term.2371

Šupová, M. (2015). Substituted hydroxyapatites for biomedical applications: a review. Ceram. Int. 41, 9203-9231. doi: 10.1016/j.ceramint.2015.03.316

Szekely, J. (2012). Gas-solid Reactions. Amsterdam: Elsevier.

Szpalski, M., and Gunzburg, R. (2002). Applications of calcium phosphate-based cancellous bone void fillers in trauma surgery. Orthopedics 25, S601-S609.

Tajbakhsh, S., and Hajiali, F. (2017). A comprehensive study on the fabrication and properties of biocomposites of poly(lactic acid)/ceramics for bone tissue engineering. Mater. Sci. Eng. 70, 897-912. doi: 10.1016/j.msec.2016.09.008

Takano, Y., Turner, C. H., Owan, I., Martin, R. B., Lau, S. T., Forwood, M. R., et al. (1999). Elastic anisotropy and collagen orientation of osteonal bone are dependent on the mechanical strain distribution. J. Orthop. Res. 17, 59-66. doi: 10.1002/jor.1100170110

Tampieri, A., D’Alessandro, T., Sandri, M., Sprio, S., Landi, E., Bertinetti, L., et al. (2012). Intrinsic magnetism and hyperthermia in bioactive Fe-doped hydroxyapatite. Acta Biomater. 8, 843-851. doi: 10.1016/j.actbio.2011.09.032

Tampieri, A., Landi, E., Valentini, F., Sandri, M., d'Alessandro, T., Dediu, V., et al. (2010). A conceptually new type of bio-hybrid scaffold for bone regeneration. Nanotechnology 22:015104. doi: 10.1088/0957-4484/22/1/015104

Tampieri, A., Ruffini, A., Ballardini, A., Montesi, M., Panseri, S., Salamanna, F., et al. (2018). Heterogeneous chemistry in the 3-D state: an original approach to generate bioactive, mechanically-competent bone scaffolds. Biomater. Sci. 7, 307-321. doi: 10.1039/c8bm01145a

Tampieri, A., Sandri, M., Landi, E., Celotti, G., Roveri, N., Mattioli-Belmonte, M., et al. (2005). HA/alginate hybrid composites prepared through bio-inspired nucleation. Acta Biomater. 1, 343-351. doi: 10.1016/j.actbio.2005.01.001

Tampieri, A., Sandri, M., Landi, E., Sprio, S., Valentini, F., and Boskey, A. (2008). Synthetic biomineralisation yielding HA/collagen hybrid composite. Adv. Appl. Ceramics 107, 298-302. doi: 10.1179/174367608X314163

Tampieri, A., Sandri, M., Panseri, S., Adamiano, A., Montesi, M., and Sprio, S. (2016). "Biologically inspired nanomaterials and nanobiomagnetism: a synergy among new emerging concepts in regenerative medicine," in Bioinspired Regenerative Medicine: Materials, Processes and Clinical Applications, (Singapore: PAN Stanford Publishing), 1-20. doi: 10.1201/b19914-2

Tampieri, A., Sprio, S., Ruffini, A., Celotti, G., Lesci, I. G., and Roveri, N. (2009). From wood to bone: multi-step process to convert wood hierarchical structures 
into biomimetic hydroxyapatite scaffolds for bone tissue engineering. J. Mater. Chem. 19, 4973-4980. doi: 10.1039/B900333A

Tampieri, A., Sprio, S., Sandri, M., and Valentini, F. (2011). Mimicking natural biomineralization processes: a new tool for osteochondral scaffold development. Trends Biotechnol. 29, 526-535. doi: 10.1016/j.tibtech.2011.04.011

Tandon, B., Blaker, J. J., and Cartmell, S. H. (2018). Piezoelectric materials as stimulatory biomedical materials and scaffolds for bone repair. Acta Biomater. 73, 1-20. doi: 10.1016/j.actbio.2018.04.026

Tang, F., Li, L., and Chen, D. (2012). Mesoporous silica nanoparticles: synthesis, biocompatibility and drug delivery. Adv. Mater. 24, 1504-1534. doi: 10.1002/ adma.201104763

Tang, W., Lin, D., Yu, Y., Niu, H., Guo, H., Yuan, Y., et al. (2016). Bioinspired trimodal macro/micro/nano-porous scaffolds loading rhBMP-2 for complete regeneration of critical size bone defect. Acta Biomater. 32, 309-323. doi: 10. 1016/j.actbio.2015.12.006

Tang, Y., Zhao, Y., Wang, X., and Lin, T. (2014). Layer-by-layer assembly of silica nanoparticles on 3D fibrous scaffolds: enhancement of osteoblast cell adhesion, proliferation, and differentiation. J. Biomed. Mater. Res. Part A 102, 3803-3812. doi: 10.1002/jbm.a.35050

Tannoury, C. A., and An, H. S. (2014). Complications with the use of bone morphogenetic protein 2 (BMP-2) in spine surgery. Spine J. 14, 552-559. doi: 10.1016/j.spinee.2013.08.060

Taraballi, F., Sushnitha, M., Tsao, C., Bauza, G., Liverani, C., Shi, A., et al. (2018). Biomimetic tissue engineering: tuning the immune and inflammatory response to implantable biomaterials. Adv. Healthcare Mater. 7:1800490. doi: 10.1002/ adhm. 201800490

Tarafder, S., Dernell, W. S., Bandyopadhyay, A., and Bose, S. (2015). SrO-and $\mathrm{MgO}-$ doped microwave sintered $3 \mathrm{D}$ printed tricalcium phosphate scaffolds: mechanical properties and in vivo osteogenesis in a rabbit model. J. Biomed. Mater. Res. Part B Appl. Biomater. 103, 679-690. doi: 10.1002/jbm.b.33239

Taton, T. A. (2001). Nanotechnology, boning up on biology. Nature 412, 491-492. doi: $10.1038 / 35087687$

Tibbitt, M. W., and Anseth, K. S. (2009). Hydrogels as extracellular matrix mimics for 3D cell culture. Biotechnol. Bioeng. 103, 655-663. doi: 10.1002/bit.22361

Tichý, J. A. (2010). Fundamentals of Piezoelectric Sensorics : Mechanical, Dielectric, and Thermodynamical Properties of Piezoelectric Materials. Springer-Verlag: Berlin. doi: 10.1007/978-3-540-68427-5

Trumbull, A., Subramanian, G., and Yildirim-Ayan, E. (2016). Mechanoresponsive musculoskeletal tissue differentiation of adipose-derived stem cells. Biomed. Eng. Online 15:43. doi: 10.1186/s12938-016-0150-9

Vahabzadeh, S., and Bose, S. (2017). Effects of iron on physical and mechanical properties, and osteoblast cell interaction in $\beta$-tricalcium phosphate. Ann. Biomed. Eng. 45, 819-828. doi: 10.1007/s10439-016-1724-1

Vallet-Regí, M., Ragel, C. V., and Salinas, A. J. (2003). Glasses with medical applications. Eur. J. Inorg. Chem. 6, 1029-1042. doi: 10.1002/ejic.200390134

van Vugt, T. A., Geurts, J. A. P., Arts, J. J., and Lindfors, N. C. (2017). "3 - Biomaterials in treatment of orthopedic infections," in Management of Periprosthetic Joint Infections (PJIs), eds J. J. C. Arts and J. Geurts (Sawston: Woodhead Publishing), 41-68. doi: 10.1016/B978-0-08-100205-6.00003-3

Vasconcelos, D. M., Gonçalves, R. M., Almeida, C. R., Pereira, I. O., Oliveira, M. I., Neves, N., et al. (2016). Fibrinogen scaffolds with immunomodulatory properties promote in vivo bone regeneration. Biomaterials 111, 163-178. doi: 10.1016/j.biomaterials.2016.10.004

Vavken, J., Mameghani, A., Vavken, P., and Schaeren, S. (2016). Complications and cancer rates in spine fusion with recombinant human bone morphogenetic protein-2 (rhBMP-2). Eur. Spine J. 25, 3979-3989. doi: 10.1007/s00586-0153870-9

Vichery, C., and Nedelec, J.-M. (2016). Bioactive glass nanoparticles: from synthesis to materials design for biomedical applications. Materials 9:288. doi: 10.3390/ ma9040288

Vo, T. N., Kasper, F. K., and Mikos, A. G. (2012). Strategies for controlled delivery of growth factors and cells for bone regeneration. Adv. Drug Deliv. Rev. 64, 1292-1309. doi: 10.1016/j.addr.2012.01.016

Walsh, M. C., Kim, N., Kadono, Y., Rho, J., Lee, S. Y., Lorenzo, J., et al. (2006). Osteoimmunology: interplay between the immune system and bone metabolism. Annu. Rev. Immunol. 24, 33-63. doi: 10.1146/annurev.immunol. 24.021605.090646
Wang, B., Guo, Y., Chen, X., Zeng, C., Hu, Q., Yin, W., et al. (2018). Nanoparticlemodified chitosan-agarose-gelatin scaffold for sustained release of SDF-1 and BMP-2. Int. J. Nanomed. 13:7395. doi: 10.2147/IJN.S180859

Wang, J., An, Y., Li, F., Li, D., Jing, D., Guo, T., et al. (2014). The effects of pulsed electromagnetic field on the functions of osteoblasts on implant surfaces with different topographies. Acta Biomater. 10, 975-985. doi: 10.1016/j.actbio.2013. 10.008

Wang, L., and Nancollas, G. H. (2008). Calcium orthophosphates: crystallization and dissolution. Chem. Rev. 108, 4628-4669. doi: 10.1021/cr0782574

Wang, N., Zhou, Z., Xia, L., Dai, Y., and Liu, H. (2013). Fabrication and characterization of bioactive beta-Ca2SiO4/PHBV composite scaffolds. Mater. Sci. Eng. C Mater. Biol. Appl. 33, 2294-2301. doi: 10.1016/j.msec.2013.01.059

Wang, Q., Yan, J., Yang, J., and Li, B. (2016). Nanomaterials promise better bone repair. Mater. Today 19, 451-463. doi: 10.1016/j.mattod.2015.12.003

Wang, Y., Hu, X., Dai, J., Wang, J., Tan, Y., Yang, X., et al. (2017). A 3D graphene coated bioglass scaffold for bone defect therapy based on the molecular targeting approach. J. Mater. Chem. 5, 6794-6800. doi: 10.1039/C7TB01515A

Wang, Y., Pan, H., and Chen, X. (2019). The preparation of hollow mesoporous bioglass nanoparticles with excellent drug delivery capacity for bone tissue regeneration. Front. Chem. 7:283. doi: 10.3389/fchem.2019.00283

Wang, Z., Chen, L., Wang, Y., Chen, X., and Zhang, P. (2016). Improved cell adhesion and osteogenesis of op-HA/PLGA composite by poly (dopamine)assisted immobilization of collagen mimetic peptide and osteogenic growth peptide. ACS Appl. Mater. Interf. 8, 26559-26569. doi: 10.1021/acsami.6b08733

Webster, T. J., Ergun, C., Doremus, R. H., Siegel, R. W., and Bizios, R. (2000). Enhanced functions of osteoblasts on nanophase ceramics. Biomaterials 21, 1803-1810. doi: 10.1016/s0142-9612(00)00075-2

Wei, Y., Zhang, X., Song, Y., Han, B., Hu, X., Wang, X., et al. (2011). Magnetic biodegradable Fe3O4/CS/PVA nanofibrous membranes for bone regeneration. Biomed. Mater. 6:055008. doi: 10.1088/1748-6041/6/5/055008

Wen, Y., Xun, S., Haoye, M., Baichuan, S., Peng, C., Xuejian, L., et al. (2017). 3D printed porous ceramic scaffolds for bone tissue engineering: a review. Biomater. Sci. 5, 1690-1698. doi: 10.1039/C7BM00315C

Weng, L., Boda, S. K., Teusink, M. J., Shuler, F. D., Li, X., and Xie, J. (2017). Binary doping of strontium and copper enhancing osteogenesis and angiogenesis of bioactive glass nanofibers while suppressing osteoclast activity. ACS Appl. Mater. Interf. 9, 24484-24496. doi: 10.1021/acsami.7b06521

Whulanza, Y., Battini, E., Vannozzi, L., Vomero, M., Ahluwalia, A., and Vozzi, G. (2013). Electrical and mechanical characterisation of single wall carbon nanotubes based composites for tissue engineering applications. J. Nanosci. Nanotechnol. 13, 188-197. doi: 10.1166/jnn.2013.6708

Wong, C., Lu, W., Chan, W., Cheung, K., Luk, K., Lu, D., et al. (2004). In vivo cancellous bone remodeling on a strontium-containing hydroxyapatite (sr-HA) bioactive cement. J. Biomed. Mater. Res. Part A 68, 513-521. doi: 10.1002/jbm.a.20089

Wu, X., Liu, Y., Li, X., Wen, P., Zhang, Y., Long, Y., et al. (2010a). Preparation of aligned porous gelatin scaffolds by unidirectional freeze-drying method. Acta Biomater. 6, 1167-1177. doi: 10.1016/j.actbio.2009.08.041

Wu, X., Tan, Y., Mao, H., and Zhang, M. (2010b). Toxic effects of iron oxide nanoparticles on human umbilical vein endothelial cells. Int. J. Nanomedicine 5, 385-399. doi: 10.2147/ijn.s10458

Wu, Y., Jiang, W., Wen, X., He, B., Zeng, X., Wang, G., et al. (2010). A novel calcium phosphate ceramic-magnetic nanoparticle composite as a potential bone substitute. Biomed. Mater. 5:15001. doi: 10.1088/1748-6041/5/1/015001

Wynn, T. A., and Vannella, K. M. (2016). Macrophages in tissue repair, regeneration, and fibrosis. Immunity 44, 450-462. doi: 10.1016/j.immuni.2016. 02.015

Xie, G., Sun, J., Zhong, G., Liu, C., and Wei, J. (2010). Hydroxyapatite nanoparticles as a controlled-release carrier of BMP-2: absorption and release kinetics in vitro. J. Mater. Sci. Mater. Med. 21, 1875-1880. doi: 10.1007/s10856-010-4038-0

Xie, H., Cao, T., Gomes, J. V., Castro Neto, A. H., and Rosa, V. (2015). Two and three-dimensional graphene substrates to magnify osteogenic differentiation of periodontal ligament stem cells. Carbon 93, 266-275. doi: 10.1016/j.carbon. 2015.05.071

Xu, D., and Esko, J. D. (2014). Demystifying heparan sulfate-protein interactions. Annu. Rev. Biochem. 83, 129-157. doi: 10.1146/annurev-biochem-060713035314 
Xu, T., Yang, H., Yang, D., and Yu, Z.-Z. (2017). Polylactic acid nanofiber scaffold decorated with chitosan islandlike topography for bone tissue engineering. ACS Appl. Mater. Interf. 9, 21094-21104. doi: 10.1021/acsami.7b0 1176

Yamaguchi, M., and Weitzmann, M. N. (2011). Zinc stimulates osteoblastogenesis and suppresses osteoclastogenesis by antagonizing NF-кB activation. Mol. Cell. Biochem. 355:179. doi: 10.1007/s11010-011-0852-z

Yang, F., Wang, J., Hou, J., Guo, H., and Liu, C. (2013). Bone regeneration using cell-mediated responsive degradable PEG-based scaffolds incorporating with rhBMP-2. Biomaterials 34, 1514-1528. doi: 10.1016/j.biomaterials.2012. 10.058

Yi, H., Rehman, F. U., Zhao, C., Liu, B., and He, N. (2016). Recent advances in nano scaffolds for bone repair. Bone Res. 4, 1-11. doi: 10.1038/boneres.2016.50

Yuan, H., Fernandes, H., Habibovic, P., de Boer, J., Barradas, A. M., de Ruiter, A., et al. (2010). Osteoinductive ceramics as a synthetic alternative to autologous bone grafting. Proc. Natl. Acade. Sci. U.S.A. 107, 13614-13619. doi: 10.1073/ pnas. 1003600107

Yun, H.-M., Ahn, S.-J., Park, K.-R., Kim, M.-J., Kim, J.-J., Jin, G.-Z., et al. (2016). Magnetic nanocomposite scaffolds combined with static magnetic field in the stimulation of osteoblastic differentiation and bone formation. Biomaterials 85 , 88-98. doi: 10.1016/j.biomaterials.2016.01.035

Yun, Y.-P., Kim, S. E., Kang, E. Y., Kim, H.-J., Park, K., and Song, H.-R. (2013). The effect of bone morphogenic protein-2 (BMP-2)-immobilizing heparinizedchitosan scaffolds for enhanced osteoblast activity. Tissue Eng. Regen. Med. 10, 122-130. doi: 10.1007/s13770-013-0386-4

Zadegan, S. A., Abedi, A., Jazayeri, S. B., Nasiri Bonaki, H., Jazayeri, S. B., Vaccaro, A. R., et al. (2017). Bone morphogenetic proteins in anterior cervical fusion: a systematic review and meta-analysis. World Neurosurg. 104, 752-787. doi: 10.1016/j.wneu.2017.02.098

Zarins, J., Pilmane, M., Sidhoma, E., and Salma, I. (2016). Does local application of strontium increase osteogenesis and biomaterial osteointegration in osteoporotic and other bone tissue conditions: review of literature. Acta Chirurgica Latviensis 16:17. doi: 10.1515/chilat-20170004

Zhang, K., Wang, S., Zhou, C., Cheng, L., Gao, X., Xie, X., et al. (2018). Advanced smart biomaterials and constructs for hard tissue engineering and regeneration. Bone Res. 6:31. doi: 10.1038/s41413-018-0032-9

Zhang, Q., Qin, M., Zhou, X., Nie, W., Wang, W., Li, L., et al. (2018). Porous nanofibrous scaffold incorporated with S1P loaded mesoporous silica nanoparticles and BMP-2 encapsulated PLGA microspheres for enhancing angiogenesis and osteogenesis. J. Mater. Chem. B 6, 6731-6743. doi: 10.1039/ C8TB02138D

Zhang, R., Liu, X., Xiong, Z., Huang, Q., Yang, X., Yan, H., et al. (2018). The immunomodulatory effects of $\mathrm{Zn}$-incorporated micro/nanostructured coating in inducing osteogenesis. Artif. Cells Nanomed. Biotechnol. 46(Suppl. 1), 11231130. doi: 10.1080/21691401.2018.1446442

Zhang, X., Zhang, C., Lin, Y., Hu, P., Shen, Y., Wang, K., et al. (2016). Nanocomposite membranes enhance bone regeneration through restoring physiological electric microenvironment. ACS Nano 10, 7279-7286. doi: 10. 1021/acsnano.6b02247

Zhang, X. Q., Xu, X., Bertrand, N., Pridgen, E., Swami, A., and Farokhzad, O. C. (2012). Interactions of nanomaterials and biological systems: implications to personalized nanomedicine. Adv. Drug Deliv. Rev. 64, 1363-1384. doi: 10.1016/ j.addr.2012.08.005

Zhang, Y., Chen, L., Zeng, J., Zhou, K., and Zhang, D. (2014). Aligned porous barium titanate/hydroxyapatite composites with high piezoelectric coefficients for bone tissue engineering. Mater. Sci. Eng. 39, 143-149. doi: 10.1016/j.msec. 2014.02.022
Zhang, Y., Venugopal, J. R., El-Turki, A., Ramakrishna, S., Su, B., and Lim, C. T. (2008). Electrospun biomimetic nanocomposite nanofibers of hydroxyapatite/chitosan for bone tissue engineering. Biomaterials 29, 43144322. doi: 10.1016/j.biomaterials.2008.07.038

Zhao, F., Lei, B., Li, X., Mo, Y., Wang, R., Chen, D., et al. (2018). Promoting in vivo early angiogenesis with sub-micrometer strontium-contained bioactive microspheres through modulating macrophage phenotypes. Biomaterials 178, 36-47. doi: 10.1016/j.biomaterials.2018.06.004

Zhao, X., Kim, J., Cezar, C. A., Huebsch, N., Lee, K., Bouhadir, K., et al. (2011). Active scaffolds for on-demand drug and cell delivery. Proc. Natl. Acad. Sci. U.S.A. 108, 67-72. doi: 10.1073/pnas.1007862108

Zheng, K., Wu, J., Li, W., Dippold, D., Wan, Y., and Boccaccini, A. R. (2018). Incorporation of $\mathrm{Cu}$-containing bioactive glass nanoparticles in gelatin-coated scaffolds enhances bioactivity and osteogenic activity. ACS Biomater. Sci. Eng. 4, 1546-1557. doi: 10.1021/acsbiomaterials.8b00051

Zhou, T., Li, G., Lin, S., Tian, T., Ma, Q., Zhang, Q., et al. (2017). Electrospun poly(3-hydroxybutyrate-co-4-hydroxybutyrate)/graphene oxide scaffold: enhanced properties and promoted in vivo bone repair in rats. ACS Appl. Mater. Interfaces 9, 42589-42600. doi: 10.1021/acsami.7b14267

Zhou, X., Castro, N. J., Zhu, W., Cui, H., Aliabouzar, M., Sarkar, K., et al. (2016). Improved human bone marrow mesenchymal stem cell osteogenesis in $3 \mathrm{D}$ bioprinted tissue scaffolds with low intensity pulsed ultrasound stimulation. Sci. Rep. 6:32876. doi: 10.1038/srep32876

Zhou, X., Feng, W., Qiu, K., Chen, L., Wang, W., Nie, W., et al. (2015). BMP-2 derived peptide and dexamethasone incorporated mesoporous silica nanoparticles for enhanced osteogenic differentiation of bone mesenchymal stem cells. ACS Appl. Mater. Interf. 7, 15777-15789. doi: 10.1021/acsami. 5 b02636

Zhou, Z., Li, W., He, T., Qian, L., Tan, G., and Ning, C. (2016). Polarization of an electroactive functional film on titanium for inducing osteogenic differentiation. Sci. Rep. 6:35512. doi: 10.1038/srep35512

Zhu, B., Lu, Q., Yin, J., Hu, J., and Wang, Z. (2005). Alignment of osteoblast-like cells and cell-produced collagen matrix induced by nanogrooves. Tissue Eng. 11, 825-834. doi: 10.1089/ten.2005.11.825

Zhu, M. T., Wang, B., Wang, Y., Yuan, L., Wang, H. J., Wang, M., et al. (2011). Endothelial dysfunction and inflammation induced by iron oxide nanoparticle exposure: risk factors for early atherosclerosis. Toxicol. Lett. 203, 162-171. doi: 10.1016/j.toxlet.2011.03.021

Zhu, W., Guo, D., Peng, L., Chen, Y. F., Cui, J., Xiong, J., et al. (2017). Repair of rabbit cartilage defect based on the fusion of rabbit bone marrow stromal cells and Nano-HA/PLLA composite material. Artif. Cells Nanomed. Biotechnol. 45, 115-119. doi: 10.3109/21691401.2016.1138482

Zofková, I., Nemcikova, P., and Matucha, P. (2013). Trace elements and bone health. Clin. Chem. Lab. Med. 51, 1555-1561. doi: 10.1515/cclm-2012-0868

Zura, R., Xiong, Z., Einhorn, T., Watson, J. T., Ostrum, R. F., Prayson, M. J., et al. (2016). Epidemiology of fracture nonunion in 18 human bones. JAMA Surg. 151:e162775. doi: 10.1001/jamasurg.2016.2775

Conflict of Interest: The authors declare that the research was conducted in the absence of any commercial or financial relationships that could be construed as a potential conflict of interest.

Copyright (c) 2020 Lyons, Plantz, Hsu, Hsu and Minardi. This is an open-access article distributed under the terms of the Creative Commons Attribution License (CC BY). The use, distribution or reproduction in other forums is permitted, provided the original author(s) and the copyright owner(s) are credited and that the original publication in this journal is cited, in accordance with accepted academic practice. No use, distribution or reproduction is permitted which does not comply with these terms. 